\title{
MILANKOVITCH THEORY AND CLIMATE
}

\section{A. Berger}

Institut d'Astronomie et de Géophysique G. Lémâ̂tre, Université Catholique de Louvain Louvain-1a-Neuve, Be1gium

\begin{abstract}
Among the longest astrophysical and astronomical cycles that might influence climate (and even among all forcting mechanisms external to the climatic system itself), only those involving variations in the elements of the Earth's orbit have been found to be significantly related to the long-term climatic data deduced from the geological record. The aim of the astronomical theory of paleoclimates, a particular version of which being due to M1lankovitch, is to study this relationship
\end{abstract} between Insolation and climate at the global scale. It comprises four different parts: the orbital elements, the insolation, the climate model, and the geological data. In the nineteenth century, Croll and Pilgrim stressed the importance of severe winters as a cause of ice ages. Later, mainly during the first half of the twentleth century, Köppen, Spitaler, and Milankovitch regarded mild winters and cool summers as favoring glaciation. After Köppen and Wegener related the Milankovitch new radiation curve to Penck and Brulckner's subdivision of the Quaternary, there was a long-lasting debate on whether or not such changes in the insolation can explain the Quaternary glacial-interglacial cycles. In the 1970s, with the improvements in dating, in acquiring, and in interpreting the geological data, with the advent of computers, and with the development of astronomical and climate models, the Milankovitch theory revived. Over the last 5 years it overcame most of the geological, astronomical, and climatological difficulties. The accuracy of the longterm variations of the astronomical elements and of the insolation values and the stability of their spectra have been analyzed by comparing seven different astronomical solutions and four different time spans $(0-0.8$ million years before present (Myr B.P.), 0.8-1.6 Myr B.P., 1.6-2.4 Myr B.P., and 2.4-3.2 Myr B.P.). For accuracy in the time domain, improvements are necessary for periods earlier than 2 Myr B.P. As for the stability of the frequencies, the fundamental periods (around 40, 23, and $19 \mathrm{kyr}$ ) do not deteriorate with time over the last 5 Myr, but their relative importance for each insolation and each astronomical parameter is a function of the period considered. Spectral analysis of paleoclimatic records has provided substantial evidence that, at least near the obliquity and precession frequencies, a considerable fraction of the climatic variance is driven in some way by insolation changes forced by changes in the Earth's orbit. Not only are the fundamental astronomical and climatic frequencies alike, but also the climatic series are phaselocked and strongly coherent with orbital variations. Provided that monthly insolation (i.e., a

Copyright 1988 by the American Geophysical Union.

Paper number 8R0239.

8755-1209/88/008R-0239\$05.00 detailed seasonal cycle) is considered for the different latitudes, their long-term deviations can be as large as $13 \%$ of the long-term average, and sometimes considerable changes between extreme values can occur in less than 10,000 years. Models of different categories of complexity, from conceptual ones to three-dimensional atmospheric general circulation models and two-dimensional time-dependent models of the whole climate system, have now been astronomically forced in order to test the physical reality of the astronomical theory. The output of most recent modeling efforts compares favorably with data of the past 400,000 years. Accordingly, the model predictions for the next 100,000 years are used as a basis for forecasting how climate would evolve when forced by orbital variations in the absence of anthropogenic disturbance. The long-term cooling trend which began some 6,000 years ago will continue for the next 5,000 years; this first temperature minimun w1ll be followed by an amelioration at around $15 \mathrm{kyr}$ A.P. (after present), by a cold interval centered at $23 \mathrm{kyr}$ A.P., and by a major glaciation at around $60 \mathrm{kyr} \mathrm{A.P.}$

\section{Introduction}

The main purpose of this paper 18 to explain and to review the astronomical theory of paleoclimates that provides us with the opportunity to better understand the dynamical behavior of the climate system. In the process I will also tllustrate this theory (Figure 1) to be both at a crossing point of geology, astronomy, physics, chemistry, biology, and geophysics (all unions of the International Council of Scientific Unions) and related to processes of the solid Earth, the atmosphere, the hydrosphere, and the oceans (al1 at the basis of the International Union of Geodesy and Geophysics (IUGG) associations). From this point of view, it is a most fitting subject for global change studies [Malone and Roederer, 1984; National Research Council, 1986]. It is also an example of an application of pure fundamental science that not only aims toward better understanding, in this case of climate, but has applications that are directly relevant to the future of our modern world.

This paper will be broadly subdivided into three parts: (1) climate changes at the astronomical frequencies, (2) Milankovitch theory as a particular case of astronomical theories, and (3) revival of the astronomical theory since 1975, including modeling.

\section{Paleoclimates and Quaternary Glacial-Interglactal Cycles}

If we first assume that a record of the atmospheric global mean temperature for the Earth's surface is available for the whole history of the Earth, then its idealized variance spectrum (Fig- 


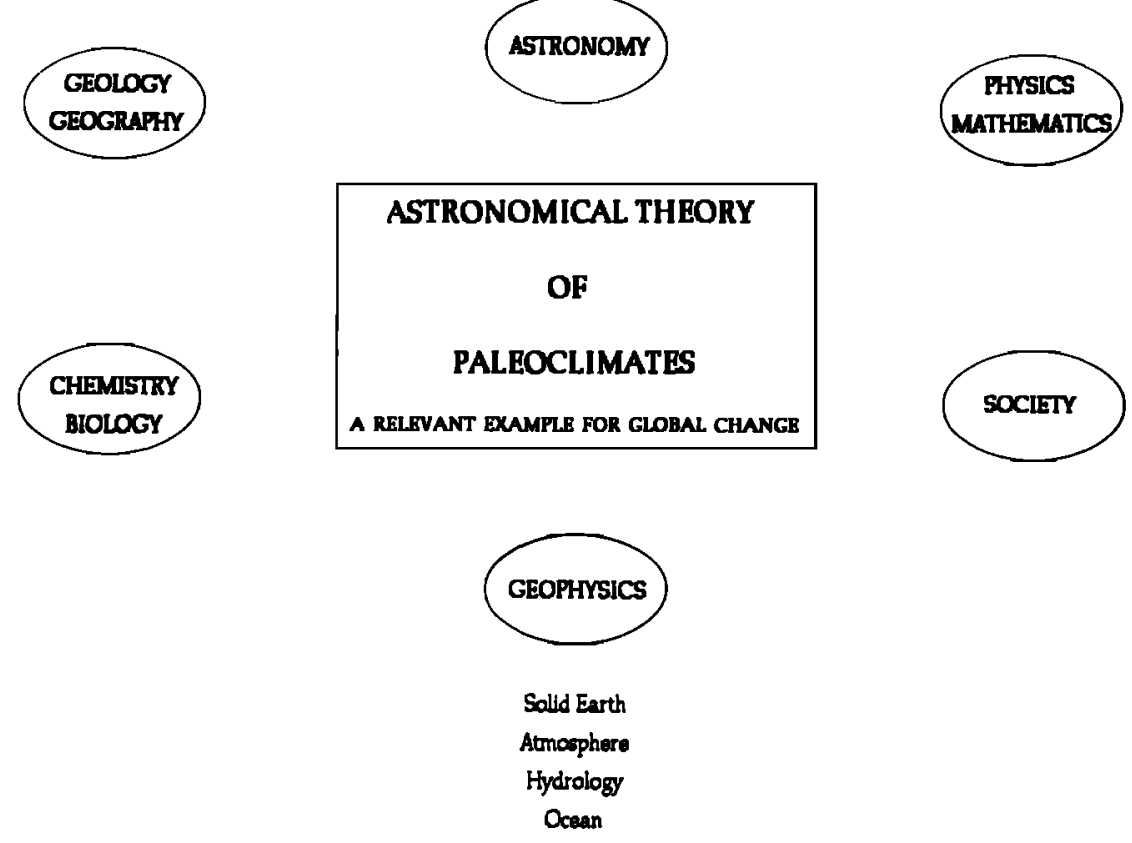

Fig. 1. The astronomical theory of paleoclimates, an inter-union and IUGG inter-assoclation problem.

ure 2) would illustrate the large variability in time of this parameter. (Recently, Imbrie and Shackleton [1986] have started collaborating on a project to evaluate such a distribution of climatic variance over a broad range of frequencies. This project uses soine of the records that have been generated from Deep-Sea Drilling Project sites as well as Pleistocene and Holocene records and should provide fundamental insights into the character of climatlc change in Earth history.) As visualized by Mitchell [1976], the spectrum shows a background level of variabtlity, deriving from internal stochastic mechanisms and corresponding to a low degree of predictability, which appears to increase in amplitude toward the longer time scales, superimposed on which is band-limited variability due to external forcing processes and correspondingly to a much higher degree of predictability (narrow spikes and broader peaks). The spikes are astronomically dictated; they are strictly perlodic components of climate variation, such as the diurnal and annual variations and their harmonics, whereas the peaks represent variations that are, according to Mitchell, either quasi-periodic or aperiodic, but with a preferred time scale of energlzation. The peak at 3-7 days is associated with the synoptic disturbances main$1 y$ at middle latitudes. The slightly raised region of the spectrum at 100-400 years is associated with variations on the time scale of, for example, the "Little Ice Age," which began in the early seventeenth century with rapid expansion of the mountain glaciers in Europe. The peak near 2500 years is, perhaps, due to the cooling observed after the so-called postglacial "Climatic Optimum" (also named the Atlantic interstade or hypsithermal in the American literature) which predomfnated during the great ancient civilizations about 5000 years ago and might be related to the characteristic time scale of the ocean [Pestiaux et al., 1988]. The next three peaks are related to the ice ages (the glacial-interglacial stages of the Quaternary). They are also related to deterministic astronomical variations in the orbital parameters of the Earth [Milankovitch, 1941]: the cycle at around 21,000 years to the axial precession; the period of about 41,000 years to the change in the obliquity of the ecliptic, or the axial tilt; and the cycle at about 100,000 years to the eccentricity of the orbit of the Earth. Finally, the peaks near 45 and 350 million years may be related to glaclations due to orogenic and tectonic effects and to the "drift" of the continents (plate tectonics). The astronomical theory thus focuses on one of the very well known deterministic forcing mechanisms of the climate system, that of the variations in the Earth's orbital parameters, and on the characteristic frequencies of the climatic response [Berger et al., 1984].

Our planet Earth was born some 4.5 billion years ago. Many 1mportant events mark its evolution [Crowley, 1983]:

1. The earliest form of life dates back $3.5 \times 10^{9}$ years ago.

2. The ftrst appearance of plants on land was $450 \times 10^{6}$ years ago.

3. Extensive swamps (at the origin of coal seams) formed $300 \times 10^{6}$ years ago.

4. Opening of the Atlantic started $220 \times 10^{6}$ years ago with the breakup of Pangaea.

5. Dinosaurs disappeared $70 \times 10^{6}$ years ago, and a major radiation of modern orders of mammals occurred from 70 to $50 \times 10^{6}$ years B.P. At this time the evolution of the Rocky Mountains began.

6. Alpine orogenesis started $40 \times 10^{6}$ years ago, and the Himalayan mountain building, $20 \times 10^{6}$ years later.

This long history has been studded with periods when the climate has been markedly colder than at others. These cold events, the so-called Ice Ages, have, on the geological time scale, been relatively short lasting, covering only perhaps 5- 


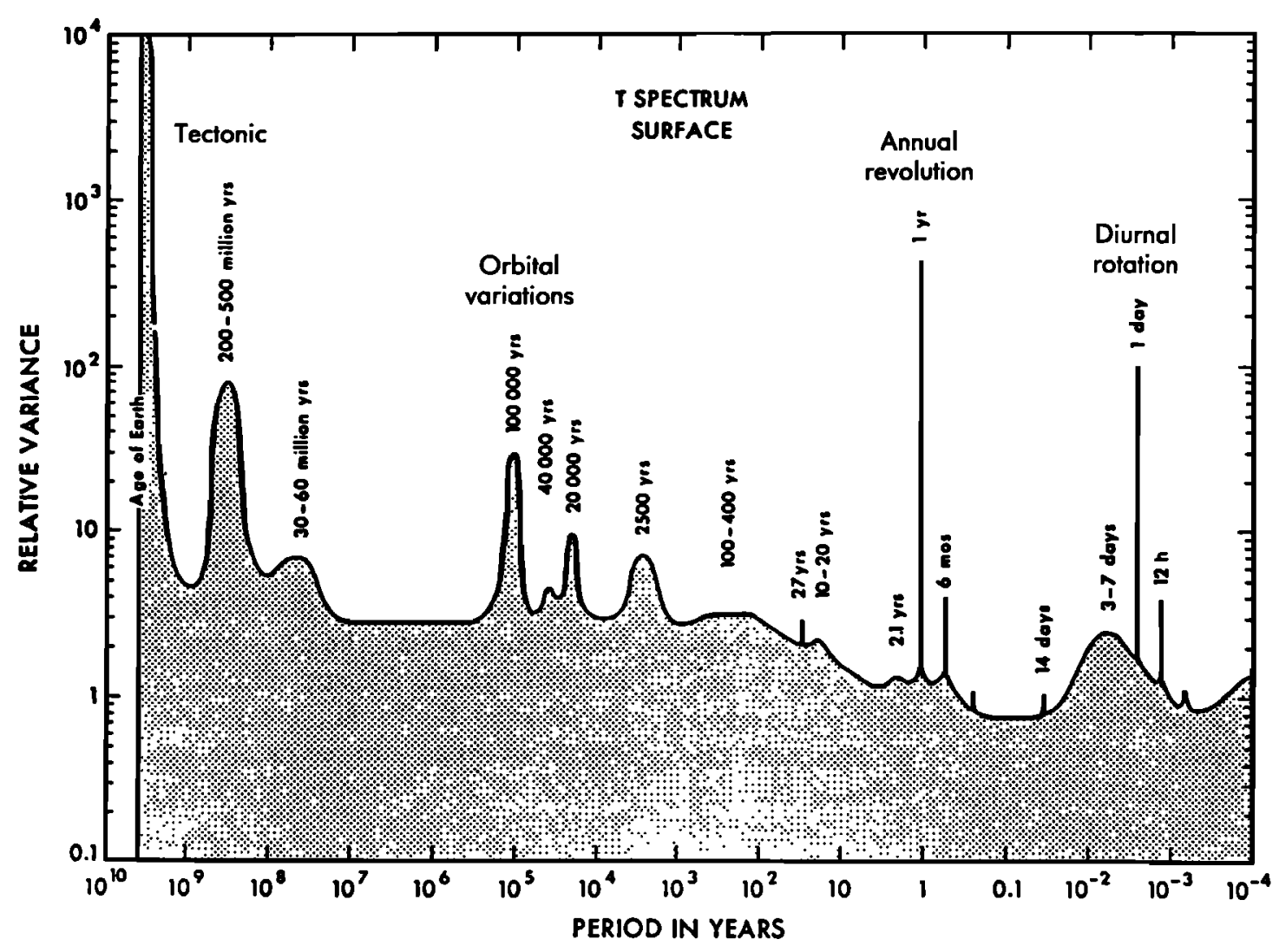

Fig. 2. Tentative spectrum of climatic variations. Estimate of relative variance of climate over all perlods of variation. A background level of variability, deriving from internal stochastic mechanisms and corresponding to a low degree of predictability, appears to increase in amplitude toward the longer time scales and to be overlaid by band-limited variability, due to external forcing processes and corresponding to a high degree of predictability (adapted from Mitchell [1976]).

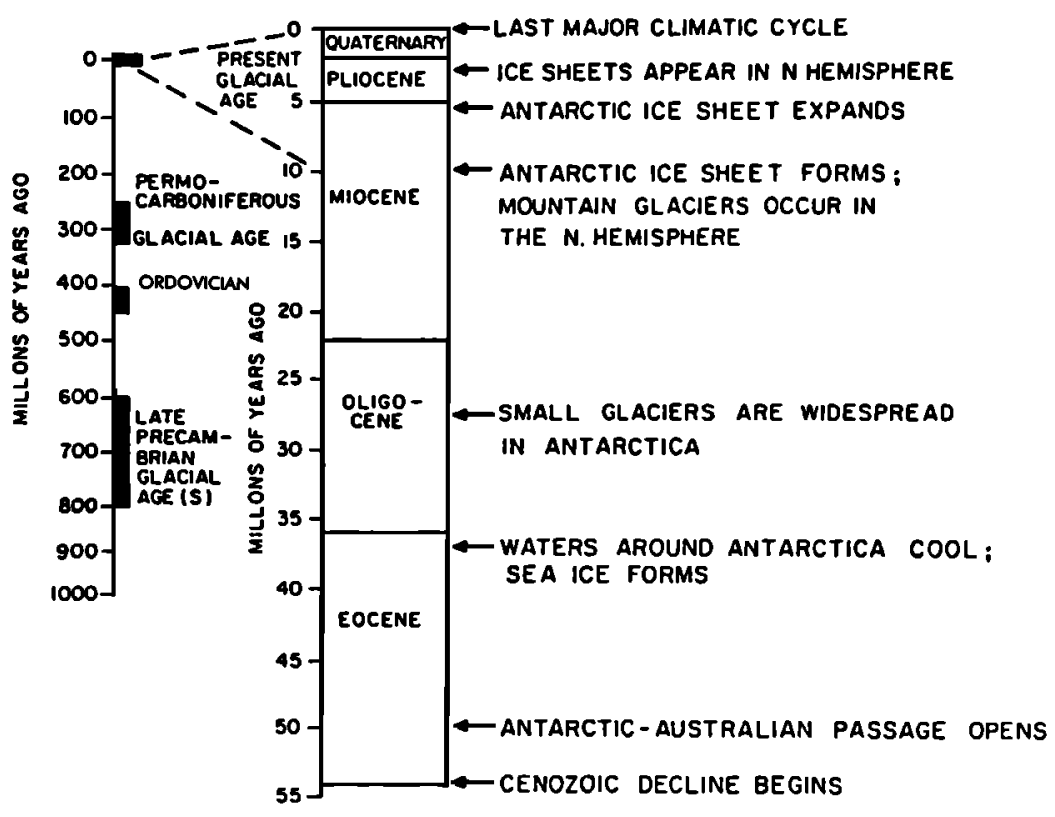

F1g. 3. The last billion years of climate. Intervals when ice sheets occurred in polar regions are indicated on the left as glacial ages [Erakes, 1979]. An outline of significant events in the Cenozoic climate decline is given on the right (adapted from Imbrie and Imbrie [1979] and reproduced with permission from the authors and Enslow Publishers). 


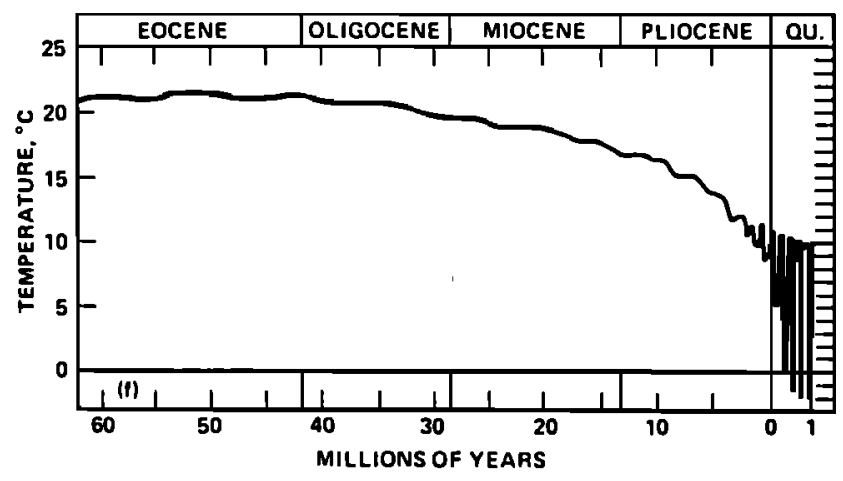

Fig. 4a. Estimate of the change in the averaged surface temperature of central Europe over the last $60 \mathrm{Myr}$ as $1 \mathrm{t}$ was given by Woldstedt [1961] (reprinted from Pollack [1982] with permission of the author and the National Academy Press). It must be pointed out that the Woldstedt time scale starts with the Quaternary. Moreover, the chronostratigraphy of the Eocene, Oligocene, Miocene, Pliocene, and Quaternary has been revised since. As shown in Figure 4b, they now begin at roughly $55,37.5,22.5,5$, and 1.8 Myr B.P., respectively [Van Eysinga, 1983]. On the other hand, the long interval of little variability of climate during the Tertlary given by Figure $4 \mathrm{a}$ reflects the temporal resolution and sampling frequency of the geological record, not the real cllmate history, which is better depicted in Figure $4 \mathrm{~b}$.

$10 \%$ of the Earth's time span. (These geological "periods" (Ice Ages with capital letters) must be distinguished from the Pleistocene glaciations called Pleistocene ice ages (with lower case letters) or glacials, which are "stages" at the geological time scale [Van Eysinga, 1983]. It is difficult to define precisely an Lce Age. According to Lamb [1977], it could be "a period when any islands or bigger landmasses which were then near the poles bore a cover of permanent ice." But it has also been characterized by "a very rapid decrease of temperature from low to high latitudes" [Brooks, 1970]. Their occurrence is illustrated in Figure 3, in which one can recognize the last Pre-Cambrian Ice Ages, the late Ordovician Ice Age, the Permo-Carboniferous Ice Age, and our Present Ice Age (within which we are enjoying the respite of a marked interglacial stage), which was preceded by the Antarctic ice sheet formation 2510 Myr B.P. [Kennett, 1977; Savin, 1977]. This last Ice Age, which the Earth entered 2-3 × $10^{6}$ years ago, is usually called the Quaternary Ice Age. (However, there are many disputes about whether or not this geological period must be differentiated from the Tertiary [Campy and Chaline, 1987]. It is composed of the Pleistocene and the Holocene, which are usually preferred terminology for this period (see Appendix A).) In central Europe, for example, the mean temperature went down from $20^{\circ}$ to $5^{\circ} \mathrm{C}$ (Figure 4 ).

This most recent Ice Age has been characterized by multiple switches of the global climate between glacial (with extensive ice sheets) and interglacial stages. For example, although paleoclimate records are still incomplete, the mean air surface temperature during the last glacial maximum, 20 kyr B.P., averaged over the whole Earth, is estimated as roughly $4^{\circ} \mathrm{C}$ lower than today [CLIMAP Project Members, 1976, 1981; Manabe and Hahn, 1977; Webb et a1., 1985]. But other changes affected also the sea surface temperatures, the sea level [Chappell and Shackleton, 1986], the intensity of the monsoons in the tropics [Kutzbach and Street-Perrott, 1985; Prell and Kutzbach, 1987], and the size of the fice sheets, particularly in middle and high latitudes of the northern hemisphere [Hughes et al., 1981]. As a matter of fact, this waxing and waning of the ice sheets occurred in a more or less regular way: in Figure 5, one can recognize a sawtooth shape with a 100-kyr quasi-cycle over which shorter quasi-cycles of roughly 41 and $21 \mathrm{kyr}$ are superimposed. It is these kinds of broad climatic features characterizing the last few million years (and probably other climatic variations of non-Ice Ages, like those which occurred during the Late Triassic [0lsen, 1986]) which are explained by the astronomical theory of paleoclimates. This theory claims that the changes in the Earth's orbital and rotational parameters have been sufficiently large during the Quaternary as to Induce significant changes in the seasonal and latitudinal distributions of the extraterrestrial insolation and so to force glacials and interglacials to recur in the manner deduced from geological records.

\section{Astronomical Theory of Paleoclimates:} A Historical Point of View

From the standpoint of climate dynamics the astronomical approach of glaciation theory is the oldest explanation of the existence of glacial periods in the geological record of the Quaternary Ice Age and through the Milankovttch approach, currently the most popular. As early as 1947 a daily newspaper in the Netherlands published a cartoon in which the present Earth climate was suddenly entering a glacial stage following a change in the Earth's axis of rotation!

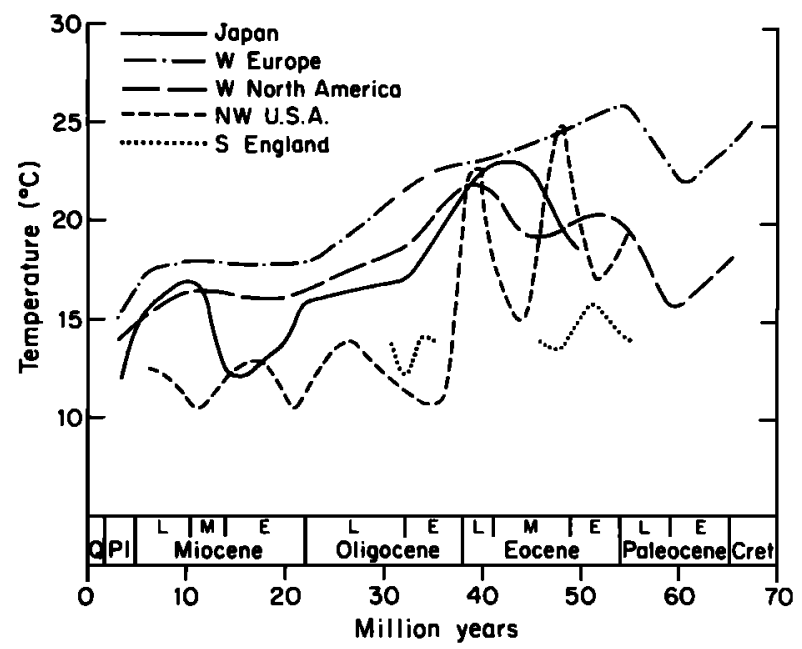

Fig. 4b. Tertiary trends of mean annual temperature from paleobotanical data [Savin, 1977; Frakes, 1979; Lloyd, 1984] (reprinted from Lloyd [1984] with permission from the author and Academic Press and from S. M. Savin and Annual Reviews). 
Core V28-238 ( $\left.\sim 1^{\circ} \mathrm{N}, 160^{\circ} \mathrm{E}\right)$

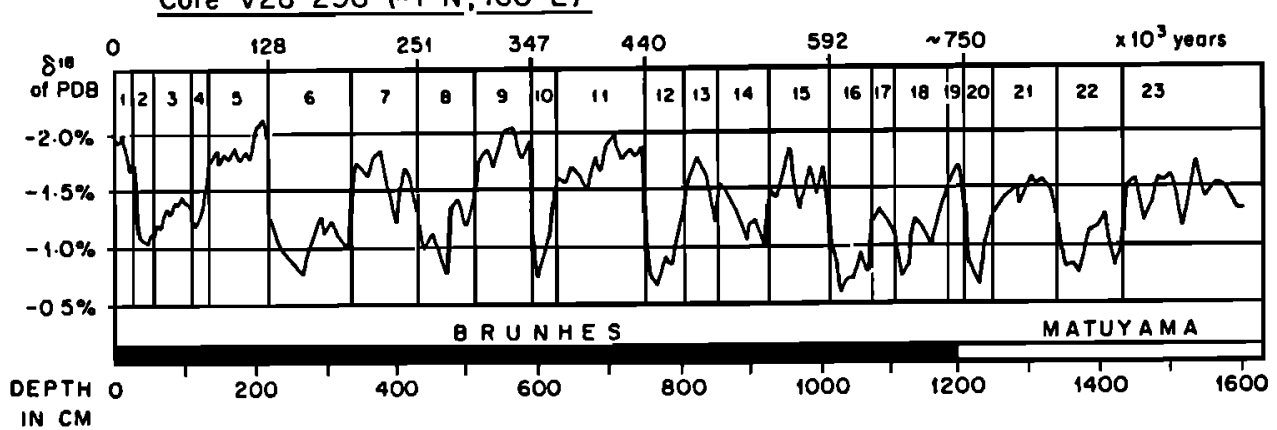

F1g. 5. Oxygen isotope and paleomagnetic record of the last $1.6 \mathrm{Myr}$ in core V28-238 from the equatorial Pacific $\left(\sim 1^{\circ} \mathrm{N}, 160^{\circ} \mathrm{E}\right)$. Isotope stages are shown in the upper part of the diagram. Isotopic values are from measurements on Globigerinoides sacculifer (after Shackleton and Opdyke [1976, p. 453] with permission from the authors and the Geological Society of America).

\subsection{Ploneers of the Astronomical Theory}

In fact, it was only a few years after the address delivered by L. Agassiz in 1837 [Agassiz, 1838] at the opening of the Helvetic Natural History Society at Neuchate1, "Upon Glaciers, Moraines and Erratic Blocks," that Adhémar [1842] published (In Paris) his book explaining Agassiz's hypothesis on the existence of ice ages on the basis of the known precession of the equinoxes (first discussed by $\mathrm{J}$. Herschel in 1830), thereby implying that there had likely been more than one (see Table 1 and Imbrie and Imbrie [1979]). An astronomer in Paris at that time Urbain Le Verrier, famed for discovering the orbital anomalies of Uranus which led to the discovery of Neptune, immediately calculated the planetary orbital changes of the Earth over the last $10^{5}$ years [Le Verrier, 1855].

Within the next decades, largely because of the discovery of the repetitive aspect of global glaciation in the Vosges, in Wales, and in the Ameri- can records of the Illinolan deposits, for example, glactal geology became strongly tied to astronomy [Meech, 1857]. Before 1864, James Croll initiated a serles of important works (they are quoted in Darwin's [1859] book) that would continue to bear much fruit into modern times. Three major astronomical factors were recognized in his model: axial tilt, orbital eccentrictty, and precession. The importance of Croll is that he approached the glaciation problem from the synergistic standpoint of the combined effects of all three of the major astronomical factors on seasonal Insolation during perihelion and aphelion [Crol1, 1875]. A specific characteristic of his model essentially lies in its hypothesis that the critical season for the initiation of glacial stages is northern hemisphere winter. He argued that a decrease in the amount of sunlight received during the winter favors the accumulation of snow and that any small initial increase in the size of the area covered by snow would be anplified by the snowfields themselves (positive feedback). After

TABLE 1. Milestones in Evolution of the Astronomical Theories of Pleistocene Ice Ages

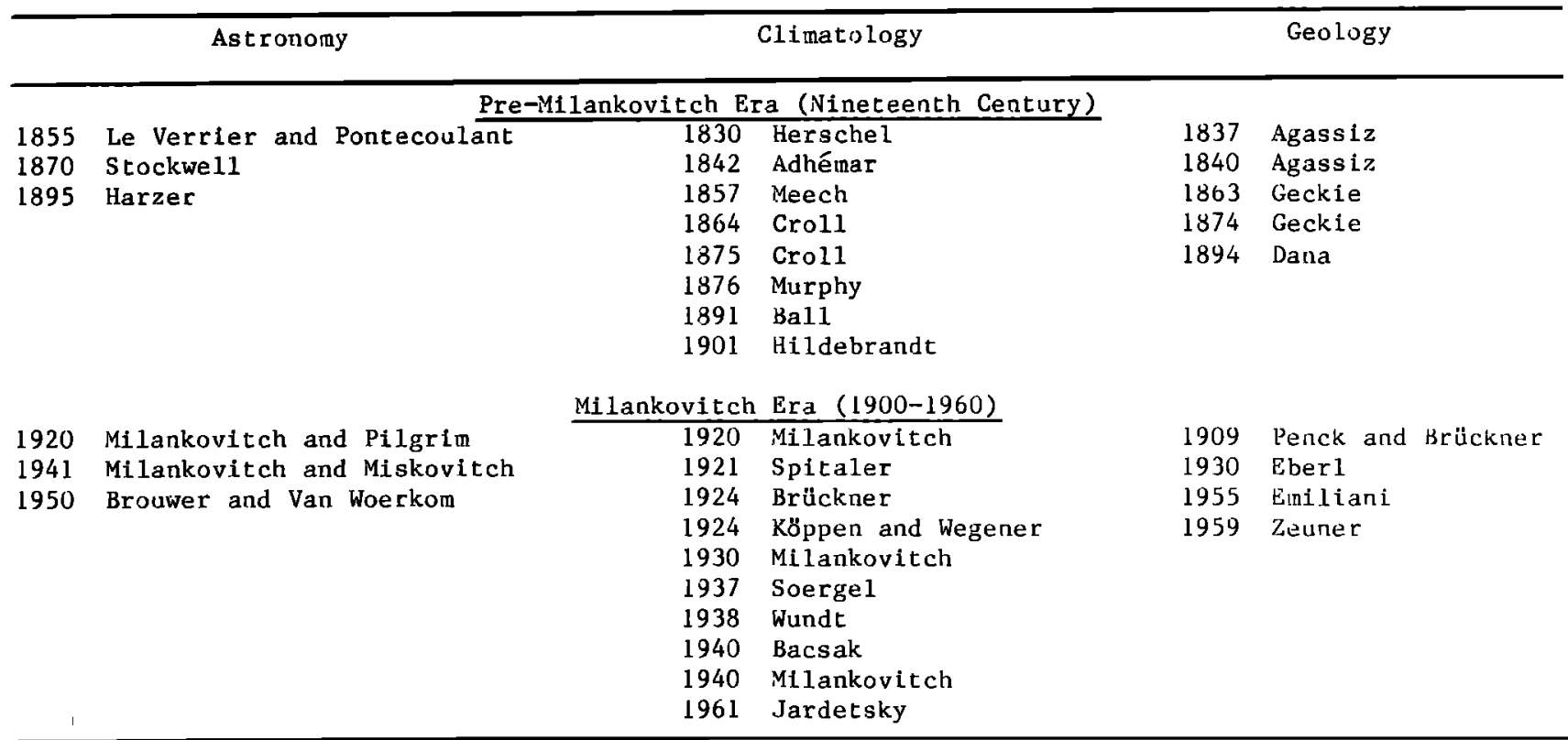



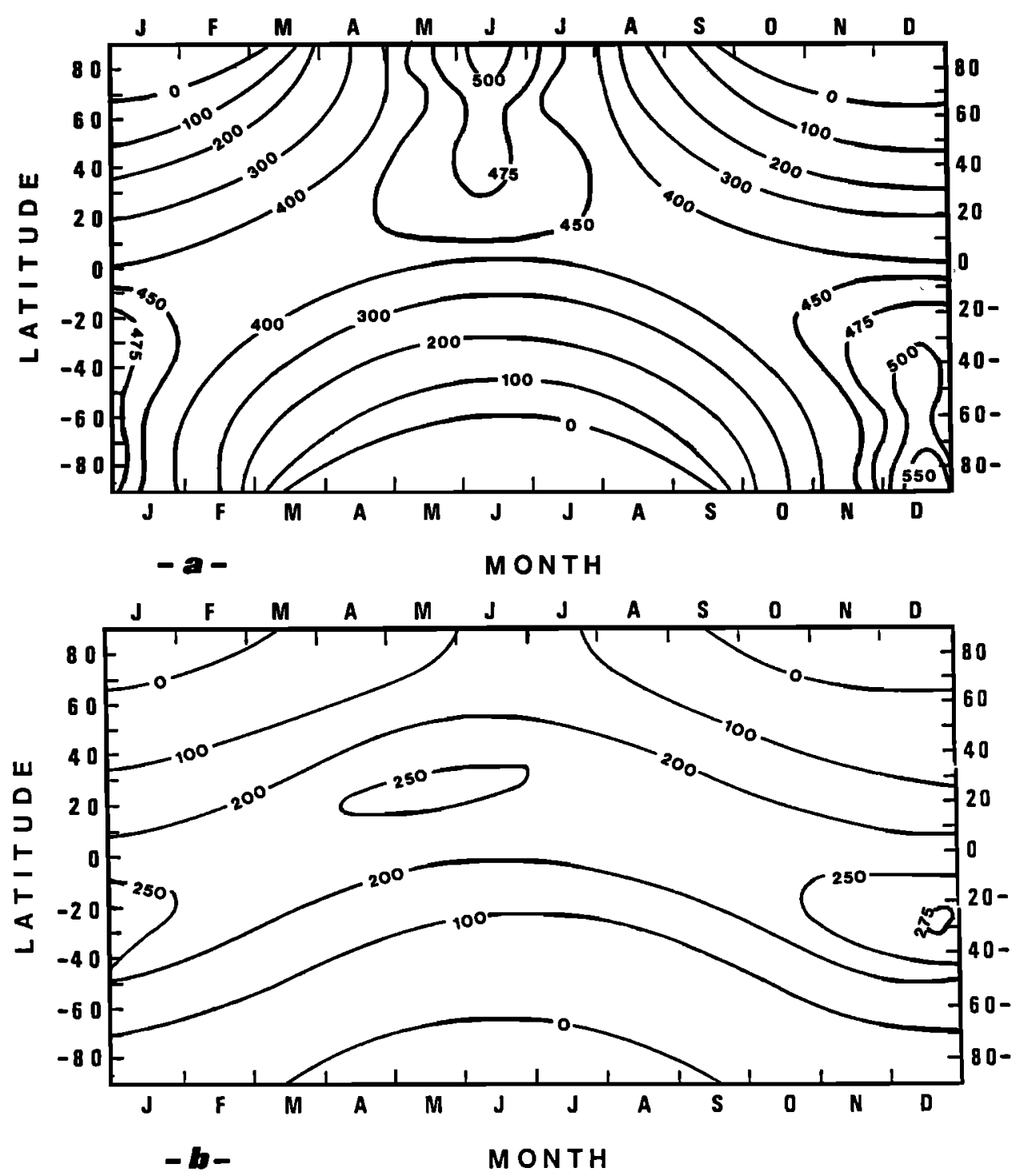

Fig. 6. Present-day insolation as a function of latitude and day of the year in watts per square meter (a) at the top of the atmosphere and (b) absorbed at the surface [after Tricot and Berger, 1988].

having determined which astronomical factors control the amount of sunlight recetved during the winter, he concluded that the precession of the equinoxes must play a decisive role. He also showed that changes in the shape of the orbit determine how effective the precessional wobble is in changing the intensity of the seasons. Croll's first theory predicts that one hemisphere or the other will experience an ice age whenever two conditions occur simultaneously: a markedly elongate orbit and a winter solstice that occurs far from the Sun. Later, Croll hypothesized that an ice age would be more 1ikely to occur during perlods when the axis is closer to vertical, for then the polar regions recelve a smaller amount of heat. Similar ideas about the astronomical influence on climate changes have been addressed by Ball [1891], Ekholm [1901], and Hildebrandt [1901], who stressed the Importance of the precession of the equinoxes, the obliquity of the ecliptic, and a small eccentricity, respectively.
As time went on, many geologists in Europe and America became more and more dissatisfled with Croll's theory, finding it at variance with new evidence that the last ice age had ended not 80,000 (according to his view) but 10,000 years ago. Moreover, theoretical argunents were advanced against the theory by meteorologists who calculated that the variations in solar heating described by Croll were too small to have any noticeable effect on climate (see appendix Table Bl for some key stages in the evolution of the astronomical theory).

\subsection{Milankovitch Era}

It was only during the first decades of the twentieth century that Spitaler [1921] rejected Croll's theory that the conjunction of a long, cold winter and a short, hot summer provides the most favorable conditions for glaciation. He adopted the opposite view, first put forward by 


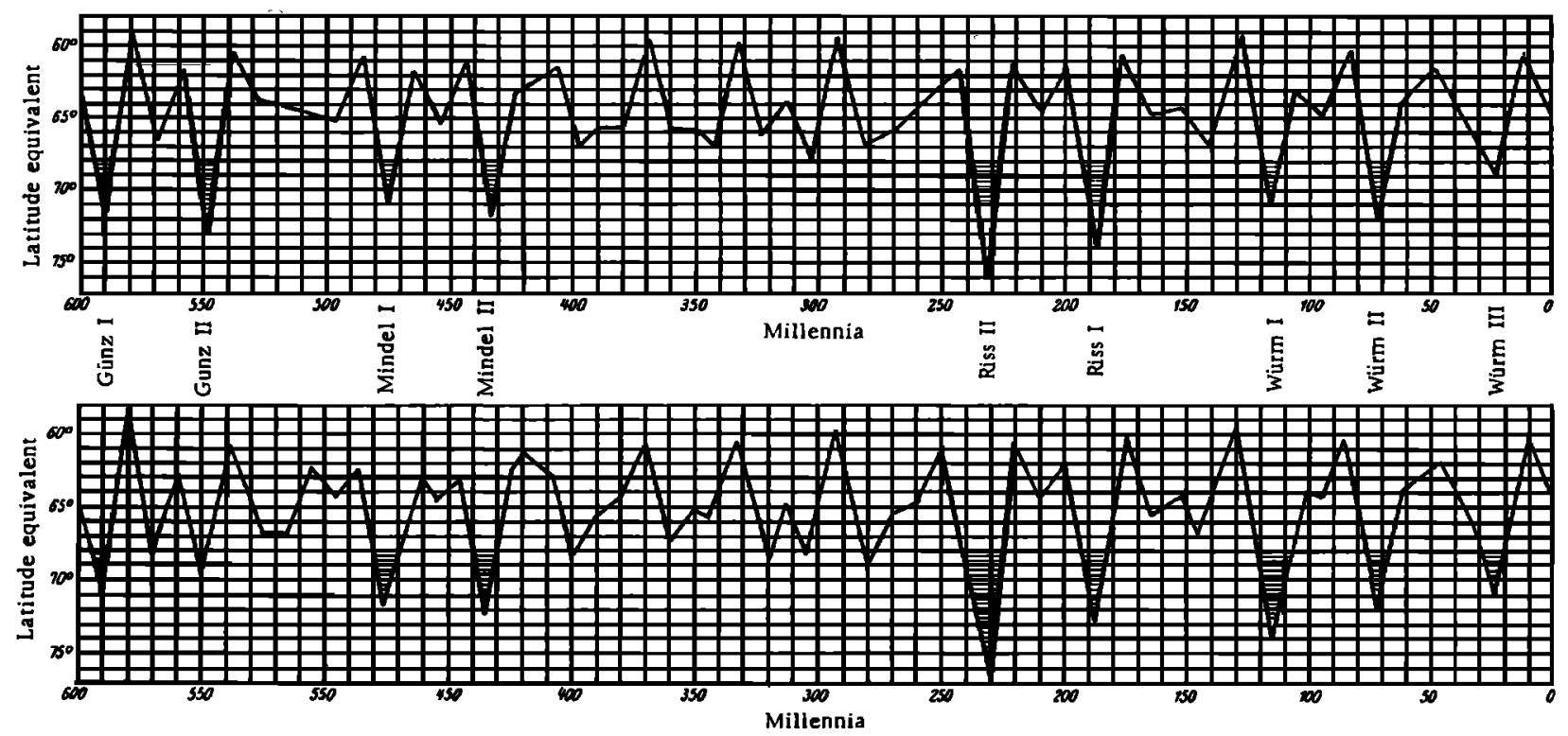

Fig. 7. The Mllankovitch radiation curves for latitude $65^{\circ} \mathrm{N}$ over the past 600,000 years. Milankovitch identified certain low points on the curve with four European lce ages [Milankovitch, 1941]. The top figure is from Milankovitch's 1920 computation according to Stockwell and PIIgrim, and the bottom figure is from his 1941 computation according to Le Verrier and Miskovitch (see Table 1). Vertical axis gives the $65^{\circ} \mathrm{N}$ Milankovitch equivalent latitudes; time along the horizontal axis is in thousands of years before present.

Murphy [1876], that a long, cool summer and a short, mild winter are the most favorable. This diminution of heat during the sumer half year was also recognized by Brückner, Köppen, and Wegener [Brückner et al., 1925] as the decisive factor in glaciation. Milankovitch, however, was the first to complete a full astronomical theory of Pleistocene ice ages, computing the orbital elements and the subsequent changes in the insolation and c1imate.

Milut in Milankovitch was a Yugoslavian astronomer who was born in Dalj in 1879 and died in Beograd in 1958. He was a contemporary of Alfred Wegener (1880-1930), with whom he became acquainted through Vladimir Köppen (1846-1940), Wegener's father-in-law [M. Milankovitch, 1950, 1952, 1957; Schwarzbach, 1985; V. Milankovitch, My Father: Milutin Milankovitch, unpublished manuscript, 1988 ].

Milankovitch's first book dates fron 1920, but his massive Special Publication of the Royal Serblan Academy of Science was published in 1941 and was translated into English only in 1969. Milankovitch's main contribution was to explore the solar irradiance at different lat ltudes and seasons in great mathematical detail, producing tabulations and charts of classical and permanent importance, and to relate these in turn with planetary heat balance as determined by the planetary albedo and by reradiation in the infrared according to Stefan's law. One of the most interesting results, shown in Figure 6a, was that although throughout most of the year insolation "at the top of the atmosphere" in equatorial regions understandably exceeds that of poleward areas, there are actually brief intervals near the summer solstice within each hemisphere when the reverse is true, particularly for southerly latitudes. This provided the basis at the heart of his argument that "under those astronomical conditions in which the heat budget around the summer solstice falls below average, so will suminer melt, with uncompensated glacial advance being the result."

This theory requires that the summer in northern high lattudes must be cold to prevent the winter snow from melting, in such a way as to allow a positive value $t n$ the annual budget of snow and ice, and to initiate a positive feedback cooling over the Earth through a further extension of the snow cover and subsequent increase of the surface albedo. On the assumption of a perfectly transparent atmosphere and of the northern high latitudes being the most sensitive to insolation changes, that hypothesis requires a minimum in the northern hemisphere summer insolation at high latitudes. The essential product of the Milankovitch theory is his curve (Figure 7) that shows how the intensity of summer sunlight varied over the past 600,000 years, on which he identifled certain low points with four European ice ages reconstructed 15 years earlier by Albrecht Penck and Eduard Brückner [Penck and Brückner, 1909].

\subsection{Milankovitch Debate}

If we consider this curve, however, we are left in no doubt that Milankovitch's success was only an apparent one, because the Quaternary has had many more glacial periods than was claimed during the first part of the twentieth century (see Figure 5 and Morley and Hays [1981]).

If irrelevant but long-standing criticisms (Appendix C) are left aside, the main factors influencing the dispute were (1) the accuracy of the astronomical solution for the Earth's orbit and rotation and of the related insolations (name- 
Iy in polar latitudes), (2) the insolation changes being too small for overcoming the resilience of the climatic system, and (3) the inaccurate geological time scale.

Until roughly 1970 the Milankovitch theory was largely disputed because the discussions were based on fragmentary geological sedimentary records and because the climate was considered too resilient to react to "such small changes" in the sumner half-year caloric insolation. This last point was already documented by Simpson [1940], using a crude climate model. Moreover, he attributed the glacial-interglacial cycles to periodic oscillations in the intensity of solar radiation, presumed to originate in the output of the Sun itself [Simpson, 1934, 1957]. He suggested that an increase in solar radiation would first raise the surface temperature and increase evaporation everywhere, leading to heavy snowfalls on high ground in high latitudes and consequently to glaclation. Although this ingentous hypothesis does not accord with the present observational evidence, it has led to the generation of many other insolation models with moderate success [Berger, [980a].

The first criteria to test the astrononical theory used a visual or statistical relationship between minima and maxima of geological and insolation curves [Brouwer, 1950; Jardetsky, 1961]. The Milankovitch summer radiation curve for $65^{\circ} \mathrm{N}$ was used more frequently because of the more extensive nature of Pleistocene glaciation in the northern hemisphere. Among the active supporters of the Milankovitch theory were Soergel [1937], who introduced a delay between the highest point of the ice masses and the lowest point of radiation; Blanc [1937], who succeeded in discovering the connection between the climatic variations and the varlations of sea level, in classifying them within the radiation curve, and thus in dating them astronomically; Wundt [1938], who recognized the importance of the albedo, of the continental. configuration, and of the air and sea currents; von Bacsak [1940], who paid more attention to the interglacial periods; Emiltani and Geiss [1957], who proposed a theury of glaciation using insolation changes to start (but not to end) glacial cycles; Zeuner [1959], who suggested that the Scandinavian ice sheet had its origin at approximately that latitude; and Bernard [1962], who extended the application of the astronomical theory to the intertropical regions.

These qualitative coincidences of the principal maxima and minima of both curves will, however, remain somewhat illusory unt 11 the ambiguities stemming from a priori assumptions about sensitive latitudes and response mechanisms are resolved. As an attempt to solve this problem, the following ideas have been proposed. Van den Heuvel [1966] used the insolation at latitudes north of $70^{\circ} \mathrm{N}$ as a guideline because there the dissymmetry between northern and southern hemispheres is largely attenuated, owing to the fact that in Arctic and Antarctic regions the caloric insolation variations caused by changes of the obliquity are much larger than those caused by changes in the precessional parameter. Following the same idea, Evans [1972] built an absolute time scale for the whole Pleistocene from insolation received at both $65^{\circ} \mathrm{N}$ and $65^{\circ} \mathrm{S}$, making an allowance for latent heat, albedo, and a 4000-year time lag. This is in opposition to Fairbridge [1961], who has referred to the northern hemisphere middle latitudes $\left(40^{\circ}-75^{\circ}\right)$ as the latitudes sensitive to climatic change, since approximately $95 \%$ of the world's mountain glaciers are located at this position. Kukla, searching for the missing link in the thermodynamic and meteorological balance of the atmosphere-hydrosphere-cryosphere system, used the insolation gradient curves [Kukla, 1972] and clained [Kukla, 1975] to have pinpointed the relevant time and space coordinates in early autumn and in the continental interiors of North America and Eurasia.

On the other hand, geologists searchlng for correlations between geological and astronomical times serles have also used the most simple models setting the equilibrium climatic state equal to a linear combination of astro-insolation curves. Analysis of the idealtzed curve for surface water temperature of the Atlantic Ocean given by EmilIani [1955] led Broecker [1966] to an astronomical-climatic curve based upon an orlginal combination of precession, tilt, and eccentricity. The overall effect of his weighting factors was to create a deep $18 \mathrm{kyr}$ B.P. minimum, two important maxima at 120 and $80 \mathrm{kyr}$ B.P., and a long period of intermediate climate between 70 and $22 \mathrm{kyr}$ B.P., where the $48 \mathrm{kyr}$ B.P. prominent warm peak found in the Milankovitch curve is greatly depressed. Assuming the half response time for the continental glaciers to be 3000 years, his ice volume curve became consistent with observations. Following this idea, Broecker et al. [1968] used the $45^{\circ} \mathrm{N}$ insolation curve (where the precession effect is given more weight than is tilt effect) in such a way that the warm peak at $50 \mathrm{kyr}$ B.P. is largely removed and a new peak appears at $106 \mathrm{kyr}$ B.P. These results clearly indicate that the last four sea level high stands, and therefore low ice volume $(122,103,82$, and 5 kyr B.P.), correspond closely in time to the last four prominent warın peaks $(127,106,82$, and 11 kyr B.P.) in the modified curve of summer insolation, not only in chronology but also in magnitude. This matching with the coral terraces of Barbados [Mesolella et al., 1969], of New Guinea [Bloom et al., 1974], and of Hawaii [Ku et al., 1974] was one of the first convincing arguments advanced in support of the orbital theory. However, on the basis of very accurate dating of core V12-122, Broecker and van Donk [1970] had to increase by $25 \%$ the absolute time scale adopted by Emiliani for deep-sea cores. They then proposed $45^{\circ}, 55^{\circ}$, and $65^{\circ} \mathrm{N}$ summer insolation as a tool to explain the gradual glacial buildups over periods averaging 90,000 years and terminated by deglaciation completed in less than one-tenth this time (this close agreement between maxima of the North At lantic paleoclimatic curve and the $55^{\circ} \mathrm{N}$ insolation curve since $225 \mathrm{kyr}$ B.P. was also found later by Ruddiman and McIntyre [1979] to suggest a causa1 relationship). At the same time, Veeh and Chappell [1970] obtained, for the last 230,000 years, a similar correlation between sea levels derived from ralsed coral reefs of New Guinea and summer insolation at $45^{\circ} \mathrm{N}$. Moreover, these sea level changes determined from dated coral reefs on rising islands are synchronous with precessional changes in solar radiation when orbital eccentricity is large, whereas oxygen isotope variations in deep-sea cores correspond in timing but not in 
amplitude, reflecting changing isotopic composition of Pleistocene ice caps [Chappe11, 1974].

Climatologists have also attacked the problem theoretically by adjusting the boundary conditions of energy balance models (EBM) and then observing the magnitude of the calculated response. If these early numerical experiments are viewed narrowly as a test of the astronomical theory, they are open to question because the model used contains untested parameterization of important physical processes. Indeed, in simple annual mean energy balance models [Budyko, 1969; Sellers, 1970] which suggested that the climatic response to orbital changes was too small to account for the succession of Pleistocene ice ages, the albedo feedback mechanisms in high latitudes, the oceanic circulation, the ocean-climate interactions, and the dynamics of the cryosphere were poorly simulated or even not simulated at all.

As changes in the orbital parameters cause only small changes in the latitudinal distribution of the annual mean incident solar radiation and as seasonal changes could be many times as large, orbital changes would perhaps lead to larger responses in a seasonal model. From Adem's thermodynamic model, Shaw and Donn [1968] made such a quantitative evaluation of the Milankovitch effect. Although their simulated temperature variations seem to be controlled by the precession at low latitudes and by the tilt at high latitudes, the mean decrease in high latitudes amounts to only $1.4^{\circ} \mathrm{C}$ for the maximum summer radiation deficiency at 25 kyr B.P. Similarly, using a statistical-dynamical model, Saltzman and Vernekar [1971] have found relatively small changes in surface temperature between 25 and $10 \mathrm{kyr}$ B.P. For such a summer radiation change of $7 \%$, temperature change amounts to only $1.4^{\circ} \mathrm{C}$ at $85^{\circ} \mathrm{N}$ and $1.2^{\circ} \mathrm{C}$ at $65^{\circ} \mathrm{N}$.

\subsection{Milankovitch Renaissance}

In the late 1960s, Judiclous use of radioactive dating and other techniques gradually clarified the details of the time scale [Broecker et al., 1968], better instrumental methods came on the scene for uging oxygen isotope as ice age relics [Shackleton and Opdyke, 1973], ecological methods of core interpretation were perfected [Imbrie and Kipp, 1971], global climates in the past were reconstructed [CLIMAP Project Members, 1976], and atmospheric general circulation models [Smagorinsky, 1963] and climate models became available [Alyea, 1972]. With these 1mprovements in dating and in interpretation of the geological data in terms of paleoclimates and with the advent of computers and the development of astronomical and climate models, it became necessary to investigate more critically all four main steps of the astronomical theory, namely, (1) computation of the astronomical elements, (2) computation of the appropriate insolation parameters, (3) the development of suitable climate models, and (4) further analysis of geological data in the time and frequency domains in order to investigate the physical mechanisms and to calibrate and validate the climate models.

\section{Earth's Orbital Parameters}

For any latitude on the Earth, the insolation available at the "top of the atmosphere" is a

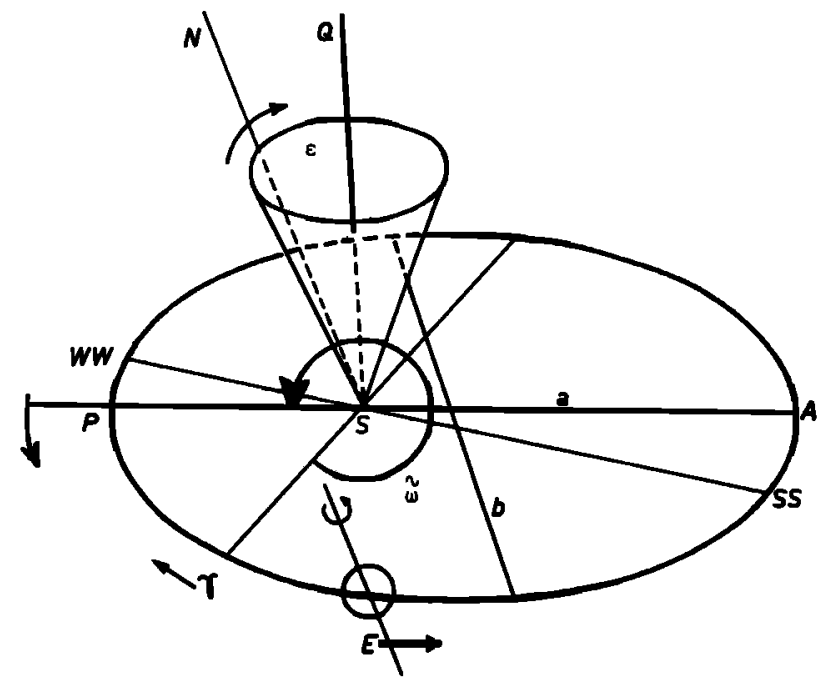

Fig. 8. Elements of the Earth's orbit. The orbit of the Earth, $F$, around the Sun, $S$, is represented by the ellipse PYEA, $P$ being the perihellon and $A$ the aphelion. Its eccentricity $e$ is given by ( $a^{2}$ - $\left.b^{2}\right)^{1 / 2} / a$, a being the semimajor axis and $b$ the semiminor axis. WW and SS are the winter and summer solstice, respectively; $\gamma$ is the vernal equinox. WW, SS, and $\gamma$ are located where they are today. $S Q$ is perpendicular to the ecliptic, and the obliquity $\varepsilon$ is the inclination of the equator upon the ecliptic; i.e., $\varepsilon$ is equal to the angle between the Earth's axis of rotation $S N$ and $S Q$. Parameter $\omega$ is the longitude of the perihelion relative to the moving vernal equinox, and is equal to $\pi+\psi$. The annual general precession in longltude, $\psi$, describes the absolute motion of $\gamma$ along the Earth's orbit relative to the fixed stars. The longltude of the perihelton, $I$, is measured from the reference vernal equinox of A.D. 1950 and describes the absolute motion of the perihelion relative to the fixed stars. For any numerical value of $\tilde{\omega}, 180^{\circ}$ is subtracted for a practical purpose: observations are made from the Earth, and the Sun is considered as revolving around the Earth [Berger, 1980b].

single-valued function of the solar constant $\mathrm{S}_{0}$; of the semimajor axis of the Earth's orbit, a (related to the length of the year); of the orbital eccentricity $e$ and its obliquity $\epsilon$; of the longttude of the perihelion, $\omega$, measured from the moving vernal equinox; and of the rotational angular velocity of the Earth (related to the length of the day and to the general circulation) (Figure 8). Parameters $e$ and $\underset{\omega}{\omega}$ combine to form the climate precessional parameter e sin $\tilde{\omega}$. This parameter plays an opposite role in each hemisphere and is a measure of the difference in length between half-year astronomical seasons and of the difference between the Earth-Sun distance at both solstices. Obliquity affects mainly the seasonal contrast and the latitudinal gradient of Insolation. While $\varepsilon$ and $e$ sin $\omega$ only act to redistribute insolation among latitudes and seasons, the energy influx integrated over all latitudes and over an entire year is found to depend only on $e$ (a and $\mathrm{s}_{0}$ being assumed constant here).

Eccentricity defines the shape of the orbit (presently 0.016), the obliquity measures the 
TABLE 2. Evolution in the Computation of Long-Term Variations of the Earth's Orbital Elements

Power as to

the Disturbing
Degree in Planetary Eccentricities and Inclinations

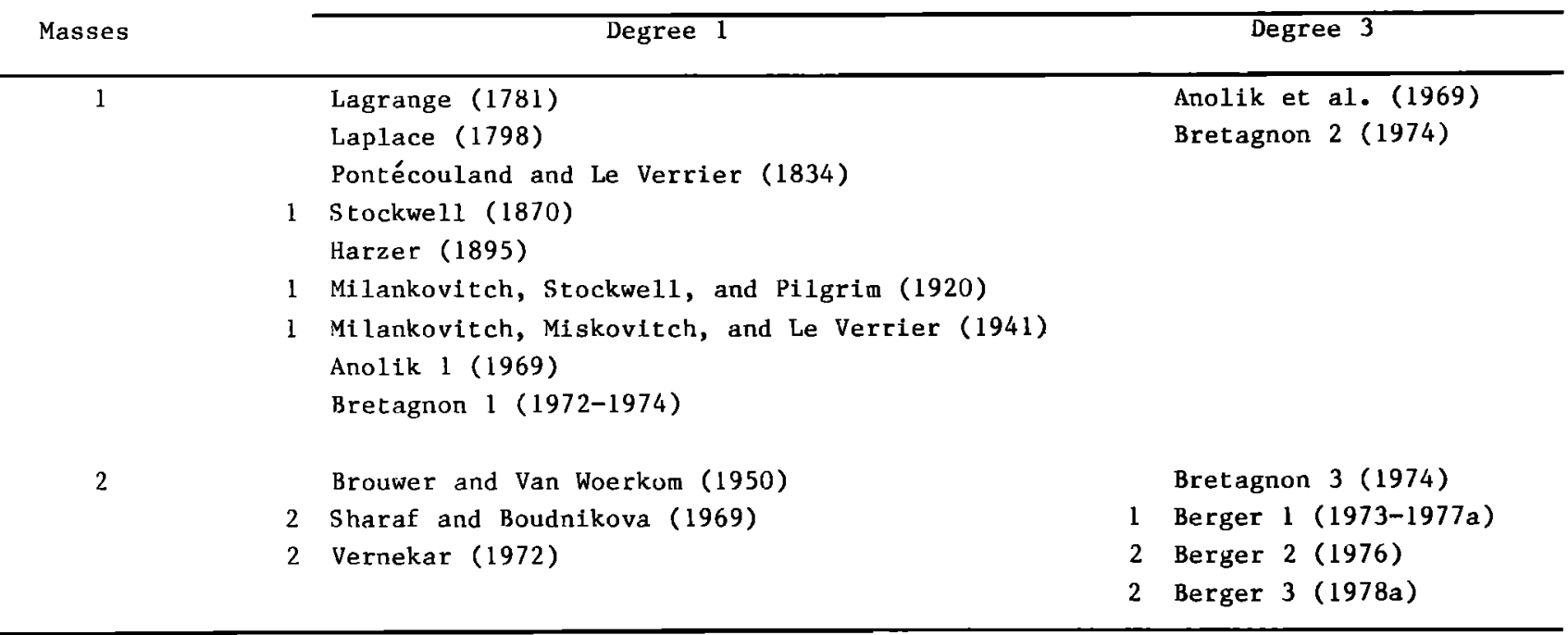

Numerals preceding entries indicate the degree of the expansion of obliquity and climatic precession with respect to the Earth eccentricity. Numerals after some names give the number of the solution.

angle between the Earth's axis of rotation and the perpendicular to the ecliptic (its present value is $23^{\circ} 27^{\prime}$ ), and the longitude of the perthelton is a measure of the Earth-Sun distance at a particular season (for example, at the present day, the Earth is about at the perihelion at the northern hemisphere winter solstice). The perturbations of these orbital elements are due to the gravitational effects of the different planets on the Earth's orbit. The differential equations of the planetary motions can be formulated as

$$
\begin{aligned}
& \frac{d \sigma_{k, n}}{d t}=\sum_{\substack{j=1 \\
j \neq n}}^{8} \sum_{i=1}^{6} f_{i, n}\left(\sigma_{1, n}, \cdots, \sigma_{6, n}\right) \frac{\partial R_{j, n}}{\partial \sigma_{i, n}} \\
& \sigma_{i, n}=\{h, k, p, q, a, \lambda\}_{\text {in }} \quad 1<i<6 \quad 1<n<9 \\
& R_{j, n}=\sum_{r, s, t, u} A\left(a_{j}, a_{n}, m_{j}, m_{n}\right) e_{j}^{r} e_{n}^{s}\left(\sin i_{j} / 2\right){ }^{t} \\
& \cdot\left(\sin i_{n} / 2\right)^{u} \cos \phi_{j, n} \\
& \phi_{j, n}=b_{1} \lambda_{j}+b_{2} \lambda_{n}+b_{3} \pi_{j}+b_{4} \pi_{n}+b_{5} \Omega_{j}+b_{6} \Omega_{n}
\end{aligned}
$$

The $\sigma$ represent the six orbital parameters: ( $h$, $k$ ) combine the eccentricity and the longitude of the perihelion; ( $p, q$ ) combine the inclination of the ecliptic and the longitude of the node; $a$ is the semimajor axis, and $\lambda$ is the longitude of the Earth; $\lambda, \pi$, and $\Omega$ are the longitude of the planet, the perihelion, and the node, respectively; $r$, $s, t, u$, and the $b$ are integers. $R$, the perturbation function, shows that the solutions will progress in powers of small parameters: the ratio m of the mass of the planets to that of the Sun, and the eccentricity e of the planets' orbit and their inclination $i$ to the reference plane. A similar system of equations governs the Earth's rotation and precession laws. The most up-to-date solution (Table 2) is now to the second order in the masses and to the third degree to the planetary eccentricities and inclinations. Critical analysis of theories of the long-term variations of the elements of the Earth's orbit and their numerical comparisons lead to conviction that the most upto-date solution that I published in 1978 [Berger, $1978 \mathrm{a}, \mathrm{b}, \mathrm{c}, \mathrm{d}, \mathrm{e}]$ is close to the ideal one and most probably provides valuable information back to 2 Myr B.P. (at least the accuracy of the frequencles of my 1978 solution seems to be much higher than was assumed by Berger [1984], according to one recent computation made by Laskar [1984, personal communication, 1987]. For example, when the Milankovitch eccentricity is compared to the Bretagnon [1974] values used in my solution for the last $1,000,000$ years, large departures occur as early as $300 \mathrm{kyr}$ B.P. (Figure 9).

If the most important high-order terms are included, each of the classical astro-insolation parameters can be expressed as a quasi-periodic function of time:

$$
\begin{aligned}
& e=e_{0}+\sum_{i} E_{i} \cos \left(\lambda_{i} t+\beta_{i}\right) \\
& e \sin \tilde{\omega}=\sum_{i} P_{i} \sin \left(\alpha_{i} t+\zeta_{1}\right) \\
& \epsilon=\varepsilon *+\sum_{i} A_{i} \cos \left(\tilde{f}_{i} t+\tilde{\delta}_{i}\right)
\end{aligned}
$$

Besides its simplicity and practicality for easy computation, this form allows us also to obtain the main perlods assoclated with the astronomical theory of climate as shown in Table 3. The main periodicities of $100,41,23$, and $19 \mathrm{kyr}$ and the 54-kyr periodicity are found in spectra of 

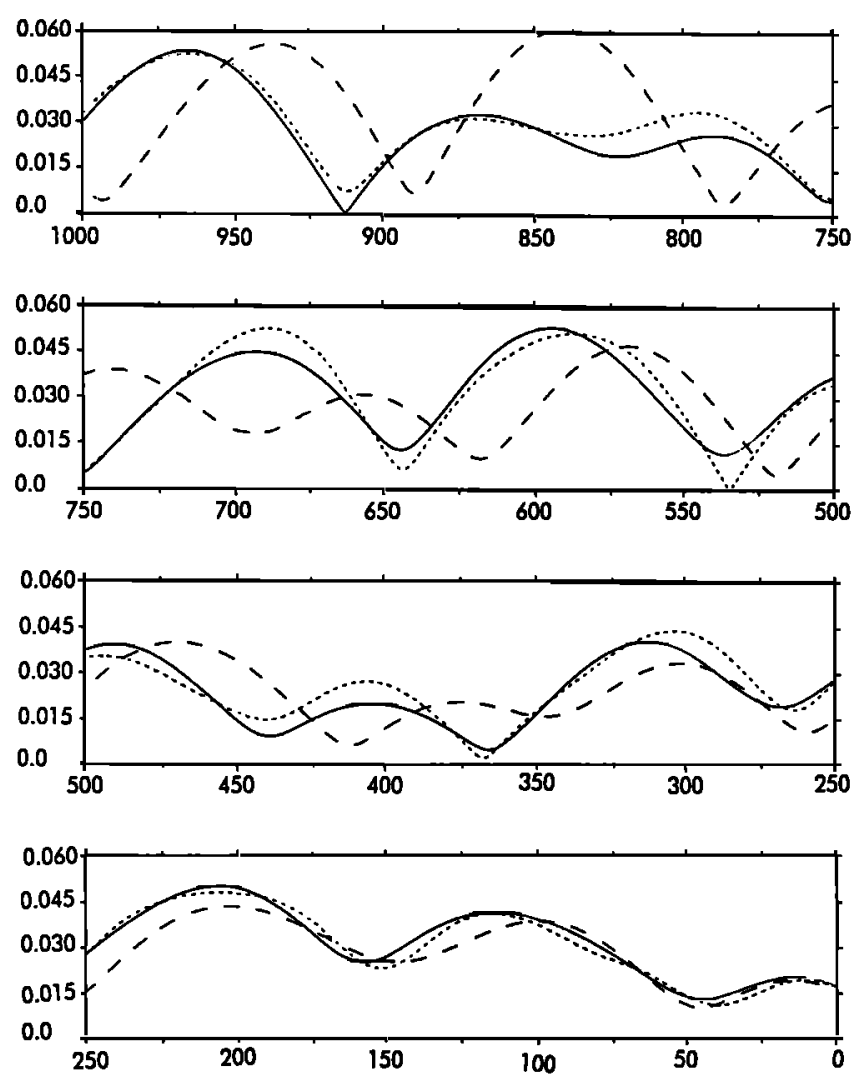

Fig. 9. Long-term variations of the eccentricity of the Earth's orbit over the last $10^{6}$ years. The solid curve represents the Berger 3 solution [Berger, 1978c], the dotted curve the Sharaf-Budnikova-Vernekar solution [Vernekar, 1972], and the dashed curve the Milankovitch-Miskovitch-Le Verrier solution [M1lankovitch, 1941] (see Table 2).

geological records. These periods come from a set of fundamental periods of the planetary system (the most important ones are related to Venus, to Jupiter, and to the general precession in longitude; see Table 4). The method used for solving the set of differential equations analytically makes it possible to trace each period directly Involved in the astronomical theory of paleoclimates back to its source [Berger et al., 1987]. The 23-kyr perlodicity originates directly from perlodicities at 308,000 and 25,700 years (Figure 10). That for $41 \mathrm{kyr}$ has an origin which is a little more complicated, as is also the case for $100 \mathrm{kyr}$.

If one analyses the parameters on which the main frequencies of precession and obliquity depend [Berger, 1976a], one finds that they are directly proportional to the dynamical flattening of the Earth, (C-A)/C, and related to the cube of the Inverse Earth-Moon mean distance. The latter is roughly constant over our period of interest, as the Moon has moved away from the Earth by only about $200 \mathrm{~km}$ (compared with a mean distance of over $380,000 \mathrm{~km}$ ) since $5 \mathrm{Myr}$ B.P. As far as (CA)/C is concerned, the problem is more compllcated, as it clearly changes with the accumulation of huge ice sheets in polar regions. The problem is by how much. A rapid circulation [Berger et al., 1987] of this effect at $20 \mathrm{kyr}$ B.P., a time when the American and Eurasian ice sheets accumulated roughly $40 \times 10^{6} \mathrm{~km}^{3}$ of ice in northern polar latitudes, shows that in the absence of a loading depression of the Earth's crust, it affects the frequencles by $1 \%$ at the very maximum. The main periods of precession and obliquity would thus be decreased by 130,210 , and 660 years respective1y, which would lead to a shift in the insolation curves of 1000 years maximum over a full l00-kyr glactal cycle. These results, however, are sensitive to the isostatic response of the lithosphere, and the total effect seems to be negligible over the whole Plelstocene period.

Computations to reconstruct the astronomical parameters over the last $5 \mathrm{Myr}$ (only the last 250,000 and the next 100,000 years are shown in Figure 11) show that e varies between 0.0 and 0.0607 with an average quasi-period of $95 \mathrm{kyr}$, and that $\varepsilon$ varies between $22^{\circ}$ and $24^{\circ} 30^{\prime}$ with a quasiperiod of $41 \mathrm{kyr}$. The revolution of the vernal point relative to the moving perihelion (which is related to climatlc precession) has an average quas1-period of 21,700 years, whereas relative to the fixed perihelion of reference, this quasiperiod is 25,700 years (the very well known astronomical precession of the equinoxes).

The same conclusions hold for the insolation parameters [Berger and Pestiaux, 1984]. The error due to the astronomical perturbations on their main frequencies remain well within less than $1 \%$ over the last $10 \mathrm{Myr}$. The fundamental periods do not deteriorate with time over the Quaternary, but their relative importance is a function of the

TABLE 3. Periods Associated with the Main Terms [Berger, 1977] in the Analytical Expansions of Precession, Obliquity, and Eccentricity

\begin{tabular}{|c|c|c|c|c|c|c|c|c|}
\hline \multicolumn{3}{|c|}{ Precession } & \multicolumn{3}{|c|}{ Ob1iquity } & \multicolumn{3}{|c|}{ Eccentricity } \\
\hline No. & Amplitude & $\begin{array}{l}\text { Period } \\
\text { (years) }\end{array}$ & No. & Amplitude & $\begin{array}{l}\text { Period } \\
\text { (years) }\end{array}$ & No. & Amplitude & $\begin{array}{l}\text { Period } \\
\text { (years) }\end{array}$ \\
\hline $\begin{array}{l}1 \\
2 \\
3 \\
4\end{array}$ & $\begin{array}{r}0.0186080 \\
0.0162752 \\
-0.0130066 \\
0.0098883\end{array}$ & $\begin{array}{l}23,716 \\
22,428 \\
18,976 \\
19,155\end{array}$ & $\begin{array}{l}1 \\
2 \\
3 \\
4 \\
5\end{array}$ & $\begin{array}{r}-2462.22 \\
-857.32 \\
-629.32 \\
-414.28 \\
-311.76\end{array}$ & $\begin{array}{l}41,000 \\
39,730 \\
53,615 \\
40,521 \\
28,910\end{array}$ & $\begin{array}{l}1 \\
2 \\
3 \\
4 \\
5 \\
6\end{array}$ & $\begin{array}{r}0.011029 \\
-0.008733 \\
-0.007493 \\
0.006724 \\
0.005812 \\
-0.004701\end{array}$ & $\begin{array}{r}412,885 \\
94,945 \\
123,297 \\
99,590 \\
131,248 \\
2,035,441\end{array}$ \\
\hline
\end{tabular}


TABLE: 4. Fundamental Periods (in years) of Earth's Orbit and Rotation [Bretagnon, 1974; Berger, 1976a]

\begin{tabular}{|c|c|c|c|c|c|}
\hline e $\sin \pi$ & Argument & $\sin t \sin \Omega$ & Argument & $\begin{array}{c}\text { General } \\
\text { Precession }\end{array}$ & Argument \\
\hline $\begin{array}{r}176,420 \\
308,043 \\
72,576 \\
75,259 \\
249,275 \\
49,434 \\
422,814 \\
1,940,518\end{array}$ & $\begin{array}{l}\phi_{2}: \text { Venus } \\
\phi_{5}: \text { Jupiter } \\
\phi_{4}: \text { Mars } \\
\phi_{3}: \text { Earth } \\
\phi_{1}: \text { Mercury } \\
\phi_{6}: \text { Saturn } \\
\phi_{7}: \text { Uranus } \\
\phi_{8}: \text { Neptune }\end{array}$ & $\begin{array}{r}68,829 \\
230,977 \\
72,732 \\
191,404 \\
49,339 \\
432,023 \\
1,874,374\end{array}$ & $\begin{array}{l}\theta_{5} \\
\theta \\
\theta_{3}^{3} \\
\theta^{1} \\
\theta_{4}^{4} \\
\theta_{6}^{2} \\
{ }_{0}^{6} \\
{ }^{6} \\
{ }_{8}^{7}\end{array}$ & 25,694 & $\mathbf{k}$ \\
\hline
\end{tabular}

period considered: for example, the obliquity and the $19 \mathrm{kyr}$ precession signals are largely depleted between 1.6 and 2.4 Myr B.P. (Figure 12).

The degree of confidence in the basic astronomical solution makes it worth trying to answer the following three questions:

1. Are the quasi-periodicities of the Earth's orbital elements represented by significant contributions to variance as seen in climatic spectra?

2. Is there significant correlation and phase coherency between insolation and geological curves?
3. Can the insolation changes induce climatic changes of magnitudes similar to those which have been recorded in geological data? If so, what physical mechanisms are involved?

The answer to these questions is yes provided that solar output and paleogeography were constant over the last $3 \mathrm{Myr}$ and provided that astronomical variations in the Earth's orbital parameters are the ultimate modulaters of the climate. Other factors may be required to explain other, more detailed climatic variations found in geological
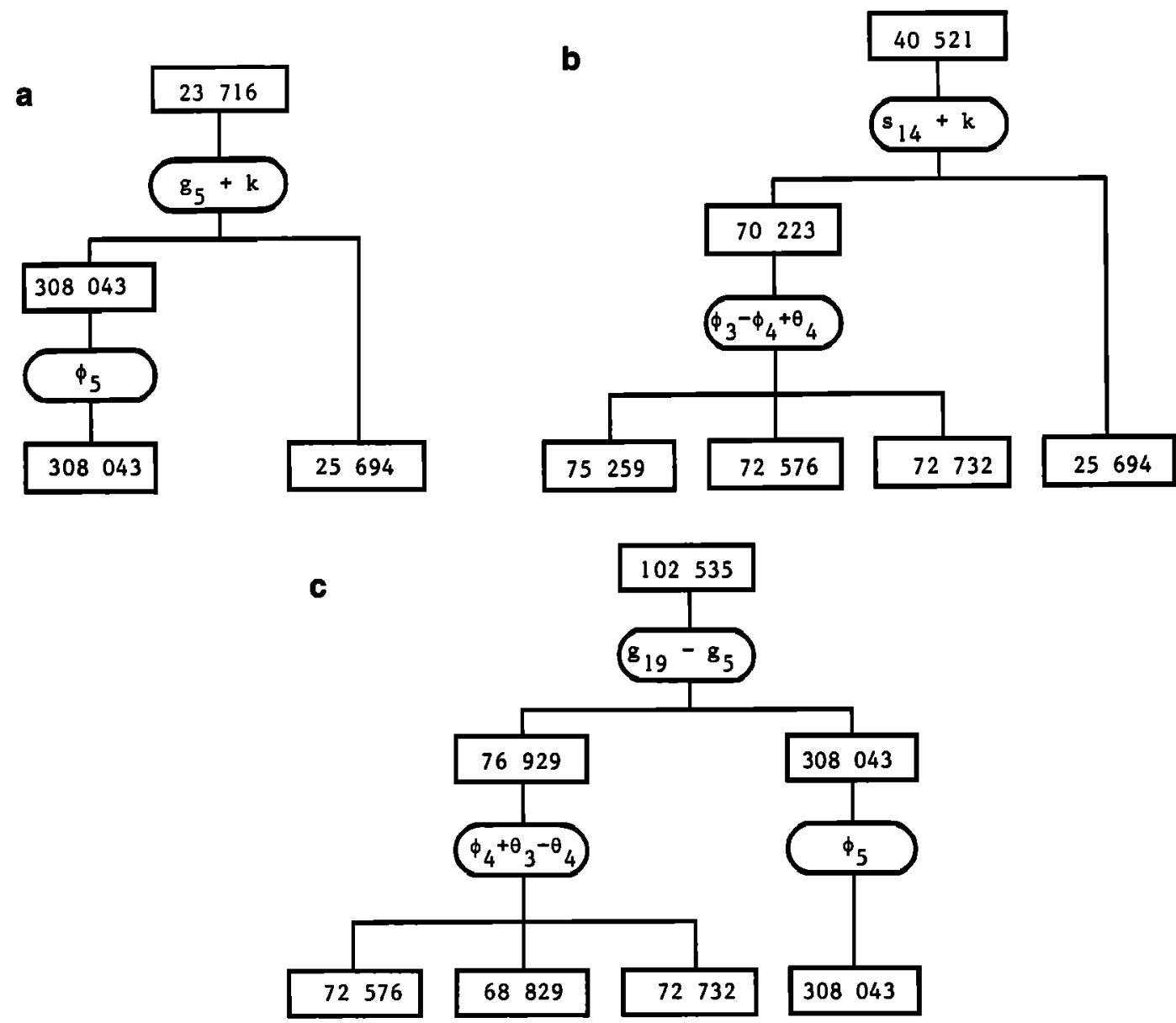

Fig. 10. Branch diagram for (a) the climatic precession e sin $\tilde{\omega},(b)$ obliquity, and (c) eccentricity [Berger et al., 1987]. This procedure, like a family tree, allows each period to be traced back to its source through linear combinations of the frequencies listed in Table 4 for the $\phi$ and $\theta$ and in Table 1 of Berger [1976a] for the $g$ and $\mathrm{s}$; the $k$ correspond to the astronomical precession of 25,694 years. 


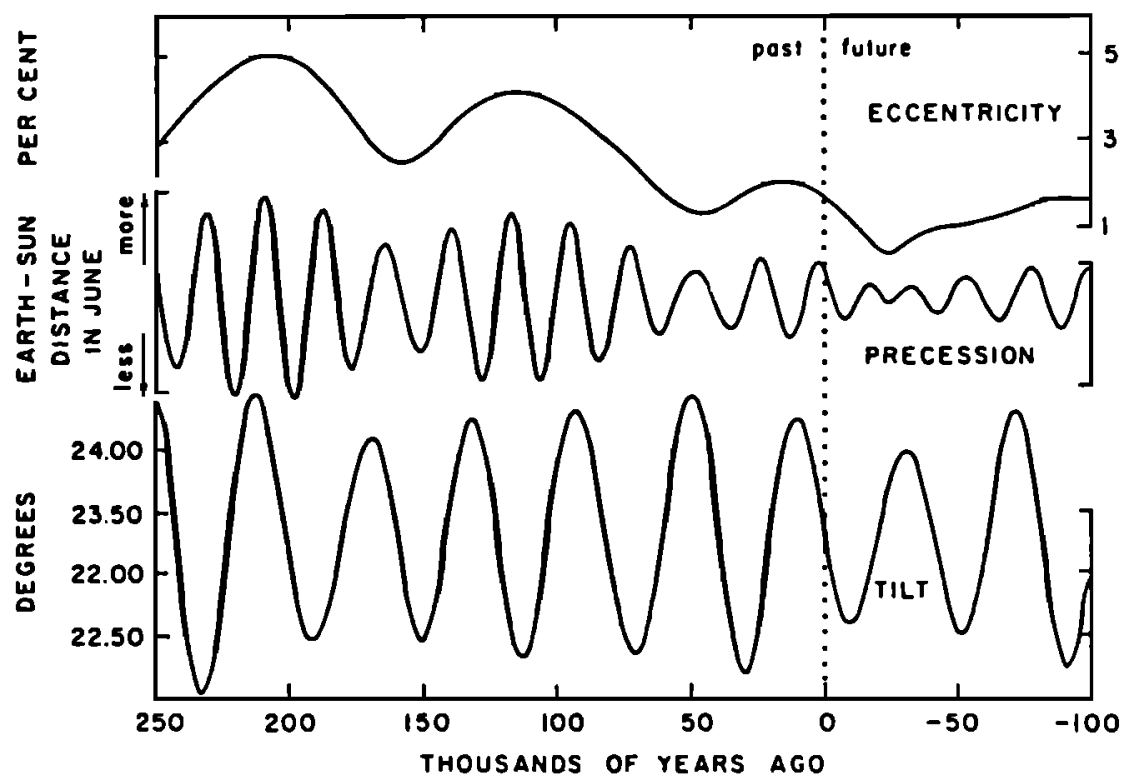

F1g. 11. Long-term variations of eccentricity, precession, and tilt from 250,000 years B.P. to 100,000 years A.P. [Berger, 1978c].

records and to shape them correctly, but the orbital variations are assumed to be the dominant forcling functions.

\section{Spectra of Geological Records}

In 1976, Hays, Imbrie, and Shackleton demonstrated that the astronomical frequencies that I computed in a totally independent way [Berger, 1977] were significantly present tn paleoclimatic data [Hays et a1., 1976]. The 100-, 41-, 23-, and 19-kyr pertods are indeed significantly superimposed upon a general red noise spectrum (Figure 13). It is the geological observation of this bipartition of the precessional peak, confirmed to be real in astronomical computations, which was one of the first most delicate and impressive of a11 tests for the Milankovitch theory. Since 1976, spectral analysis of climatic records of the past 800,000 years or so has provided substantial

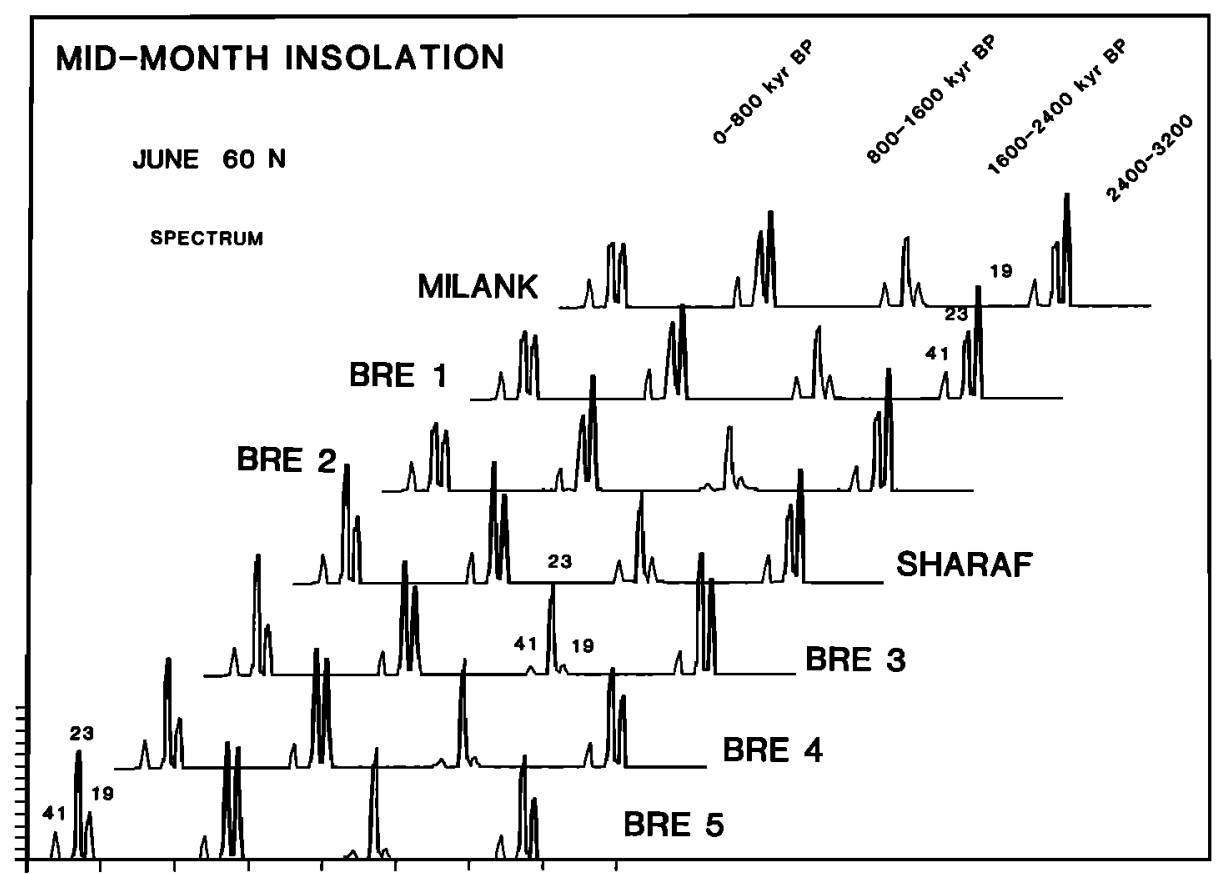

F1g. 12. Spectral analysis of June insolation at $60^{\circ} \mathrm{N}$ for four different periods: $0-$ $800,800-1600,1600-2400$, and 2400-3200 kyr B.P. The vertical axis is in relative unit and $1 \mathrm{~s}$ proportional to the amount of variance explained by each frequency band (periods are given in thousands of years). Seven different astronomical solutions have been used as described by Berger [1984] and Berger and Pestiaux [1984]. 


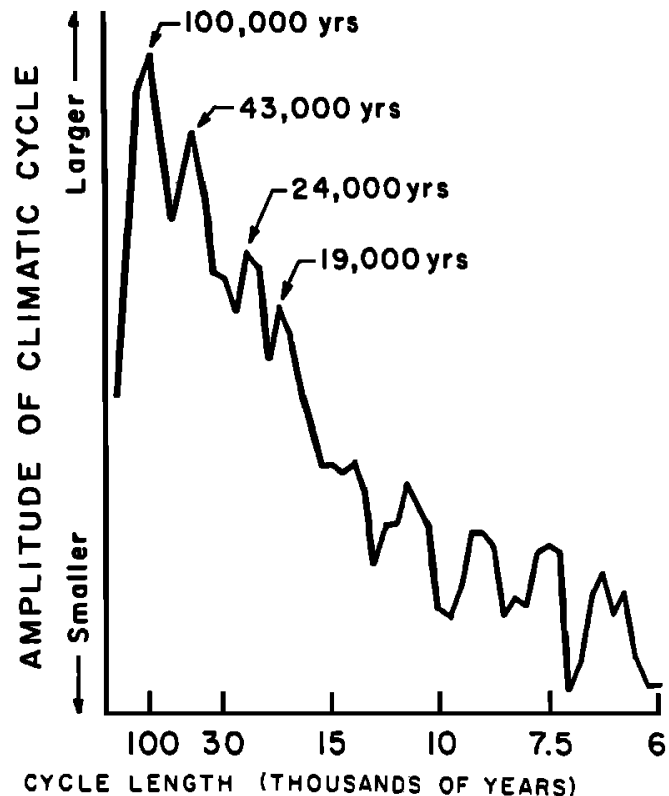

Fig. 13. Spectrum of climatic variation over the past half-million years. This graph, showing the relative importance for different climatic cycles in the isotopic record of two Indian Ocean cores, confirmed many predictions of the Milankovitch theory. (Data are from Hays et al. [1976]. Reprinted from Inbrie and Imbrie [1979] with permission from the authors and Enslow Publishers.)

evidence that, at least near the frequencies of variation in obliquity and precession, a considerable fraction of the climatic variance is driven in some way by insolation changes accompanying changes in the Earth's orbit [Imbrie and Imbrie, 1980; Berger, 1987]. If some long deep-sea cores are used and the uncertainty in the geological time scale and in the spectral analysis is accounted for, Berger and Pestiaux [1987] have shown that the following peaks are significantly present In the astronomical bands: (1) 103,000 with a standard deviation of 24,000, (2) 42,000 with a standard devlation of 8000 , and (3) 23,000 with a standard deviation of 4000 . In addition, Pestiaux et al. [1988] used cores with a high sedimentation rate and covering the last glacial-interglacial cycle to resolve the higher-frequency part of the spectrum. Besides the 19-kyr precessional peak, three other periods were indeed significantly detected: (1) 10,300 with a standard deviation of 2200 , (2) 4700 with a standard deviation of 800 , and (3) 2500 with a standard deviation of 500 .

These preferential frequency bands of climatic variability outside the direct orbital forcing band are still too broad to allow for a definite physical explanation. A tentative interpretation, though, may be given in terms of the climatic system's nonlinear response to variations in the insolation available at the top of the atmosphere. The first characteristic of the 10.3-, 4.7-, and 2.5-kyr near periodicities is, indeed, that they are roughly comblnations tones of the 41-, 23-, and 19-kyr peaks found in the insolation parameters. Moreover, Pestlaux et al. [1988] used the Ghil-Le Treut-Kallen nonlinear oscillator climate model [Ghil and Le Treut, 1981; Le Treut and Ghil, 1983] to predict these shorter periods.

The varlance components centered near a 100-kyr cycle, which dominates most climatic records, seems in phase with the eccentricity cycle, although the exceptional strength of this cycle needs a nonlinear amplification by the deep ocean circulation, the carbon dioxide, the glacial ice sheets themselves, and related mechanisms such as the Ice albedo feedback, the elastic 11thosphere, the viscous mantle, and ocean-ice interactions

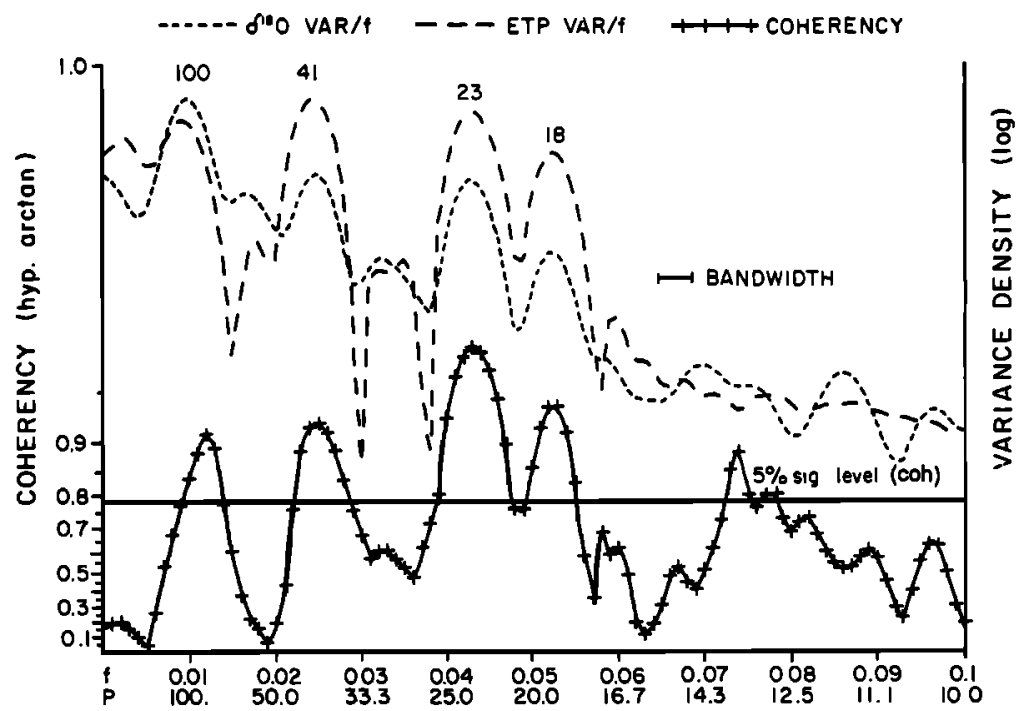

Fig. 14. Coherency and variance spectra calculated from records of climatic and orbital variation spanning the past 780,000 years. Two signals have been processed: (1) ETP, a signal formed by pgrmalizing and adding variations in eccentricity, obliquity, and precession and (2) $\delta$, the unsmoothed, stacked isotope record plotted on the SPECMAP time scale. (Top) Variance spectra for the two signals plotted on arbitrary log scales. (Bottom) Coherency spectrum plotted on a hyperbolic arctangent scale and provided with a 5\% significance level. Frequencies are in cycles per thousand years. (Reprinted from Imbrie et al. [1984] with permission from the authors and D. Reidel.) 


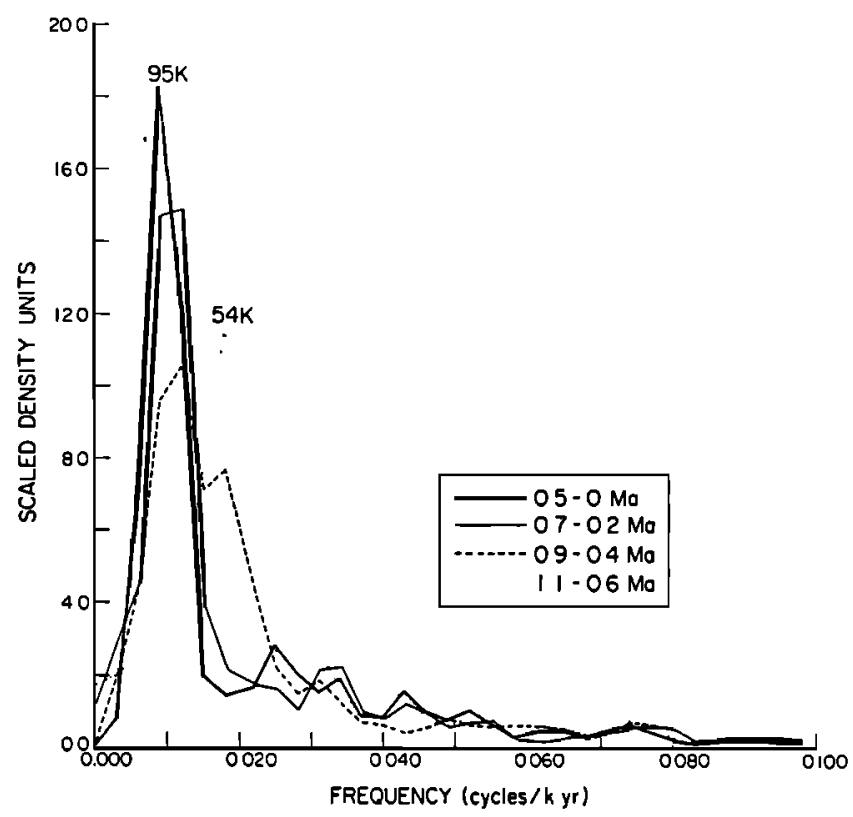

Fig. 15. Area/variance composite of spectral analysis of winter sea surface temperature record fron four record segments of deep-sea core K7087/site 552A. (Reprinted from Ruddiman et al. [1986, p. 162] with perinission from the authors and the Geological Society of America.)

(remember that the eccentricity variations alter the total sunlight falling on the Earth by only $0.2 \%$ at most). The 100-kyr climatic cycle can, tndeed, be explained both by (1) a beat between the two main precessional components (Wigley [1976] demonstrated thts point from nonlinear climate theory), as is also the case for the 100kyr eccentricity cycle in celestial mechanics (The frequency corresponding to the second period of the eccentricity in Table $3\left(1 / 94945 \mathrm{y}^{-1}\right)$ is obtained from precession frequencies 3 and 1 $(1 / 18976-1 / 23716)$. Frequencies $1,3,4,5$, and 6 come from the combinations $2-1,3-2,4-1,4-2$, and 3-4, respectively [Berger et al., 1987].) or by (2) the eccentricity signal directly, provided an amplification mechanism can be found as in the double potential theory of Nicolis [1980, 1982] and Benzi et al. [1982].

Imbrie et al. [1984] have made it clear that the coherency of orbital and climatic variables in the 100,000-year band is enhanced significantly when the geologic record is tuned precisely to the obliquity and precession bands. Using the socalled orbitally tuned SPHCMAP time scale (also developed by Martinson et al. [1987] for the last 300,000 years), they indeed found a coherency in the astronomical bands significant at better than the $99 \%$ level of confidence (Figure 14) (for another tuning procedure, see, for example, Herterich and Sarnthein [1984]).

A fairly coherent phase relationship is also reasonably well defined between insolation and ice volume, for example. Kominz and Pisias [1979] were the ffrst to show that obliquity consistently leads the ${ }^{18} 0$ record by about 10,000 years, whereas precession seemed to be in phase with the 23kyr geological signal. However, the recent results obtained by SPFCMAP show that these leads and lags are more compllcated. Finally, Ruddiman et a1. [1986] succeeded in finding one of the secondary astronomical periods that I discovered in 1976, the 54-kyr period (Figure 15).

All these results lead me to conclude that, at least on the basis of statistical analysis, evidence has accumulated that $60 \pm 10 \%$ of the isotopic variance in the perlodicity range 10-100 kyr per cycle over the last $1 \mathrm{Myr}$ is a linear response to orbital forcing [Imbrie et al., 1984].

However, the interpretation of the results is not always as clear. The 100-kyr cycle, so dominant a feature of the late Pleistocene record, does not exhibit a constant amplitude over the past 2-3 Myr as displayed on a three-dimensional time evolutionary spectrum of deep-sea core V28239 (Figure 16). Clearly, this periodicity disappears before $10^{6}$ years ago, at a time when the ice sheets were much less developed over the Earth, reinforcing the idea that the major ice sheets may have played a role themselves in modulating this 100-kyr cycle. SPECMAP has also shown that the phase lags in the climate response to orbital forcing depend upon the nature of the climatic parameters themselves and upon their geographical

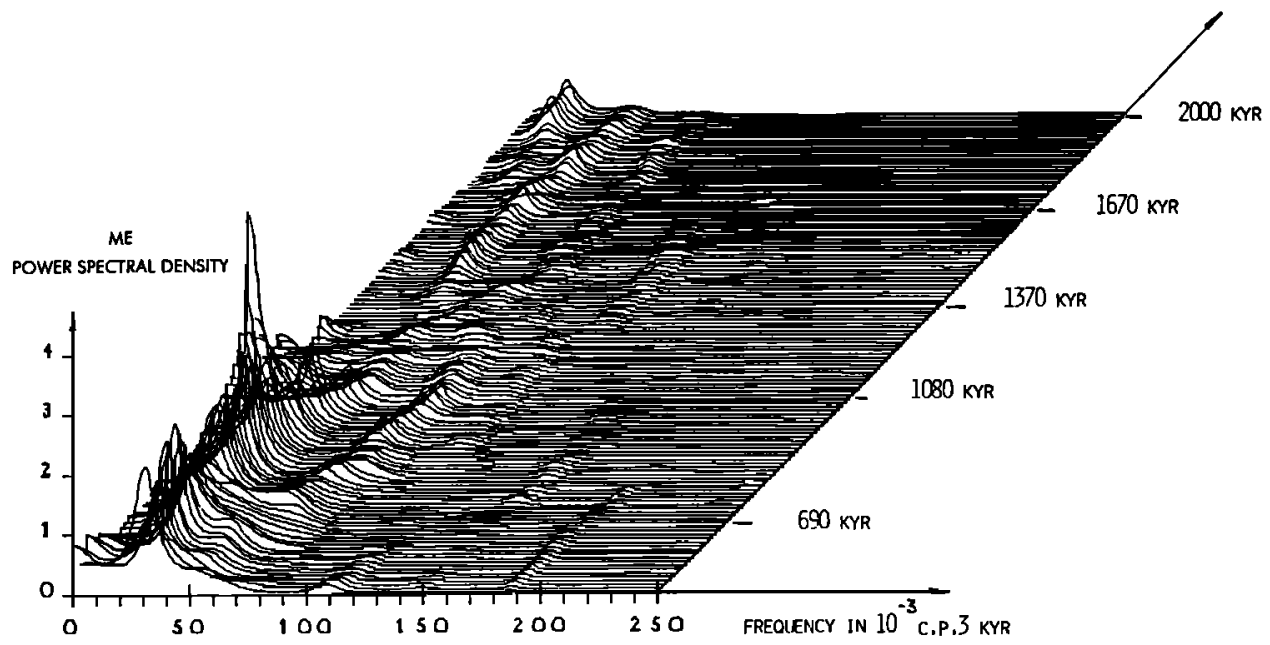

F1g. 16. Evolutive maximum entropy spectral analysis of the whole record V28-239 [Pestiaux and Berger, 1984]. 


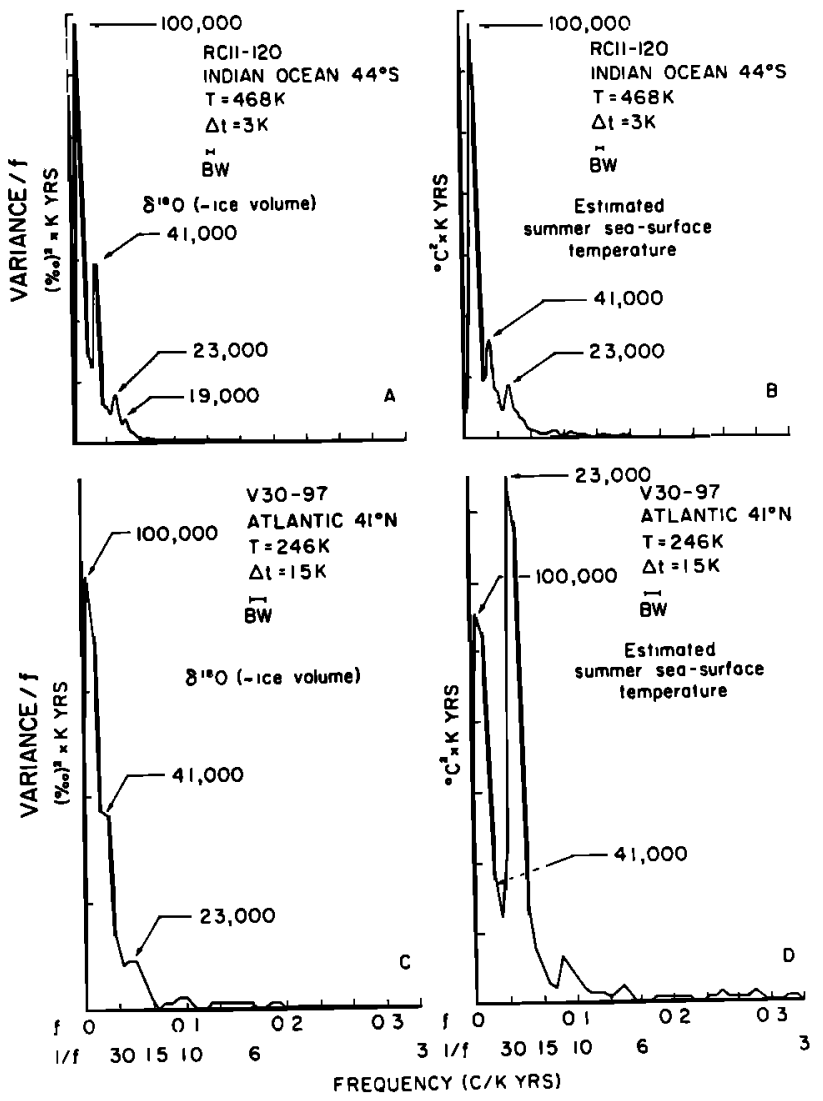

Fig. 17. Spectra of isotopic and sea surface temperature variations measured at two different sites. Spectra in Figures 17a and 17b are taken from Hays et a1. [1976]. Spectra in Figures 17c and $17 \mathrm{~d}$ are taken fron Ruddiman and McIntyre [1981]. The isotopic spectra, which reflect variations in global ice volume, are nearly identical. apart from differences due to different bandwidths (BW). But the temperature spectra are very different: the southern hemisphere site responds mainly at periods near 100,000 years, whereas the North Atlantic at this latitude responds mainly at periods near 23,000 years. (Reprinted from Imbrie [1982] with permission From the author and Academic Press.)

location. For example, the sea surface temperature of the southern oceans seems to lead the response of the northern hemisphere ice sheets by roughly 3000 years.

The shape of the spectrum depends also upon the location of the core and the nature of the climatic parameter analyzed [Hays et al., 1976; Ruddiman and McIntyre, 1981; Inbrie, 1982]. For example, the 41-kyr cycle is not seen and the 23-kyr cycle is dominant in Atlantic sea surface temperatures of the last 250,000 years (Figure 17). This is not too surprising, as these spectra depend upon the way the climate system reacts to the Insolation forcing and upon the type of insolation to which it is sensitive. Indeed, contrary to the well-received Milankovitch idea that the high polar latitudes must record the obliquity signal. whereas low latitudes record only the precessional one (Figure 18a), the latitudinal dependence of the Insolation parameters is more complex: clear- 1y, midmonth high-lat tude insolation in summer displays a stronger signal in the precession band than in the obliquity band (Figure 18b) [Berger and Pestiaux, 1984].

\section{Astronomical Insolation}

Another important advantage in considering monthly insolation instead of half-yearly values which were used by Milankovitch [1941], Bernard [1962], Sharaf and Budnikova [1969], Vernekar [1972], and Berger [1978f] is that fluctuations that are otherwise masked becone easily recognizable. For example, 125,000 years ago (Figure 19), during the Eemian Interglacial, all latitudes were overinsolated in July, particularly the northern polar regions, where the positive anomaly amounted to up to $12 \%$, the same being true at the last climatic optimum 10,000 years ago. This is especially significant when a delay of some few thousand years, required for the ice sheets to start to melt, is taken into account.

But the evolution of the detailed seasonal cycle that I introduced in 1975 [Berger, 1976b] is even more significant, leading to the concept of the so-called insolation signature [Berger, l979b]. The well-known stages associated with the Barbados III (124 kyr B.P.) and II ( $103 \mathrm{kyr}$ B.P.) high stands of the sea [Broecker et al., 1968] clearly correspond (Figure 20) to an overinsolation that amounts to some $10 \%$ and are separated by an abortive glaciation at $115 \mathrm{kyr}$ B.P. corresponding to isotopic stage $5 \mathrm{~d}$. The main glacial transition between stages 5 and 4 , at $72 \mathrm{kyr} \mathrm{B.P.,} \mathrm{is}$ underinsolated (Figure 21), and, more important, this drop in insolation was not compensated by any significant increase during the whole main Wurm glaciation phase. On the contrary, yet another important decrease at $25 \mathrm{kyr}$ B.P. augers the 18 kyr B.P. maximum extent of ice in the northern herisphere. Indeed, between $83 \mathrm{kyr}$ and $18 \mathrm{kyr}$ B.P. there was an overall solar energy deficiency of $2.5 \times 10^{25}$ cal north of $45^{\circ} \mathrm{N}$, almost sufficient to compensate for the latent heat liberated in the atmosphere during the formation of snow required by the buildup of the huge $18 \mathrm{kyr}$ B.P. ice sheets [Mason, 1976]. Finally, it was not before $15 \mathrm{kyr}$ B.P. that the summer insolation started to increase sufficiently, leading to the $6 \mathrm{kyr}$ B.P. Climate Optimum.

As an int roduction to the modeling of the climate response to these significant orbitally induced insolation changes, these extra-terrestrial insolation variations can be compared to those in the insolation incident and absorbed at the Earth's surface [Ohmura et al., 1984]. In the radiative model by Tricot and Berger [1988] the atmosphere is divided into three layers, with the second one filled up with an averaged cloud. The interactions between molecular absorption (by $\mathrm{H}_{2} \mathrm{O}$, $\mathrm{CO}_{2}, \mathrm{O}_{3}$, and aerosols) and scattering (by air, aerosols, and clouds) are handled by the deltaEddington technique. Combining the reflection and transmission of each homogeneous layer, the downward and upward fluxes are computed following the ascending method presented by Fouquart and Bonnel [1980]. Comparisons with other theoretical calculations and observations show that this solar radiative scheme is sufficiently accurate for reproducing correctly the present-day atmospheric conditions. As expected, the amplitude of the 


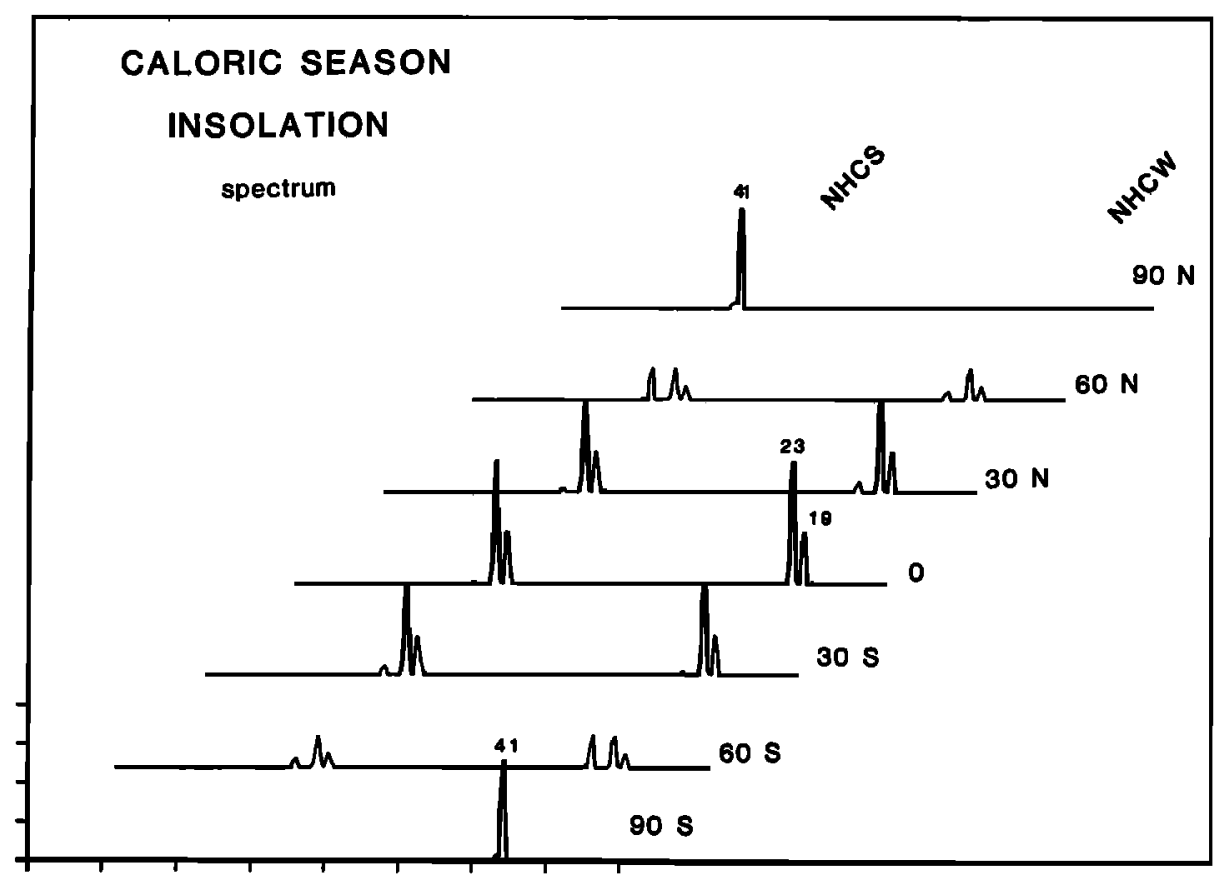

Fig. 18a. Spectral analysis of caloric insolation for northern hemtsphere caloric summer (NHCS) and northern hemisphere caloric winter (NHCW) for seven latitudes. The vertical scale is in relative units and is proportional to the amount of variance explained by each frequency band (periods are given in thousands of years) [Berger and Pestiaux, 1984].

long-term variations of the insolation "at the top of the atmosphere" calculated from this radiative model in which present-day parameters were assumed is reduced by roughly a factor of 2 , but the overall general pattern remains, except in high polar latitudes of the summer hemisphere, particularly the southern one (Figure 22). This change in high lattudes is essentially due to atmospheric attenuation that is larger in polar than in tropical latitudes and to the high surface albedo of the polar regions. Both of these factors are also responsible for a specific behavior of the largescale latitudinal gradient of insolation (F1gure 23): the latitudinal gradient of extraterrestrial

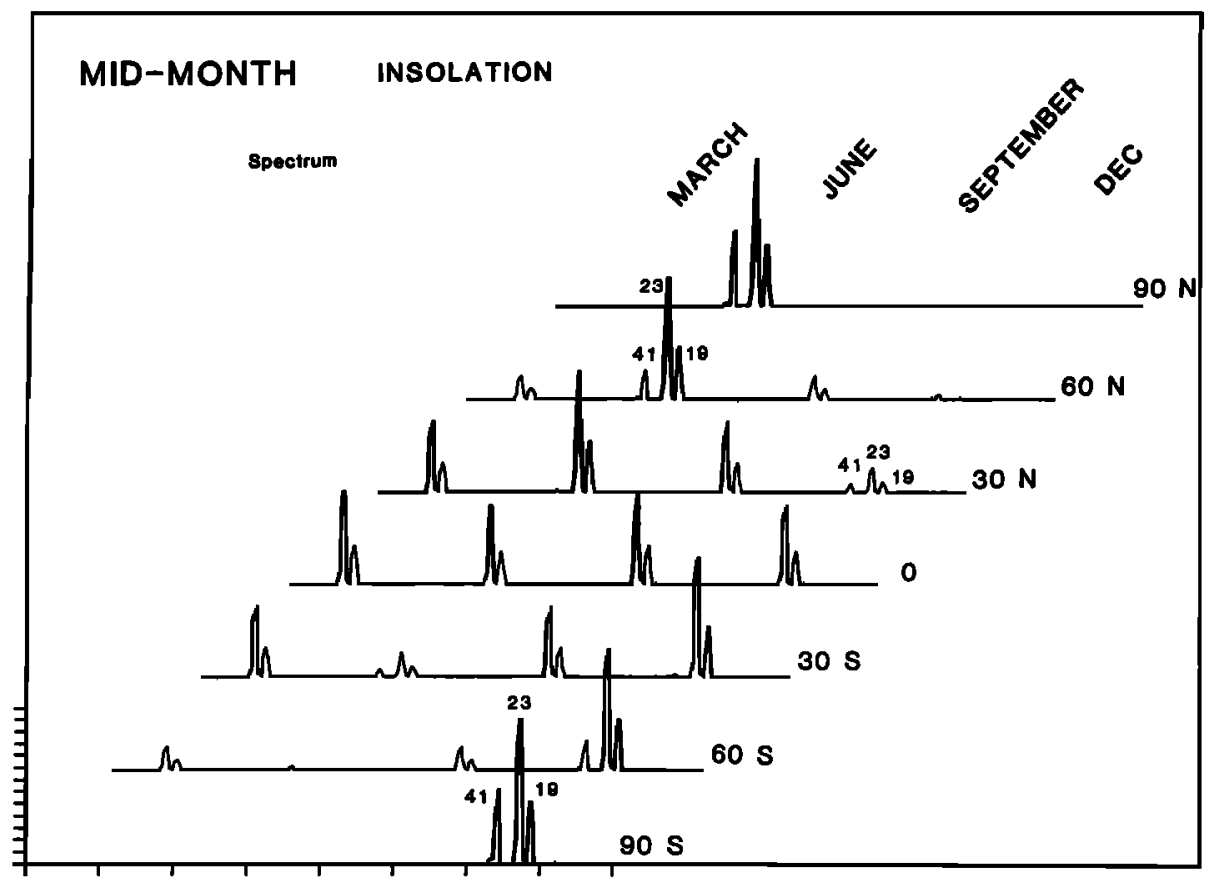

Fig. 18b. Same as Figure 18a for four midmonth insolations: March, June, September, and December [Berger and Pestlaux, 1984]. 


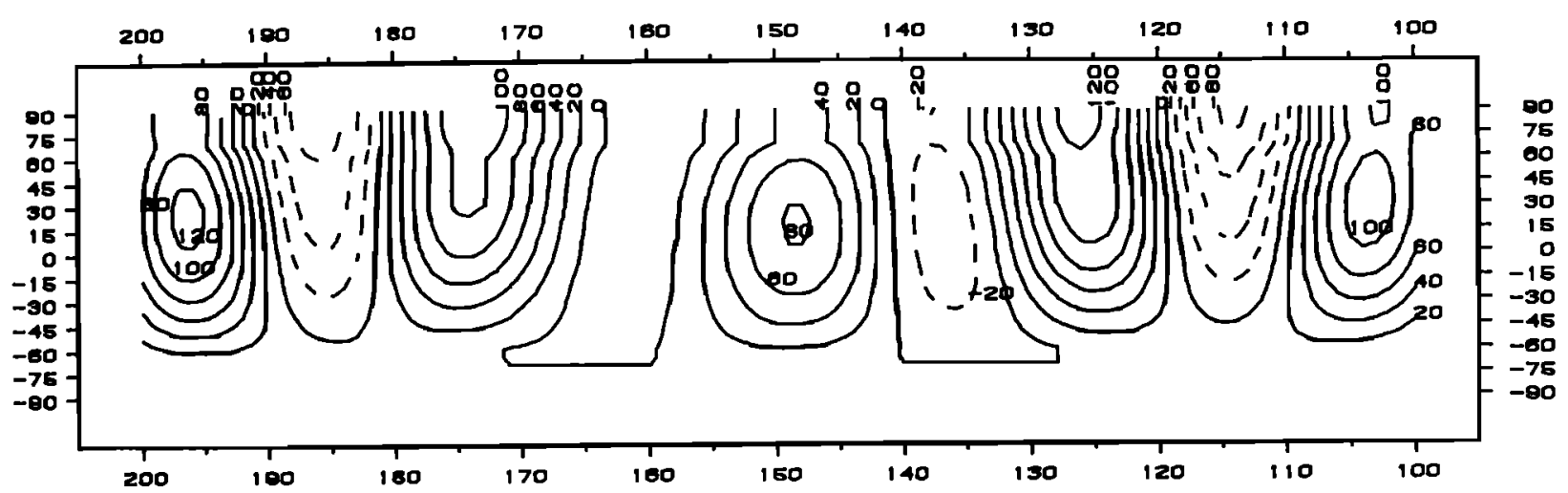

Fig. 19. Long-term variations of the deviations of solar radiation from their A.D.

1950 values. These values are given for each latitude from the north pole to the south pole and for a period extending from $200 \mathrm{kyr}$ B.P. to $100 \mathrm{kyr}$ B.P. The solid lines are for the postive deviations (insolation higher than it is today), and the dashed lines characterize the insolation below their actual values [Berger, 1978a, b, d] (units are calories per square centimeter per day).

insolation is characterized by a periodicity of 40,000 years, whereas for the absorbed insolation (and also the insolation incident at the surface) it exhibits a higher frequency which corresponds to a pertod in the range of 21,000 years. In fact, for the insolation reaching the surface, the large attenuation in polar latitudes is responsible for insolation at $30^{\circ}$ driving the frequency behavior of the gradient. These results mean that we must be careful when we use astronomical fre- quencles as a clock for the geological record, especially if one uses a combination of insolation parameters.

\section{Paleoclimate Modeling}

Many researchers have tested the astronomical theory with numerical climate models of different complexities (involving the energy balance to the general circulation). These models can be dist-

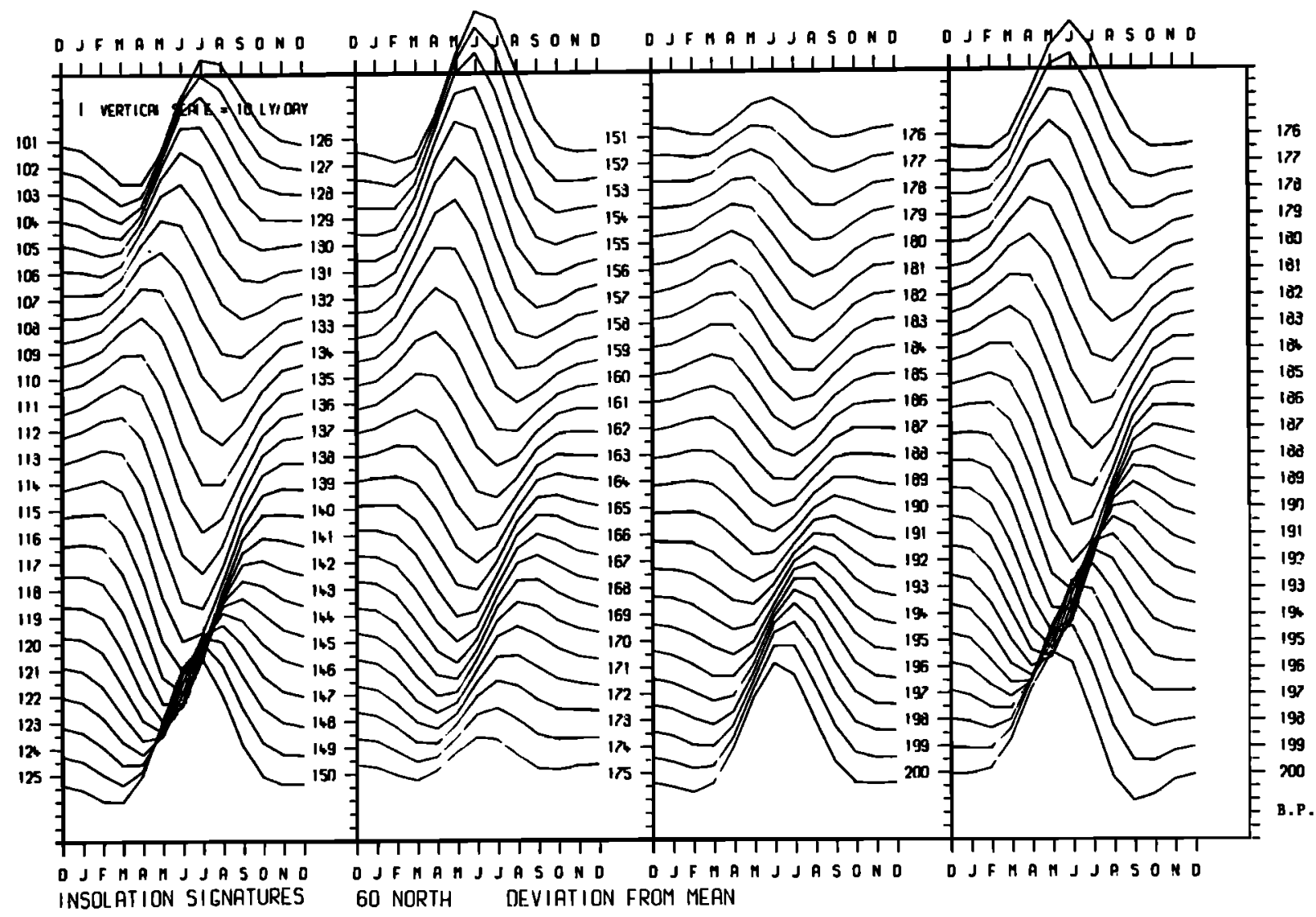

Fig. 20. Insolation signatures from $200 \mathrm{kyr}$ B.P. to $100 \mathrm{kyr}$ B.P. Long-term variation of the deviations from the mean state of the midmonth daily insolations for $60^{\circ} \mathrm{N}$ (annual cycle). The vertical scale is indicated in the upper left corner of the figure. Time is in thousands of years, and the time step is 1000 years [Berger, 1979b]. 


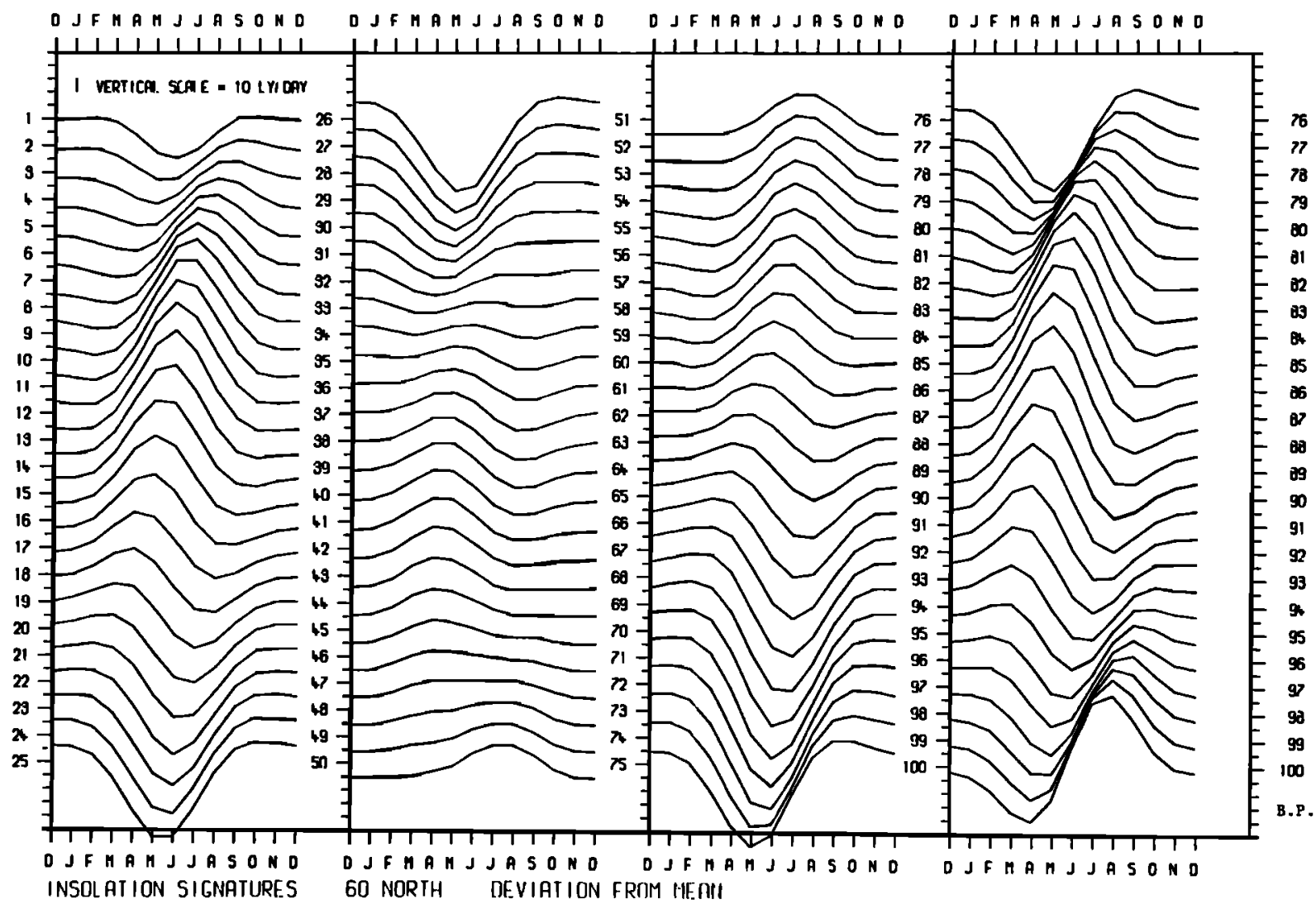

Fig. 21. Same as Figure 20 for $100 \mathrm{kyr}$ B.P. to present time [Berger, 1979b].

ributed into four main types: (1) zero-dimensional mathematical models, (2) seasonal climate models not explicitly coupled to ice sheet models, (3) pure 1ce sheet models not driven by climate models, and (4) models of the atmosphere-ocean climate coupled to ice sheets. This modeling effort has led to recent progress in understanding the physical mechanisms by which the climate system responds to the astronomically forced changes in the pattern of incoming solar radiation. Such mechanisms are related, in particular, to the ice sheets, the lithosphere, the hydrological cycle, the cloud properties, the albedo-temperature feedback, the land-sea temperature gradient, the $\mathrm{CO}_{2}$ cycle, and the oceanic circulation. For example, employing crude parameterization within a simple climate model, Cess and Wronka [1979] concluded that zenith angle, bio-albedo, and latent heat feedbacks could, collectively, enhance by several factors the sensitivity of the Earth's simulated climate to change induced by orbital variability. As the cryosphere is probably the only part of the climatic system whose characteristic time scales of response are of the same order as those of the orbital forcing, it is most likely that to prove the viability of the Milankovitch theory, the seasonal extent of ice cover and nonlinear feedbacks related to the polar ice caps must also be included properly. In this respect, Suarez and Held [1979] have used a zonally symmetric model of the global energy balance, incorporating the heat storage in an isothermal ocean $40 \mathrm{~m}$ deep, positive feedbacks due to the high albedo of snow and sea ice, and a seasonally varying insolation. They get a response qualitatively similar to the geological record over the past 150,000 years. When their model is forced with the orbital variations, the northern hemisphere snow limit shifts southward by a realistic $20^{\circ}$ during an ice age (this is not the case in a calculation by North and Coakley [1979], where the tce line moves by only $3^{\circ}$ of latitude equatorward when forced at the $25 \mathrm{kyr}$ B.P. obliquity minimum). Schneider and Thompson [1979] also introduced a seasonal version of a zona1ly averaged energy balance climate model. The seasonal and zonal variation of albedo and the zonal variation of thermal inertia are shown to interact with the astronomical insolation perturbation, so that the simulation exhibits some of the features of the long-term climate record. However, although the computed record simulates well the gross features of the glacial-interglacial transitions, the temperature amplitude of the $60^{\circ} \mathrm{N}$ glacial maximum-to-climatic optimum is only about $0.8^{\circ} \mathrm{K}$, whereas CLIMAP data suggest it should be a factor severalfold greater, and the phase is several thousand years too early.

\subsection{Ice Sheet Models and the 100-kyr Cycle}

This phase lag discrepancy, also found by Suarez and Held [1979], was expected from the equilibrium model and arises probably from the fact that the deep ocean circulation is neglected and from the lack of simulating the growth and decay of ice sheets. As recalled by Imbrie and Imbrie [1980], there are indeed several indications that one source of nonlinear behavior is the 


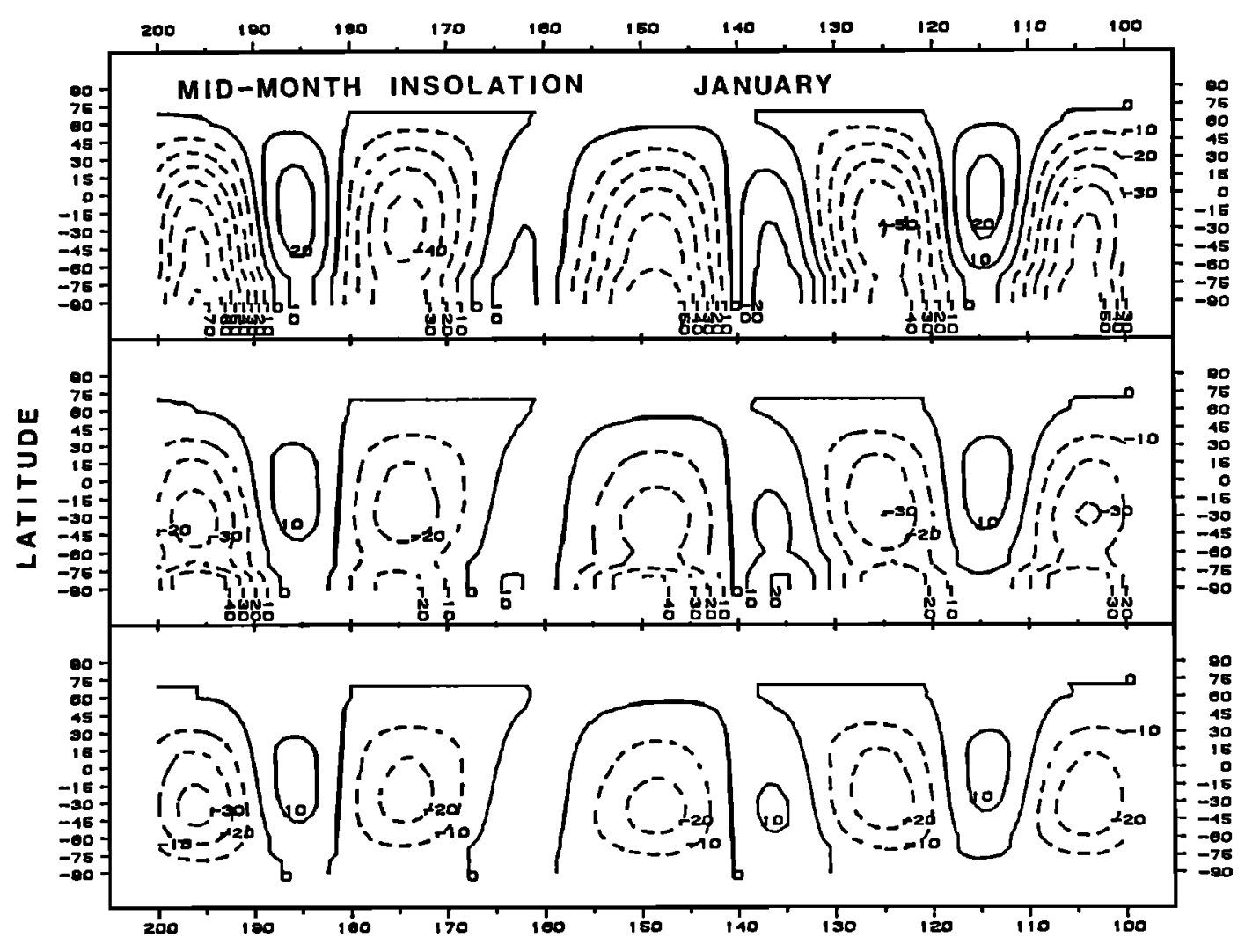

YEARS BEFORE PRESENT

Fig. 22. Long-term variations of the deviations from their present-day values of midmonth daily insolations for January. These values are given in watts per square meter and for a period extending from 200,000 to 100,000 years B.P. (Top) Insolation at the "top of the atmosphere." (Middle) Incident insolation at the surface. (Bottom) Absorbed insolation at the surface. The solid lines are for the positive deviations, and the dashed lines characterize the insolation below their present-day values [Tricot and Berger, 1988].

tendency for ice sheets to shrink faster than they grow, a time-dependent model being thus required to understand these observed lags between orbital forcing and the modeled climatic response. As a ploneer, using a perfectly plastic ice sheet model, Weertman [1976] has shown that a relatively small reduction of the $50^{\circ} \mathrm{N}$ summer half-year insolation may trigger the buildup of the ice sheets, which are then allowed to grow through a strong positive feedback. Incorporating Weertman's ice sheet into an energy balance climate mode1, Pollard [1978] came to the same conclusion, although the internal freedom of the model was in fact increased. The curve of his model's ice ages compares favorably with some aspects of the deepsea record, with a sea level air temperature difference between maximum and minimum ice sheet extents reaching $9^{\circ} \mathrm{C}$ in the polar region's summer. These simple models seem thus to simulate correctly the phase and approximate amplitude of the 40-kyr and the 23-kyr cycles, but not the dominant $100 \mathrm{kyr}$ sawtooth cycle at all.

To contribute to the solution of the origin of this 100-kyr cycle, Birchfield and Weertman [1978] modified the Weertman continental ice sheet model in such a way that larger ice sheets were obtained owing to a larger accumulation region with the inclusion of the rear half of the lce sheet.
Using the caloric insolation anomalies, their model can produce continental ice sheets of the scale of those occurring in the late Cenozoic and also with time lags consistent with the astronomical data. While forcing is at periods near 19 $\mathrm{kyr}, 23 \mathrm{kyr}$, and $41 \mathrm{kyr}$, the model consistently predicts dominant long-period responses, most commonly at $100 \mathrm{kyr}$ and/or $400 \mathrm{kyr}$, in addition to significant responses at the forcing periods. The model output thus lends support to the hypothesis that nonlinear response of the Earth system (associated with the growth and decay of the continental ice sheets) to fluctuations of the orbital parameters is responsible for the long-period climate fluctuations recorded in deep-sea cores.

A more sophisticated three-dimensional timedependent ice sheet model based on present measured ice sheets has been used to study the effects of the orbital radiation changes [Budd and Smith, $1979,1987]$. A reasonable match with the inferred growth and retreat of the ice sheet from $120 \mathrm{kyr}$ B.P. up to the present has been found possible, but only with the inclusion of the effects of albedo feedbacks and isostatic changes in the bedrock elevation. It thus seems that the role of ice sheets in determining the long-period climate response will possibly be clarified only with more realistic parametric modeling of the cryosphere- 


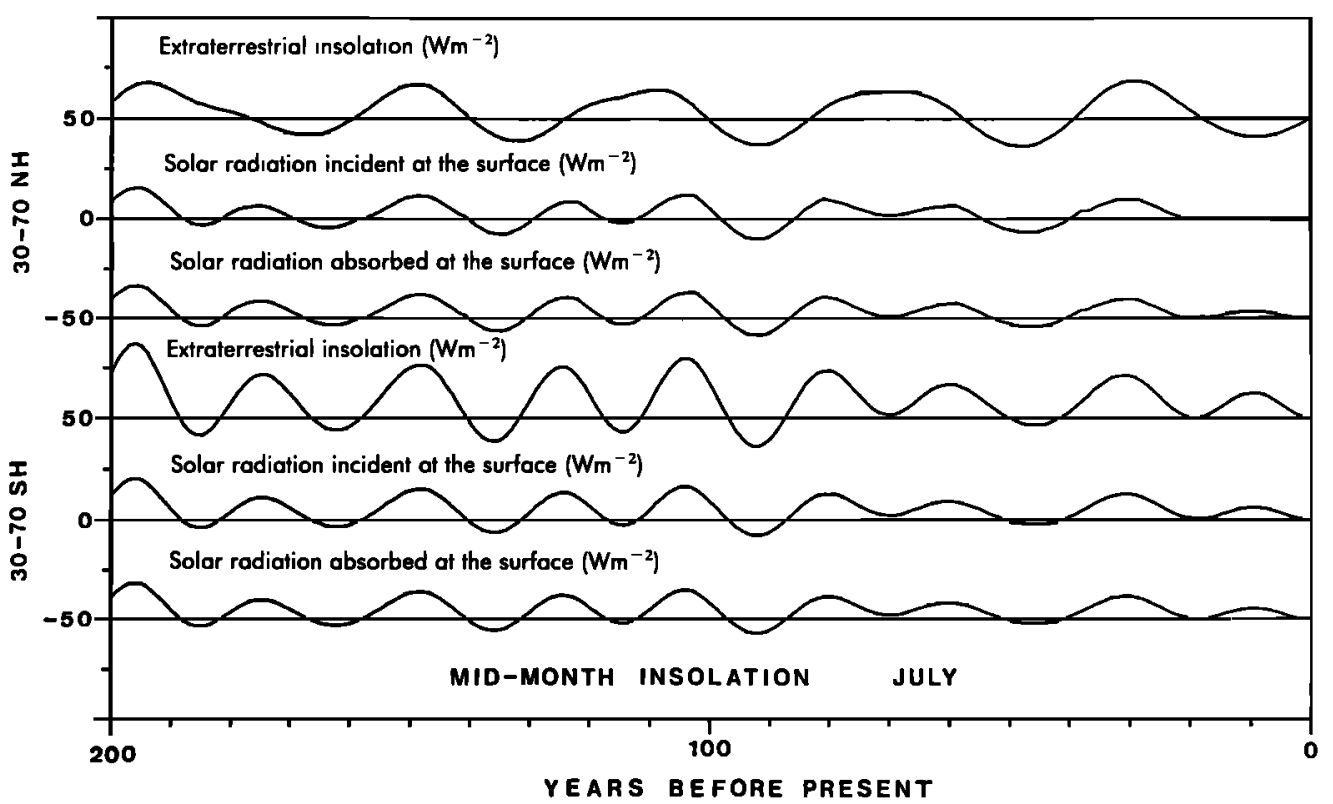

Fig. 23. Long-term variations of July midmonth large-scale gradient of insolation over the last $200 \mathrm{kyr}$ (in watts per square meters for the northern hemisphere (the three upper curves) and for the southern hemisphere (the three lower curves). The left scale gives the deviation from the present-day values of the gradient defined as the difference between $30^{\circ}$ and $70^{\circ}$. For each hemisphere the upper curve gives the solar radiation at the "top of the atmosphere," the middle curve the radiation incident at the Earth's surface, and the lower curve the absorbed radiation at the Earth's surface [Tricot and Berger, 1988].

lithosphere. Noting the strong asymmetry of the 100-kry cycle, Oerlemans [1980] showed that a 50,000 - to 100,000 -year time scale, needed to create a full-size tce sheet, is in accordance with Ice sheet/Earth's crust dynamics. In his model, a continental northern hemisphere ice sheet is initiated in periods of minimum summer halfyear insolation at $65^{\circ} \mathrm{N}$. Once an ice sheet is established, it keeps on growing even if insolation is above normal. Because of bedrock sinking, ice sheets grow very slowly. If the lice sheet reaches a certaln critical thickness, basal sliding occurs, and the mean height of the ice surface decrease substantially. The consequent decrease in the mass balance causes the ice sheet to disappear within a few thousand years. The glacial cycle starts again when two conditions are fulfilled: summer insolation should be well below normal, and the bedrock should have been raised again. Such a reconstruction of the ice volume record over the lagt 600,000 years has given the best fit to the $\delta{ }_{0}$ records when an internal time scale of 75,000 years is taken. Oerlemans and Bienfait [1980] have also pointed out the important role of the daily cycle in the process of melting. They have designed a simple energy balance model of the 1ce/snow surface layer which simulates this daily cycle and whose result is used to parameterize the mass balance of their dynamical model of a northern hemisphere ice sheet. Forcing this mode1 with the insolation variations in time and latitude provides a very reasonable simulation of the global ice volume record of the last 700,000 years. Even if some objection can be made to such model, for example, the passive role of the southern hemisphere and the lack of ocean-climate interactions, the dominant 100-kyr signal and its asymmetry are well reproduced.

A much simpler differential-type model was proposed earlier by Calder [1974], who assumed that a decline in summer sunshine at $50^{\circ} \mathrm{N}(410 \mathrm{~W}$ $\mathrm{m}^{-2}$ ) below a certain level $\left(8 \mathrm{~W} \mathrm{~m}^{-2}\right)$ allows the volume of glaciers and ice sheets to grow in simple proportion to the deficit, while summer sunshine above that level melts ice with a different proportionality. With a melting rate 5 times the freezing rate, a realistic curve for the most recent glaciation (the last 78,000 years) has been obtained and applied over the past 860,000 years. According to the experiments performed by Imbrie and Imbrie [1980], results for the past 150,000 years are quite good, and the spectrum of this output contains significant power at cycles of $100 \mathrm{kyr}$ and longer (not found in the orbital input), although the 41-kyr, 23-kyr, and 19-kyr cycles are dominant.

Imbrie and Imbrie [1980] have also developed a simplified glactal dynamics model especially designed for the explicit purpose of reproducing the Pleistocene ice volume record from orbital forcing. The rate of climatic change is made inverse1y proportional to a time constant that assumes one of two specified values, depending on whether the climate is warming or cooling. Such a model tuned over the last 150,000 years is forced with orbital input corresponding to an irradiation curve for July at $65^{\circ} \mathrm{N}$, with a mean time constant of 17,000 years and a ratio of $4: 1$ between the time constants of glacial growth and melting. The 


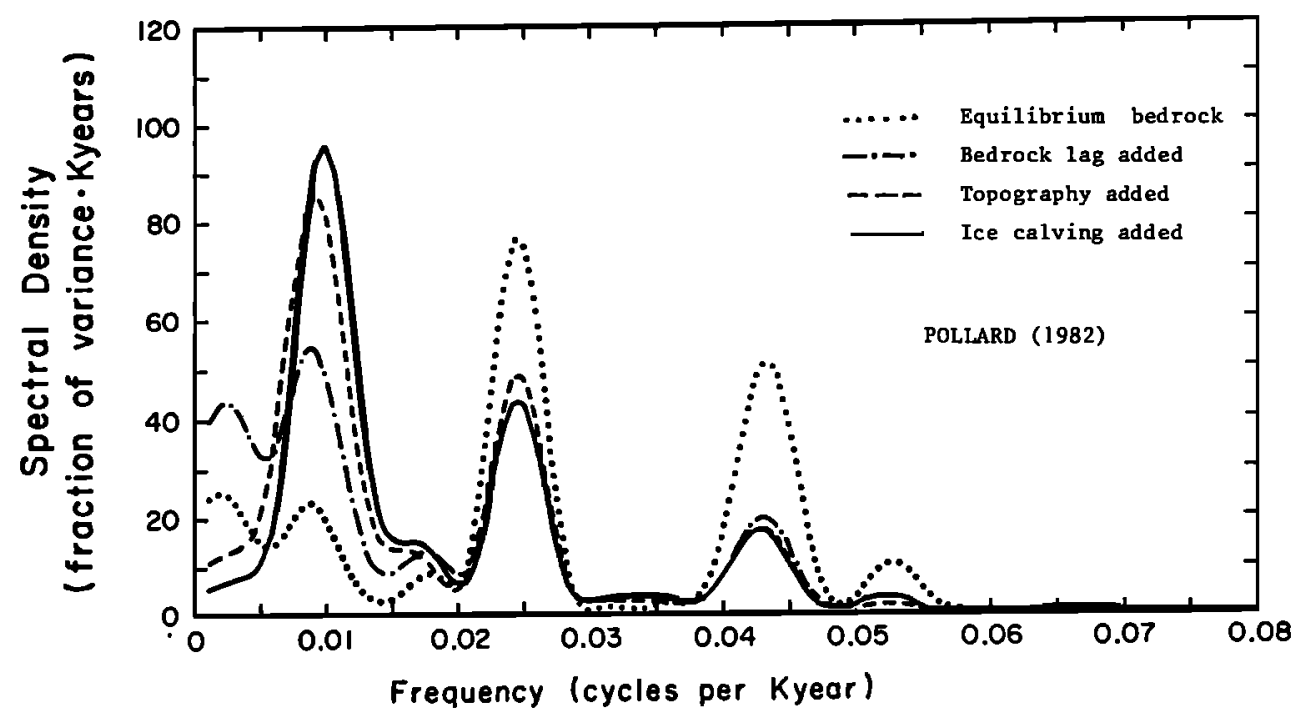

Fig. 24. Power spectral density of the ice volume simulated by four different models: no topography and the bedrock in isostatic equilibrium (dotted curve); with a bedrock lag added (chain-dotted curve); model run with piecewise-linear topography (dashed curve); model with a calving mechanism (solid curve) [Pollard, 1982].

model's simulation of the isotoplc record of ice volume over the past 150,000 years is reasonably good, but results for earlier times are mixed, and parametric adjustments do little or nothing to improve matters. This goal of the modeling effort to simulate the climatic response to orbital variations over the past 500,000 years also fails to produce sufficient $100-\mathrm{kyr}$ power and produces too much 19-kyr, 23-kyr, and 413-kyr powers. Moreover, the rodel loses its match with the record around the time of the last 413-kyr eccentricity minimum. This could be related to the fact that although the character of climatic record is falrly constant over the past 600,000 years, older Pleistocene records may be quite different. If the nature of orbital variation is thought to have remalned constant over the past 2 Myr, Imbrie and Imbrie [1980] then conclude that to understand the long climatic records, it may be necessary (1) to develop almost intransitive models [Lorenz, 1968], (2) to build stochastic models to understand variations unexplained by deterministic models [Hasselman, 1976], (3) to use models whose parameters vary with time, or (4) to produce in the climatic system an intrinsic tendency to oscillate at 100 kyr or a resonance. Along this line, it must be noted that the strong response of the Oerlemans [1980] cryosphere on the 100-kyr time scale, as compared to the $20-\mathrm{kyr}$ and $40-\mathrm{kyr}$ peaks, points also to such a resonance which enables variations in eccentricity to be supported by the internal dynamics of the climate system to create a strong signal in global ice volume.

On the other hand, a tendency to obtain free oscillations at periods of the order of several tens of thousands of years in complex climate models has also been mentioned by Sergin [1979], Kallen et al. [1979], and Ghil [1981]. Indeed, the main physical mechanisms active on time scales of $10^{4}-10^{5}$ years have been recognized by Ghil [1981] to be global radiation balance changes, thermal inertia of the oceans, changes in the hydrologic cycle, continental ice sheet dynamics, and isostatic rebound. He showed that simple models which comprise the interaction of two or more of these mechanisms are capable, in the absence of any varlations in solar radiation, of self-sustained oscillations in the range of $10^{4}$ years (definttely below the major glaciation cycle peak of $100 \mathrm{kyr}$ ) and are only slightly blurred by fluctuations on smaller time scales. These oscillations have the correct amplitudes and exhibit phase differences between temperature and ice extent which correspond to the best currently available paleoclimatological evidence. Concerning the dominant periodictty of $100 \mathrm{kyr}$, Ghil proposes two possible processes. One consists of subharmonic response of a nonlinear climatic oscillation of suitable amplitude to precessional periodicities in irradiation. The other consists of the mutual amplification of internal random perturbations and of the small changes in irradiation caused by eccentricity in the Earth's orbit. This last model provides grounds to solve the basic conflict between the apparent predictability shown by the phase coherence of the 100kyr climatic and eccentricity cycles [see Imbrie and Imbrie, 1980, Figure 10] and the very strong sensitivity that the model needs in order to reproduce the record accurately from eccentricity forcing. The resonance found between a deterministic small external forcing and a stochastic internal mechanism in a zero-dimensional climate model has indeed allowed reproduction of the observed 100-kyr cycle, a small change in the eccentricity forcing inducing a large change in the probability of jumping between two observable climate states [Nicolis, 1980; Benzi et al., 1982 ].

As a consequence, recent ice sheet models show that the 100-kyr cycle can be simulated with [Ghil and Le Treut, 1981; Saltzman et al., 1984] or without [Lindzen, 1986] internal free oscillations related to resonances when astronomically forced but is significantly reinforced when isostatic rebound [Hyde and Peltier, 1985] and iceberg calv- 
ing are taken into account (Figure 24) [Pollard, 1982].

\subsection{General Circulation Models} and Equilibrium Response

Another suggestion that has generated considerable interest ts that geography may help explain climate's sensitivity [North et al., 1983]. So, when orbital variations are used that favor increasingly cooler summers (as at the transition between 125,000 and 115,000 years B.P. and at the last glacial maximum 18,000 years B.P.), models with realistic distribution of continents and oceans generate the ice cap mostly over northern Canada and Scandinavia. The strongest orbital influences act at the most sensitive spots of the climate system. For example, Royer et al. [1983] slmulated a cooling of more than $2^{\circ} \mathrm{C}$ over northern America with an increase of precipitation over the same area. Another suggestion for amplifying the response of northern ice to orbital variations has come also from the possibility that North Atlantic surface water remained warm well after insolation in northern hemisphere high lattudes had favored cooler summers and northern ice had even begun to grow. If so, at least at the precession frequencles, insolation variations may combine both to increase the latitudinal gradients and to keep up the supply of moisture in high latitudes, where it is retained as ice [Ruddiman and McIntyre, 1984].

Glacial ice has generally received most of the attention, but evidence exists that orbital variations also influence the behavior of the North Atlantic deep ocean water and atmospheric features such as the intensity of the westerly winds and of the Indian monsoon. For example, changing the orbital configuration to that of $9 \mathrm{kyr}$ B.P., when insolation seasonality was $14 \%$ higher than it is today, leads to an intensified southwest monsoon (Flgure 25) [Kutzbach, 1981]. This has beea confirmed by the results obtained from Kutzbach's atmospheric general circulation experiments to simulate the clinates of January and July from 18 to $10 \mathrm{kyr}$ B.P. at 3000-year intervals [Kutzbach and Guetter, 1986]. In these integrations, external forcing (the astronomical solar radiation) and internal boundary conditions (land and sea ice, aerosol and $\mathrm{CO}_{2}$ loadings) were taken into account. From 15 kyr B.P. onward this model simulates a strengthened monsoon circulation and increased precipitation in the northern hemisphere tropics, culminating in a maximum impact at 9-6 kyr B.P. [Kutzbach and Street-Perrott, 1985].

Prell and Kutzbach [1987] have used the NCAR Community Climate Model [Washington and Parkinson, 1986] to study the processes causing such changes in monsoon circulation for the past 150,000 years. The simulated spatial patterns of climate variables and their zonal and regional averages revealed that under interglacial conditions, increased northern hemisphere solar radiation produced a larger land-ocean pressure gradient, stronger winds, and greater precipitation over southern Asia and North Africa. Under glacial conditions the simulated monsoon is weakened in southern Asia, but precipitation is increased in the equatorial west Indian Ocean and equatorial North Africa. Moreover, the monsoon is strongly tied to the precession parameter (their maxima colncide), as is also the case for the variations

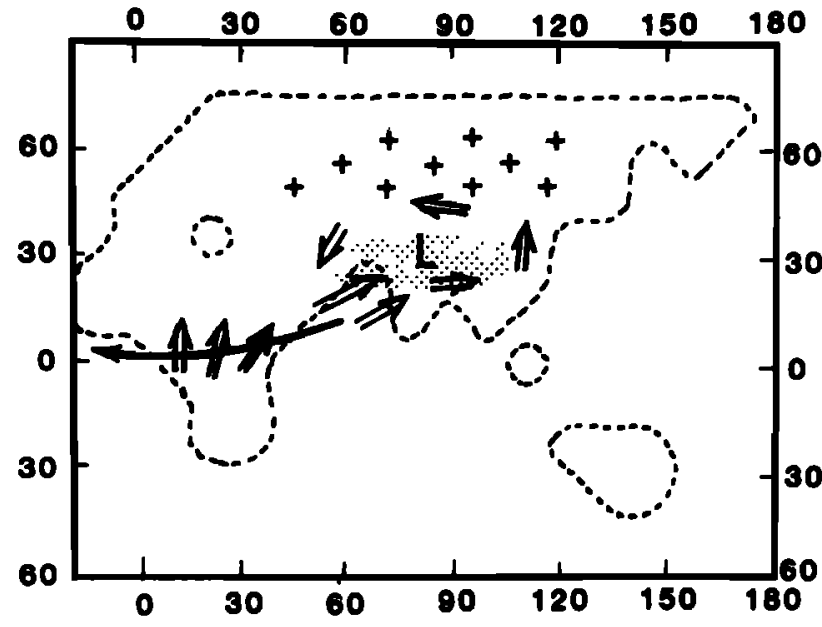

Fig. 25. Schematic of simulated temperature, pressure, wind, and precipitation differences, 9000 years B.P. minus present, for June-JulyAugust: higher temperature (pluses), intensified monsoon low (L), stronger low-level wind (doubleshafted arrows), stronger upper-level wind (curved arrow), increased precipitation (shading). (Reprinted from Kutzbach and Otto-Bliesner [1982] with permission from the authors and the Arerican Meteorological Society.)

in tropical [Bernard, 1962; Rossignol-Strick, 1983; Short and Mengel, 1986] and equatorial climate [Pokras and Mix, 1987].

From a similar simulation of the climate at 9 kyr B.P., Mitchell et al. [1987] found that in the northern heintsphere the simulated warming in high lattudes is greatest in autumn and winter because of changes in sea $i c e$, the mid-latitudes are warmer throughout the year because of changes in cloud, and the simulated surface temperature change over land in summer is reduced in low latitudes and enhanced in mid-latitudes because of changes in cloud and soll moisture.

Adem [1988] completed a study of the last 20,000 years using a thermodynamic model of the northern hemisphere. From 18 to $12 \mathrm{kyr}$ B.P. the surface albedo feedback maintains the northern hemisphere cool with stronger seasonal variations, the decrease of the atmospheric $\mathrm{CO}_{2}$ reinforcing the anomalies. From $12 \mathrm{kyr}$ B.P. to the present time the computed monthly average northern hemisphere surface temperature anomalies have the pattern of Insolation anomalies, except for a lag associated with the storage of heat in the oceans.

\subsection{Climate Models and Transient Response}

In addition to the calculation of the Earth's climate which is in equilibrium with a particular insolation pattern and other boundary conditions (the ice sheets, for example), the simulation of the transient response of a realistic climate system to orbital variations must allow a better understanding of the physical mechanisms involved in the relationship between the astronomical forcing and climate. I suggested earlier [Berger, $1979 \mathrm{~b}$ ] that the long-term astronomical variation of the latitudinal distribution of the seasonal pattern of insolation (Figures 20 and 21) is the 


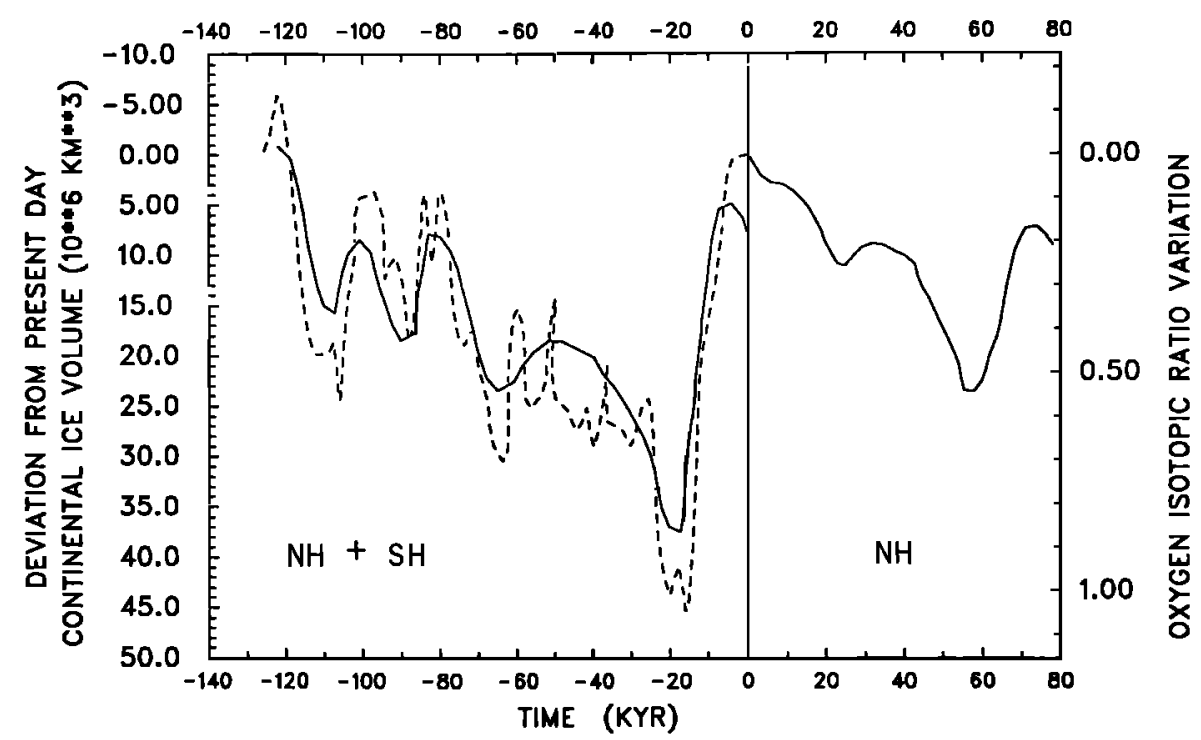

Fig. 26. Long-term variations over the last glacial-interglacial cycle (1) of the devlation from its present-day value (assumed to be $30.5 \times 10^{6} \mathrm{~km}^{2}$ ) of the total continental ice volume over the Earth (full curve) simulated by Berger et al. [1988] and (2) of the oxygen isotopic ratio variations (dashed curve) given by Labeyrie et al. [1987] and Duplessy et al. [1988]. The integration over the next 80,000 years has been carried out by H. Gallée Eor the northern hemisphere ice sheets only, starting with the observed present-day conditions.

key factor driving the climate system, the complex interactions between its different parts taking turns with this orbital perturbation. A 2.5dimensional time-dependent physical climate model, taking into account the feedbacks between the atmosphere, the upper ocean, the sea ice, the ice sheets, and the lithosphere, has confirmed this hypothesis [Berger et al., 1988]. The simulated long-term variations of the global ice volume over the past 125,000 years (Figure 26) agree remarkably well with the sea level curves of Chappell and Shackleton [1986] and Labeyrie et al.

[1987]: significantly, the northern heinisphere ice sheets were growing owing to snowfalls, the water vapor pumped from the oceans being carried out by the atmospheric general circulation.

All the mechanisms for generating northern tce sheets in response to orbital forcing share, apparently, a common problem, namely, the synchroneity of glaciations in both hemispheres. A possible inter-hemispheric link might be the ocean circulation [Duplessy and Shackleton, 1985; Duplessy et a1., 1987] or the worldwide effect of changes in atmospheric carbon dioxide concentrations [Manabe and Broccoli, 1985]. Recent reconstructions of these past $\mathrm{CO}_{2}$ variations have been possible because of the analysis of oceanic data [Shackleton et al., 1983] and ice data (Figure 27) [Barnola et al., 1987; Lorius et al., 1985; Jouzel et a1., 1987; Neftel et al., 1982], and evidence shows that orbital changes lead the changes in $\mathrm{CO}_{2}$, which in turn lead those in ice volume by an average of 2500 years [Pisias and Shackleton, 1984]. In such a case the variations in atmospheric $\mathrm{CO}_{2}$ could be, in some indirect way, part of the forcing of ice ages [Genthon et al., 1987] or, better, modulate the response of the climate system to orbital forcing [Berger et al., 1988]. Climate and the carbon cycle appear thus to have been more tightly linked than was pre- viously thought [Sundquist and Broecker, 1985]. They could also have been linked in producing the higher temperatures of the Cretaceous, $100 \mathrm{Myr}$ ago [Berner and Barron, 1984]. In the context of the antropogenic $\mathrm{CO}_{2}$ impact on our future climate, this fleld undeniably merits nore investigation.

\section{Conclusions}

Recent new evidence seems to have laid to rest the arguments that orbital variations might cause only minor climate fluctuations but not the major climatic changes manifested in the ice ages, the largest and most abrupt climatic changes known during the past 2 Myr. Among the competing theories to explain the coming and going of the Quaternary ice ages and other similar climatic varithons of the past, only the astronomical theory (of which the Milankovitch theory is a particular version) has been supported so far by substantial physical evidence.

This evidence shows that, both in the frequency and in the time domains, orbital influences are felt by the climate system and implies that the astronomical theory might provide a clock with which to date old Quaternary sediments with a precision several times greater than is now possible. On the other hand, there is evidence that the orbital variations-climate link (namely, at periods shorter than 100,000 years) has been a viable mechanism during the past few hundred million years, also at times when major ice masses were probably absent [Herbert and Fisher, 1986]. If we accept the astronomical theory as a fundanental principle, a time will come when geology will provide astronomers with estimates of periodicities in the range of tens of thousands to hundreds of thousand years, allowing us to test theories of the planetary system and its stability over the whole of Earth's history. 


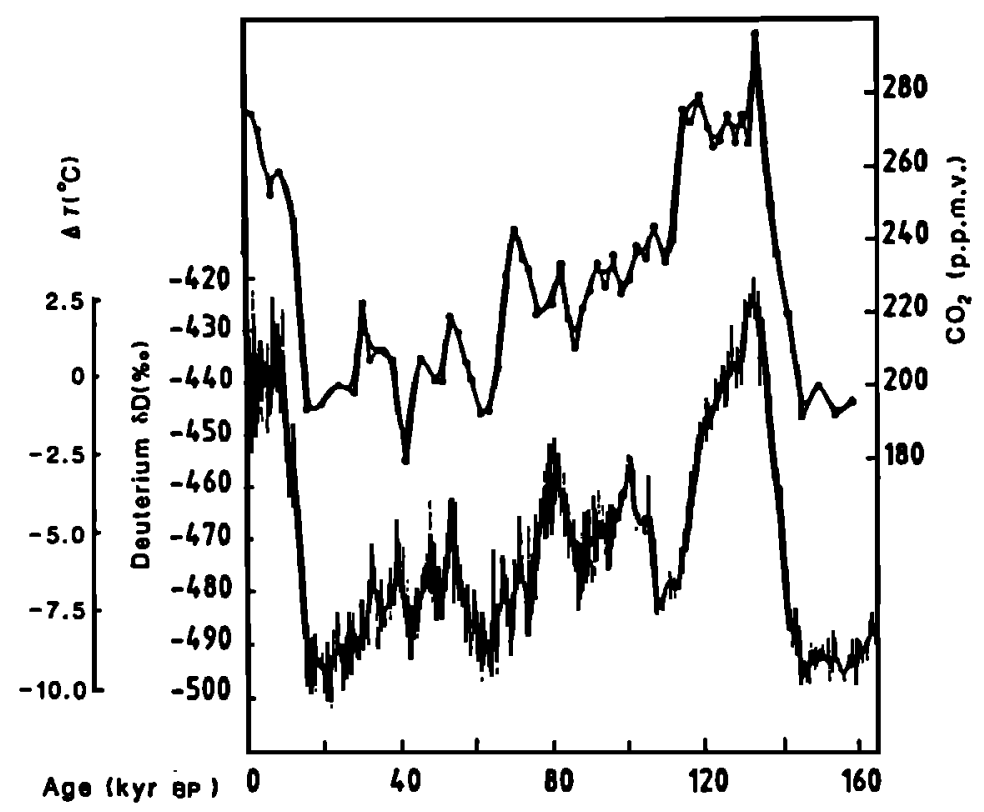

Fig. 27. $\mathrm{CO}_{2}$ concentrations ("best estimates") and smoothed values (spline function) in parts per million by volume versus age in the Vostok record (upper curve) [Barnola et al., 1987]. Atmospheric temperature change derived from the isotopic profile (lower curve) [Jouzel et al., 1987]. (Reprinted from Barnola et al. [1987] with permission from the authors and MacMillan Magazines.)

Along the lines of these reconstructions of the climatic rhythms recorded in pre-Quaternary strata [Fisher, 1986], we have computed the effect of the varying Earth-Moon distance on the main astronomical periods over the last 2 billion years (Table 5). The nonlinearity of the relationship between this Earth-Moon distance and the "constant" of the astronomical precession is responsible for a faster decrease of the obliquity period, in such a way that before $2 \times 10^{9}$ years $B . P$. the precession periods are as long as the obliquity period.

Finally, significant advances made in climate theory combined with advances in paleoclimatology indicate that there is now a unique opportunity to use the geological record as a criterion against which to judge the performance of physically motivated models of climate and so to identify mechanisms by which different parts of the climate system respond to changes in radiative boundary conditions. The importance of this opportunity is that both the temporal and the spatial pattern of these changes can be specified exactly. Except for the dally and annual cycles we know no other place in the climatic spectrum for which this exactitude is possible. Consequently, the astronomical theory is the only one that can be used to predict precisely the duration of natural quasiperiodic changes in climate. Using a simple model astronomlcally forced, researchers have shown that the dynamic behavior of the climate over the last 400,000 years reproduced fairly well [Imbrie and Imbr1e, 1980; Berger, 1980a; Berger et al., 1988]. Extrapolation thus begins slowly but sure1y to be allowed (Figures 26 and 28) [Berger, $1980 \mathrm{~b}]$, at least for a period over which we can assume that there is sufficient predictability [Nicolis and Nicolis, 1986]: assuming no human interference at the astronomical scale, orbital forcing predicts that the general cooling that began 6 kyr B.P. will continue with a first moder- ate cold peak around 5 kyr A.P., a major cooling about $23 \mathrm{kyr}$ A.P., and full ice age conditions 60 kyr A.P.

\section{Implications for the Future}

This kind (see Appendix D for a summary) of simulation is now of real practical interest; the time scale is compatible with the decay of radioactive elements trapped in nuclear wastes produced in atomic energy power plants, and for the safety of our future generations, there is a need to study in depth the stabtlity of the sites of nuclear waste disposal. In the light of all these results the relevance of the Milankovitch theory for modern climate research lies in climate model validation and sensitivity analysis and in a better understanding of the seasonal cycle and other climatic cycles. Because of its contribution to an accurate knowledge of our low-frequency climatic background (and even the high-frequency part as shown by Borisenkov et al. [1985]) and to an $1 \mathrm{~m}-$ proved theory of climate, it provides useful insights for further applications such as the study

TABLE 5. Direct Impact of the Varying Earth-Moon Distance on the Astronomical Periods

Period, Years

\begin{tabular}{clll}
$\begin{array}{c}\text { Epoch, } \\
10^{9} \begin{array}{l}\text { Years } \\
\text { B.P. }\end{array}\end{array}$ & $\begin{array}{l}19,000 \\
\text { Becomes }\end{array}$ & $\begin{array}{l}23,000 \\
\text { Becomes }\end{array}$ & $\begin{array}{l}41,000 \\
\text { Becomes }\end{array}$ \\
\hline 0.5 & 17,500 & 20,800 & 34,000 \\
1 & 16,600 & 19,500 & 29,900 \\
2 & 14,700 & 16,800 & 21,200 \\
2.5 & 13,400 & 14,750 & 14,800 \\
\hline
\end{tabular}




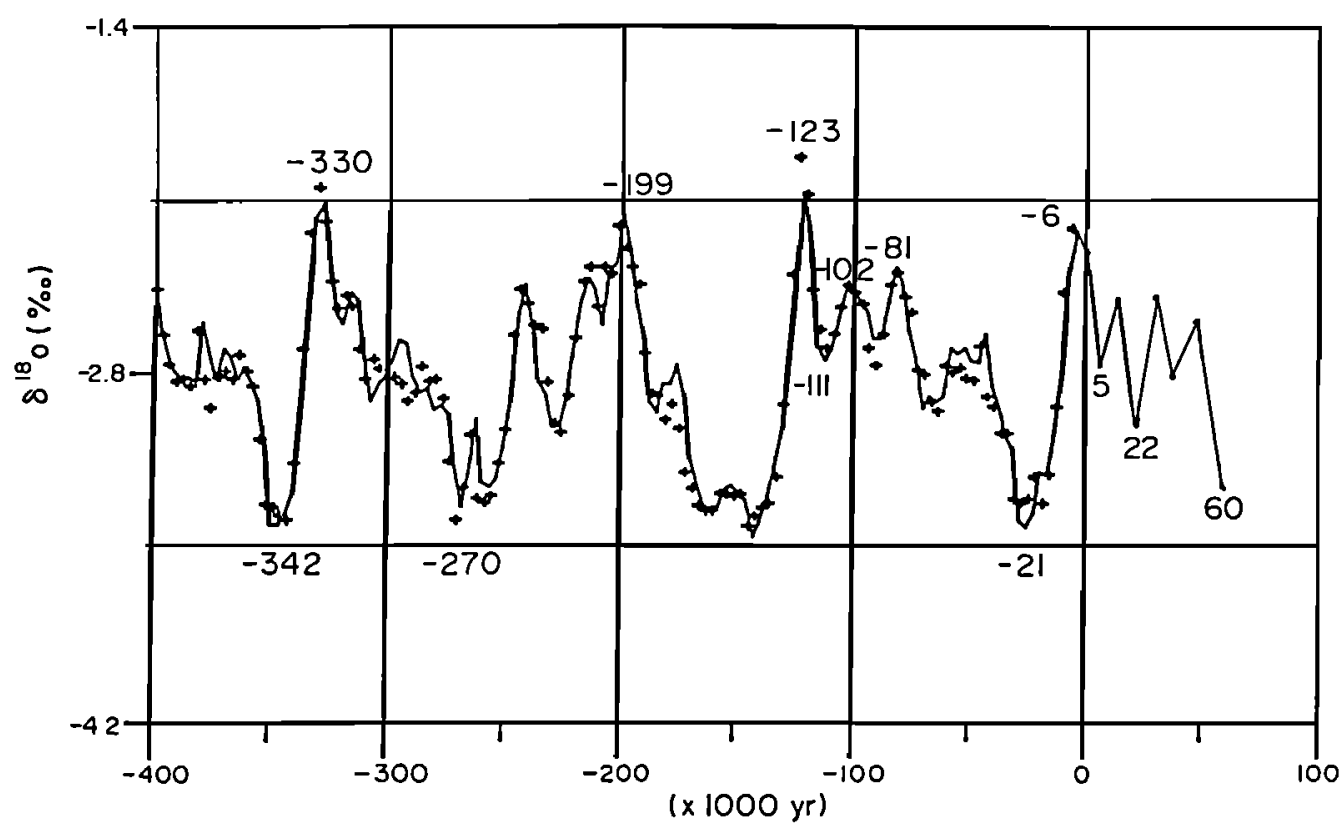

Fig. 28. Long-term climatic variations over the past 400,000 years and prediction for the next 60,000 years assuming no human interference at the astronomical time scale (pluses are data from Hays et al. [1976]; the solid curve is a simulation from a regressive model using the insolations as a forcing and allowing for a 3000-year memory of the climate system [Berger, 1980b]).

of man's impact on climate and climate forecasting at the annual to decadal time scales. Mitchell [1977] claimed that the warming effect of carbon dioxide [Bolin et al., 1986] may interact with the astrononical prediction by interposing a superinterglacial, with global mean temperatures in the next few centuries reaching levels several degrees higher than those experienced at any time in the last million years (remenber that this is happening close to a climatic optimum). Provided the climatic system does not jump into a new very warm equiltbrium state, the next ice age would have to wait until this $\mathrm{CO}_{2}$ warming has run its course, more than a thousand years from now.

The astronomtcal theory has allowed us to improve and to test advanced techniques of data analysis and models which can be transferred to evaluate climatic variations and varlability at our human time scale. Consequently, it is not merely of academic interest but really lies at the roots of any program which aims to better understand the climate system and its behavior.

\section{Appendix A: Pleistocene-Holocene Climates}

The inferred planetary evolution during the last $4.5 \times 10^{9}$ years exhibits both long-term trends and fluctuating components [Berger, 1979a, 1981; Wigley, 1981; Crowley, 1983]. The long-term climatic trends have been influenced by changes in solar luminosity, in atrnospheric composition, and in paleogeography. Glaclal-interglacial stages observed within the last Ice Age (the high-frequency part of the spectrum at the geological time scale [Bradley, 1985]) are due to orbitally induced forcing and to feedback interactions wthin the atmos phere-hydros phere-cryos phere-lithos pherebiosphere system and are superimposed on a global cooling of terrestrial, most probably plate tectonics, origin [Barron et al., 1984].

Although comprising less than $0.1 \%$ of Earth history, the Plelstocene-Holocene epochs have been studied more intensively than the rest of the paleoclimatic record because of relatively easy access to a wide variety of geologlcal exposures, and amenability of the data to more rigorous, quantitative analysis.

A fundamental tool for the paleoclimatic interpretation of geological records involves a technique that has been an invaluable aid in exainining the climatic history of the last million years: the $18_{0 / 16}$ stable tsotope analysis [Duplessy, 1978]. The most commonly used fossils for ${ }^{18} 0$ analyses are foraminifera, single-celled amoebalike organisms with $\mathrm{CaCO}_{3}$ shells. There are both planktonic (surface and near surface) and benthlc (bottom dwelling) varieties. The fundamental geological problem associated with 180 interprecations involves the realization by Eniliani [1955] that the 180 content of seawater can also be affected by the formation of ice sheets.

On the other hand, paleomagnetic studies and isotope techniques have provided the key to age Interpretation of Quaternary stages. For example, Shackleton and Opdyke [1973] were the first to determine that the last major reversal, the Brunhes-Matuyama boundary, occurred within $18_{0}$ stage 19. Following this work, correlations were later extended to the entire Pleistocene [Shackleton and Opdyke, 1976].

Northern hemisphere glaciation was apparently initiated several million years after Antarctic glaciation. The present best estimate is about $3.0 \times 10^{6}$ years ago, a tine when Atlantic deep water production may have increased and closely spaced, large-scale glacial-interglacial oscillations were initiated. However, analyses of North Atlantic and North Pacific records Indicate some pronounced temperature decreases that extend back to at least $10 \times 10^{6}$ years B.P., while the Arctic Ocean has been ice covered for the last $5 \times 10^{6}$ years. 
TABLE B1. Some Key Stages in the Evolution of the Astronomical Theory of Paleoclimates

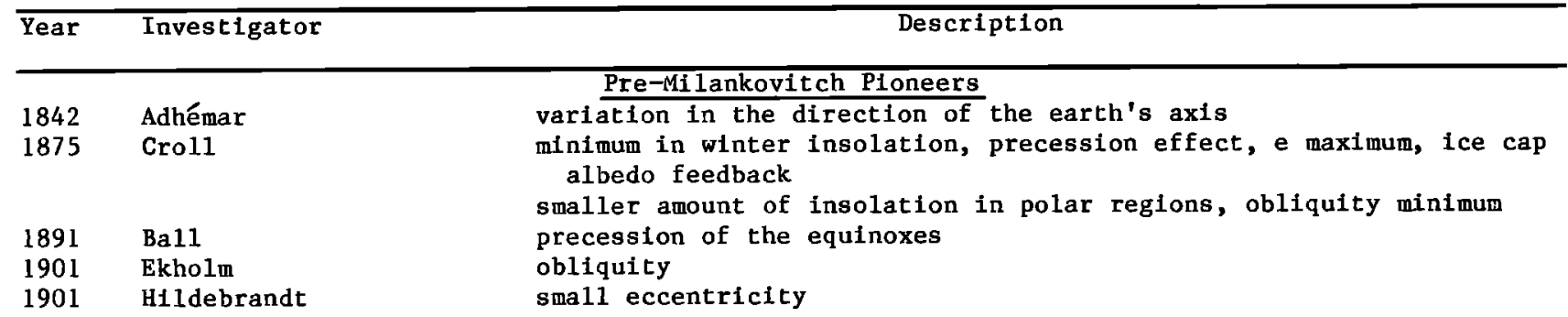

Milankovitch Era: Cool Summer at High Northern Latitudes

1876 Murphy

1921 Spitaler

1925 Brückner, Köppen, Wegener

1920 Milankovitch

1930 Milankovitch

1941 Milankovitch

1937 Soergel

1937 Blanc

1938

1940

1950

1957

Wundt

von Bacsak

Brouwer

Emiliani and Geiss Insolation only starts glaciation

$\begin{array}{ll}1959 & \text { Zeuner } \\ 1961 & \text { Jardetsky }\end{array}$

$65^{\circ} \mathrm{N}$ equivalent latitude, caloric northern hemisphere summer

lag between Insolation and extend of ice masses

sea level

albedo, continental configuration, air and sea currents

Interglacials

Insolation only starts glaciation
application to Scandinavian ice sheet

(a)

$\frac{\text { Milankovitch Debate: Caloric Seasons at Different Latitudes }}{40^{\circ}-75^{\circ} \text { caloric summer: continental area }}$

Fairbridge

Wundt

summer irradiation high latitudes in northern and southern hemi spheres

1962 Bernard

1966 van den Heuve1

pluvials and interpluvials in Africa

1966

1968

1968

1969

1969

1972

1979

1970

1970

Broecker

Kukla

Broecker et al.

Mesolella et al.

Sharaf and Budnikova

Vernekar

Vulis and Monin

Broecker and van Donk

$\phi>70^{\circ} \mathrm{N}$, obliquity, symmetry between northern and southern hemispheres

combination of precession, tilt, eccentricity; 6000 year lag

winter half-year ir radiation at $55^{\circ} \mathrm{N}$

$45^{\circ} \mathrm{N}$ caloric summer Insolation

application to Barbados: coral terraces, sea level

computation for all latitudes in northern and southern hemispheres, of summer and winter caloric insolation

Veeh and Chappell

$45^{\circ}-55^{\circ}-65^{\circ} \mathrm{N}$ caloric summer insolation

$45^{\circ} \mathrm{N}$, application to New Guinea

1929

1964

1966

1967

1967

1967

1969

1968

1969

1970

1971

1972

1972

1973

1978

1974

1974

1974

1974

1976

1976
Bradley

van Houten

van den Heuvel

Kemp and Eger

Bond and Stock1mayer

Mann

Dansgaard et al.

Shaw and Donn

Budyko

Sellers

Saltzman and Vernekar

Milankovitch Debate: Spectrum of Geological Data

21 kyr: varves of the Tertiary Green kiver epoch

21 kyr: nonmarine Triassic strata

obiquity and half precession (precession following Hays et al. from Emillani's curves)

precession (obliquity following Hays et al. [1976]; Caribbean cores P6304-8/9

21 kyr; upper Paleozoic strata in Rhodesia

$109 \mathrm{kyr}, 30.8 \mathrm{kyr}, 24.25 \mathrm{kyr}$; Missourlan rocks

$13 \mathrm{kyr}$; Camp Century ice cover

Milankovitch Debate: Physical Models

Adem's model, $\Delta \mathrm{T}=1.4^{\circ} \mathrm{C}$ (25 kyr B.P. high latitudes)

energy balance model; $\Delta$ glacial boundary $\sim 1^{\circ}$ latitude

energy balance model; $\Delta \mathrm{T} \sim 0.1^{\circ} \mathrm{C}$ (minimum obliquity, high latitudes)

statistical-dynamical model, $\Delta \mathrm{T}=1.4^{\circ} \mathrm{C}\left(25 \mathrm{kyr}\right.$ B.P., $\left.85^{\circ} \mathrm{N}\right)$

Kuk 1a

Evans

Berger

Berger $\}$

Bloom et al.

Ku et al.

Chappe11

Calder

Mason

Milankovitch Renaissance: Caloric Seasons

season-to-season difference in winter insolation for $25^{\circ}-75^{\circ} \mathrm{N}$

$65^{\circ} \mathrm{N}$ and $65^{\circ} \mathrm{S}$; time lag $4 \mathrm{kyr}$

computation for all latitudes $\mathrm{N}-\mathrm{S}$, summer and winter

caloric equator

application to New Gunea, coral terraces

application to Hawaii, coral terraces

precession and large eccentricity, application to coral reefs

different thresholds growth and decay of ice sheets, $50^{\circ} \mathrm{N}$ summer insolation

insolation deficit for $\phi>45^{\circ} \mathrm{N}$

Johnson and McClure

hemisphere average and $70^{\circ} \mathrm{N}$ summer irradiation 


\begin{tabular}{ll}
\hline Year & Investigator \\
\hline 1976 & Ruddiman and McIntyre \\
1979 & Ruddiman and McIntyre \\
1979 & Kukla and Berger \\
1979 & Kominz and Pisias \\
1980 & Ruddiman and McIntyre \\
1980 & Dansgaard
\end{tabular}

Description

$55^{\circ} \mathrm{N}^{-}$summer insolation

$65^{\circ} \mathrm{N}$ low caloric summer insolation

astronomic climate index, interglacials

$50^{\circ} \mathrm{N}$

$70^{\circ} \mathrm{N}$ summer insolation-oceanic moisture, precession

$65^{\circ} \mathrm{N}$ summer insolation and north-south gradient thresholds

$\begin{array}{ll}1975 & \text { Kukla } \\ 1978 & \text { Berger } \\ 1979 & \text { Berger et al. }\end{array}$

Milankovitch Renaissance: Monthly Insolation

fall insolation

insolation-climate index

1973

1975

1976

1976

1977

1978

1979

1979

1977

Berger

Milankovitch Renaissance: Spectrum of Astronomical Data

Shackleton

Kominz et a1.

Briskin and Harre11

413 kyr, V16-205 tropical North Atlantic core

85 kyr, K708-7 from NE Atlantic Ocean southern Indian Ocean

kyr, 19 kyr; western equatorial Pacific core V28-238 120/E49-18

Milankovitch Renaissance: Spectrum of Proxy Data

$100 \mathrm{kyr}, 60 \mathrm{kyr}, 45 \mathrm{kyr}$, precession (obliquity following Hays et al.

[1976]; coral reefs, Caribbean and Atlantic deep-sea cores

$105 \mathrm{kyr}, 41 \mathrm{kyr}, 23 \mathrm{kyr}, 19 \mathrm{kyr}$; RC11-120, E49-18 deep-sea cores in

$100 \mathrm{kyr}$; soil record from central Europe (up to 2 Myr B.P.)

400 kyr; Atlantic Deep Sea Drilling Project Tertiary sites

$400 \mathrm{kyr}, 104 \mathrm{kyr}, 93.2 \mathrm{kyr}, 58.5 \mathrm{kyr}, 52.2 \mathrm{kyr}, 41 \mathrm{kyr}, 30 \mathrm{kyr}, 23$

other astronomical cycles; deep-sea cores V16-205, V28-239, RC11-

1973

1976

1976

1977

1978

1978

1978

1978

1978

1979

1979

1979

1979

1979

1979

Kominz and Pisias

Kukla and Berger

Kallen et al.

Ghil

Imbrie and Imbrie

Oerlemans

Oerlemans and Bienfait

Benzi et al.

1980 Berger
$413 \mathrm{kyr}, 95 \mathrm{kyr}, 123 \mathrm{kyr}, 100 \mathrm{kyr}, 50 \mathrm{kyr}, 41 \mathrm{kyr}, 53 \mathrm{kyr}, 30 \mathrm{kyr}$, 23.7 kyr, $22.4 \mathrm{kyr}, 18.98 \mathrm{kyr}, 19.16 \mathrm{kyr}, 16 \mathrm{kyr}, 56 \mathrm{kyr}$

Milankovitch Renaissance: Climatological Models

almost periodic stochasting forcing; explained variance: $41 \%$

linear model; explained variance: $80 \%$; $\mathrm{KCl1-120/ \textrm {E } 4 9 - 1 8}$

ice sheet model; obliquity-precession cycle

energy balance model; $\Delta \mathrm{T}$ small but cooling extends to $60^{\circ} \mathrm{N}$

autoregressive integrated moving average model; Carribean, Atlantic, and Pacific deep-sea cores

terrestrial relaxation oscillation of 100,000-year cycle and obliquity and precession curves

explained variance from astronomical forcing: $10 \%$

Weertman improved model; obliquity-precession cycles

Weertman improved model, all astronomical peaks

energy balance model; $\Delta \mathrm{T}$ small

energy balance model; oceanic mixed larger, seasonal change; $\Delta$ ice line: $3^{\circ}$ latitude

amplification expected from zenith angle, bio-albedo, latent heat feedbacks

energy balance model (ocean), albedo feedback, seasonal; $\Delta$ ice line: $20^{\circ}$ latitude

energy balance model (seasonal); $\Delta$ (glacial-interglacial, $60^{\circ} \mathrm{N}$ ) = $0.8^{\circ} \mathrm{C}$

a1most nonlinear autoregressive insolation models; insolation June $85^{\circ} \mathrm{N}$, December $65^{\circ} \mathrm{N}$, March $25^{\circ} \mathrm{N}$, September $15^{\circ} \mathrm{S}$, June $55^{\circ} \mathrm{S}$, December $75^{\circ} \mathrm{S}$; climate menory: 3000-year lag; all astronomical peaks; RCl1-120/E49-18, $\mathrm{R}^{2}=50-87 \%$

stochastic forcing, $\mathrm{R}^{2}=26 \%$ from $\mathrm{V} 28-238$

astronomic climate index; 100-43-23-19-7 kyr periods

several tens of thousands of years free oscillations

several tens of thousands of years free osclllations

differential models, different time scales for growth and decay of

ice sheets, $65^{\circ} \mathrm{N}$ July insolation, all astronomical peaks; deep-sea cores RC11-120, V28-238

ice sheet/Earth crust dynamics; $100 \mathrm{kyr}$; Carribean core V12-122

Oerlemans plus daily cycle snow/ice melting; 100-kyr

stochastic resonance amplifies the 100-kyr eccentricity cycle

Milankovitch Big Bang

for references, see this paper and, For example, the work by Berger et a1. [1984], Bradley [1985], Hecht [1985], Imbrie [1982], Kutzbach [1985], and National Research Council [1982] 
Appendix C: A Discussion of Past (and Now Irrelevant) Criticisms of the Milankovitch Theory

Opponents have, in the past, made the following criticisms of the Milankovitch approach:

1. The theory goes awry by its prediction of contrapuntal or alternating insolation effects relative to the two hemispheres. Alternating hemispheric glaciation cycles are indeed not observed, and nor are they predicted by climate models which are astronomically forced. However, as the high-latitude caloric insolation is mainly dependent on obliquity, whereas that of low latitudes is essentially dependent on precession, and as the obliquity effect is the same in both hemispheres, whereas the precession effect is the opposite, the nature of the Milankovitch model itself implies an asymmetry between hemispheres which is minimal (almost nonexistent) for all latitudes higher than $70^{\circ}$ (the Milankovitch critical latitudes). On the other hand, the model also implies compensation of negative summer deviations by positive winter deviations. Under such conditions, not only would the summer temperatures in northern high latitudes be such as to tend to help prevent snow and ice from melting, but also the implied milder winters would tend to allow a substantial evaporation in the intertropical zone and more abundant snowfalls in temperate and polar latitudes, this humidity being transported there by an intensified general circulation due to the maximum in the latitudinal insolation gradient [Berger, 1976b].

Moreover, Suarez and Held [1979] demonstrated with a simple energy balance that although variations in the Earth's orbital parameters may be responsible for the large fluctuations in the extent of northera hemisphere ice sheets during the Pleistocene, it is necessary to look for mechanisms other than the interhemispheric exchange of heat in the atmosphere in order to explain the low temperatures of the southern henisphere during glacials. It was proposed that among the potential mechanisms for this cooling of the southern hemisphere are the cross-equatorial heat transport by the ocean circulation [Manabe and Broccoli, 1985] and/or the fluctuations in the concentration of carbon dloxide [Broecker, 1982] as deduced from ice cores from the Antarctic [Barnola et al., 1987] and Greenland [Neftel et al., 1982] ice sheets or in the loading of aerosols in the atmosphere.

2. The theory fails to account for the fact that all the Quaternary events have their maximuin inpact in the northern hemisphere. Within the framework of the astronomical theory by which orbital parameter changes are seen as the essential modulators of the long-tern climatic behavior (in that they place the climate system in a state which is more or less sensitive to other factors), there is absolutely no reason that this astronomical theory must account for all the climatic changes during the Quaternary. In particular, the abrupt Pleistocene climate changes [Berger, 1982] will most probably find their origin within the complex interactions and feedback mechanisms between the components of the climate system itself.

3. The theory is not needed to explain other major glaciations. It is evidently a question of time scales. Although astronomical signatures are beginning to be found in many pre-Quaternary sed- iments [e.g., Herbert and Fisher, 1986], the time scale of Cretaceous climate or of earlier Ice Ages (as in the case of the infra-equatorial glaciation of the Mesozoic era in the Sahara, South Africa, and Australia) is more related to geographical variables and plate tectonics than to orbital parameter variations [Barron and Washington, 1984; Barron et al., 1984].

Appendix D: Relevance of the Astronomical Theory to the Modern World

The astronomical theory has the following advantages:

1. It provides an absolute clock with which to date Quaternary sediments with a precision several times greater than is now possible.

2. It provides data to astronomers to test the stability of the planetary system for pre-Quaternary times.

3. It provides the boundary conditions necessary for a better understanding of the climatic system and the interactions between atmosphere, hydrosphere, cryosphere, biosphere, and lithosphere, which, at the astronomical time scale, all play a role.

4. It allows a better understanding of the seasonal cycle and allows us to test the performance of the climate models over a broad spectrum of climatic regimes.

5. It allows a better understanding of the $\mathrm{CO}_{2}$ cycle, its sensitivity to climate changes, and its interactions with the climate subsystems.

6. It predicts natural climatic variability at the geological time scale for the next 100,000 years, a period compatible with the decay of $\mathrm{ra}$ dioactive elements trapped in nuclear wastes produced in atonic power stations (climate stability of the sites of nuclear waste disposal).

7. It allows a better understanding of the sensitivity of our present-day interglacial climate and of the possible superinterglacial that could be generated by human activicies within the next 50 years or less.

8. It enables us to compute accurately the insolation changes at the decadal time scale due to change In orbital elements, in relation to the satelltte measurements of the solar constant and its variations.

9. It allows a better understanding of the planetary system and the climatic variations of the planets [Ward, 1974; Ward et al., 1979].

10. It allows us to transfer theoretical knowledge (spectral analysis, numerical schemes, etc.) and technologies (deep-sea drilling, satellites, supercomputers, etc.) to soclety at large.

Acknowledgments. Improvements in the astronomical theory have been possible only through international collaboration initiated, in particular, by the CLIMAP (Climate: Long-Range Investigation, Mapping and Prediction) and SPECMAP (Mapping Variatfons in Ocean Spectra Over a Frequency Range $10^{-5}$ to $10^{-3}$ Cycles per Year) groups in the United States and by the Commission of the European Communities. Many thanks to all colleagues for their helpful discusstons. The members of the Institut d'Astronomie et de Géophysique Georges Lemâ̂tre have significantly contributed to some recent results presented here. Works by J. Guiot, P. Pestiaux, J. P. van Ypersele, C. Tricot, H. Gal- 
16e, P. Gaspar, T. Fichefet, I. Marsiat, I. van der Meersch, F. Goffin, M. F. Loutre, and V. Dehant are gratefully acknowledged. I am indebted to H. Cattle (Meteorological office, Bracknell, England) and to unknown referees for their most helpful comments during the finalization of this review paper. N. Materne-Depoorter typed the numerous revisions of the manuscript. Thanks to the Belgian National Foundation for Scientific Research, the Ministère de la Communauté Francalse, the International Climate Commission of IUGG-IAMAP, the INQUA International Commission of Paleoclimate, and the Organizing Committee of the XIX IUGG General Assembly of Vancouver for their financial help.

\section{References}

Adem, J., Possible causes and numerical simulation of the northern hemispheric climate during the last deglaciation, Atmosfera, $1,17-38,1988$.

Adhémar, J. A., Révolution des Mers, Déluges Pérlodiques, publication privee, Paris, 1842.

Agassiz, L., Upon glaciers, moraines, and erratic blocks; address delfvered at the opening of the Helvetic History Soclety at Neuchate1, $24 \mathrm{July}$ 1837 by 1 ts president, New Philos. J. Edinburgh, $24,864-883,1838$.

Alyea, $\vec{F}$. N., Numerical simulation of an ice-age paleoclimate, Atmos. Sci. Pap. 193, 120 pp., Colo. State Univ., Fort Collins, 1972.

Ba11, R., The Cause of an Ice-Age, London, 1891. Barnola, J. M., Y. S. Korotkevitch, D. Raynaud, and C. Lorius, Vostok ice Core: A 160,000 year record of atmospheric $\mathrm{CO}_{2}$, Nature, $329(6138)$, $408-414,1987$.

Barron, E. J., and W. M. Washington, The role of geographic variables in explaining paleoclimates: Results from cretaceous climate model sensitivity studies, J. Geophys. Res., 89, $1267-1279,1984$.

Barron, E. J., S. L. Thompson, and W. W. Hay, Continental distribution as a forcing factor for global-scale temperature, Nature, 310, 574$575,1984$.

Benzi, R., G. Parisi, A. Sutera, and A. Vulpian1, Stochastic resonance in climatic change, Tel1us, 34, 10-16, 1982 .

Berger, $\overline{A_{0}}$, Obliquity and precession for the last 5,000,000 years, Astron. Astrophys., 51, 127$135,1976 a$.

Berger, A., Long-term variations of daily and monthly insolation during the last ice age, Eos Trans. AGU, 57(4), 254, 1976b.

Berger, A., Support for the astronomical theory of climatic change, Nature, 268, 44-45, 1977.

Berger, A., Long-term variations of daily insolation and Quaternary climatic changes, J. Atmos. Sci., 35(12), 2362-2367, 1978a.

Berger, A., A simple algorithm to compute longterm variations of datly and monthly insolation (with appendices $A$ and $B$ ), Contrib. 18, Inst. d'Astron, et de Géophys. G. Lemaftre, Univ. Cathollque, Louvain-la-Neuve, Belgium, 1978b.

Berger, A., Numerical values of the elements of the Earth's orbit from 5,000,000 YBP to $1,000,000$ YAP (astronomical solution of Berger, 1978), Contrib. 35, Inst. d'Astron. et de Géophys. G. Lemaître, Univ. Catholique, Louvainla-Neuve, Belgium, 1978c.

Berger, A., Numerical values of mid-month insolation from $1,000,000$ YBP to 100,000 YAP (astro- nomical solution of Berger, 1978), Contrib. 36, Inst. d'Astron. et de Géophys. G. Lemaitre, Univ. Catholique, Louvain-la-Neuve, Belgium, 1978d.

Berger, A., Numerical values of caloric insolation from 1,000,000 YBP to 100,000 YAP (astronomical solution of Berger, 1978), Contrib. 37, Inst. d'Astron. et de Géophys. G. Lemátre, Univ. Catholique, Louvain-la-Neuve, Belgium, 1978e.

Berger, A., Long-term variations of caloric 1nsolation resulting from the Earth's orbital elements, Quat. Res., 9, 139-167, 1978f.

Berger, A., Spectrum of climatic variations and their causal mechanisms, Geophys. Surv., 3, 351-402, 1979a.

Berger, A., Insolation signatures of Quaternary climatlc changes, Nuovo Cimento, 2C(1), 63-87, $1979 \mathrm{~b}$.

Berger, A., A critical review of modeling the astronomical theory of paleoclimates and the future of our climate, in Sun and Climate, pp. 325-356, Centre National d'Etudes Spatiales, Toulouse, France, 1980a.

Berger, A., Milankovitch astronomlcal theory of paleoclimates, a modern review, Vistas Astron., $24,103-122,1980 \mathrm{~b}$.

Berger, A. (Ed.), Climatic Varlations and Variability: Facts and Theories, D. Reidel, Hingham, Mass., 1981.

Berger, A., Accuracy and frequency stability of the Earth's orbital elements during the Quaternary, In Milankovitch and Climate, edited by $A$. Berger et al., pp. 3-40, D. Reide1, Hingham, Mass., 1984.

Berger, A., Pleistocene climatic variability at astronomical frequencies, in Global Change, edited by H. Faure and N. Rutter, International Quaternary Association, Ottawa, Ont., 1987.

Berger, A., and Pestlaux, P., Accuracy and stability of the Quaternary terrestrial insolation, in Milankovitch and Climate, edited by A. Berger et al., pp. 83-112, D. Reidel, Hingham, Mass., 1984.

Berger, A., and P. Pestlaux, Astronomical frequencies in paleoclimatic data, in The Climate of China and Global Climate, edited by Ye Duzheng, Fu Congbin, Chao Jiping, M. Yoshino, pp. 106-114, China Ocean Press, Springer-Verlag, New York, 1987.

Berger, A., J. Imbrie, J. Hays, G. Kukla, and B. Saltzman (Eds.), Milankovitch and Climate, D. Reide1, Hingham, Mass., 1984.

Berger, A., V. Dehant, and M. F. Loutre, Origin and stability of the frequencies in the astronomical theory of paleoclimates, Sci. Rep. 1987/5, Inst. d'Astron. et de Géophys. G. Lemattre, Univ. Catholique, Louvaln-la-Neuve, Belgium, 1987.

Berger, A., H. Gallee, Th. Fichefet, I. Marsiat, and $C$. Tricot, Testing the astronomical theory with a physical coupled climate-ice-sheets mode1, Sci. Rep. 1988/3, Inst. d'Astron. et de Geophys. G. Lemaitre, Univ. Catholique, Louvaln-la-Neuve, Belgium, 1988.

Berger, W., Climate steps in ocean history--Lessons from the Pleistocene, in Climate in Earth History, pp. 43-54, National Acadeny Press, Wash1ngton, D.C., 1982.

Bernard, E. A., Théorie astronomique des pluviaux et Interpluviaux du Quaternaire Africain, Acad. R. Scl. Outre Mer Cl. Scl. Tech. Mem. Brussels,

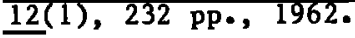


Berner, R. A., and E. J. Barron, Comments on the BLAG model: Factors affecting atmospheric $\mathrm{CO}_{2}$ and temperature over the past 100 million years, Am. J. Sc1., 284, 1183-1192, 1984.

Birchfield, G. E., and J. Weertman, A note on the spectral response of a model continental ice sheet, J. Geophys. Res., 83(C8), 4123-4125, 1978.

Blanc, A. C., Low levels of the Mediterranean Sea during the Pleistocene glaciation, Q. J. Geol. Soc. London, 93, 1937.

Bloom, A. L., W. S. Broecker, J. M. A. Chappe11, R. K. Matthews, and K. J. Mesolella, Quaternary sea leyel fluctuations on a tectonic coast: New ${ }^{230} \mathrm{Th} /{ }^{23} \mathrm{U}$ dates from the Huon Peninsula, New Guinea, Quat. Res., 4(2), 185-205, 1974.

Bolin, B., B. R. Döos, J. Jäger, and R. A. Warrick (Eds.), The Greenhouse effect, climate change and ecosystems, SCOPE Rep., 29, 400 pp., 1986.

Borisenkov, Ye. P., A. V. Tsvetkov, and J. A. Eddy, Combined effects of earth orbit perturbations and solar activity on terrestrial insolation, I, Sample days and annual mean values, J. Atmos. Sci., 42(9), 933-940, 1985.

Bradley, R. S., Methods of paleoclimatic reconstruction, Quaternary Paloeclimatology, 472 pp., Allen and Unwin, Boston, 1985.

Bretagnon, P., Ternes a longues periodes dans le systeme solaire, Astron. Asrtrophys., 30(1), 141-154, 1974.

Broecker, W. S., Absolute dating and the astronomical theory of glaciation, Science, 151, 299$304,1966$.

Broecker, W. S., Glacial to interglactal changes in ocean chemistry, Prog. Oceanogr., $11,151-$ $197,1982$.

Broecker, W. S., and J. van Donk Insolation changes, ice volume and the $0{ }^{18}$ record in deepsea cores, Rev. Geophys., $8(1), 169-198,1970$.

Broecker, W. S., D. l. Thurber, J. Goddard, T. Ku, R. K. Matthews, and K. J. Mesolella, Milankovitch hypothesis supported by precise dating of coral reefs and deep sea sediments, Science, 159, 297-300, 1968 .

Brooks, C. E. P., Climate Through the Ages, Dover, New York, 1970. (Unabridged and unaltered republication of the revised 1949 edition.)

Brouwer, A., Vormen de strallngscurven van Milankovitch een bruikbare grandslag voor de indeling van het Pleistocene?, Geol. M1jnbouw, l2(1), 9-11, 1950 .

Brückner, E., W. Köppen, and A. Wegener, Uber die Klimate der geologische Vorzeit, Z. Gletscherkd., XIV, 1925.

Budd, W. F., and I. Smith, The growth and retreat of ice sheets in response to orbital radiation changes, in UGGI Interdisciplinary Symposia Abstracts, pp. 2-27, XVII IUGG General Assembly, Canberra, 1979.

Budd, W. F., and I. N. Snith, Conditions for growth and retreat of the Laurentide ice sheet, Geogr. Physique Quat., XLI(2), 279-290, 1987.

Budyko, M. I., Effect of solar radiation variations on the climate of Earth, Tellus, 21(5), 611-620, 1969.

Calder, N., Arithmetic of ice ages, Nature, 252, 216-218, 1974.

Campy, M., and J. Chaline, Le Quaternaire, un concept depasse? une etiquette perimee? ou une privilegiee?, INQUA Newslett. Striolae, 1 , 7$12,1987$.

Cess, R. D., and J. C. Wronka, Ice ages and the
Milankovitch theory: A study of interactive climate feedback mechanisms, Tellus, 31, 185$192,1979$.

Chappel1, J., Relationship between sea levels, $0^{18}$ variations and orbital perturbations during the past 250,000 years, Nature, 252, 199-202, 1974.

Chappe11, J., and N. J. Shackleton, Oxygen isotopes and sea level, Nature, 324, 137-140, 1986.

CLIMAP Project Members, The surface of the Ice-Age Earth, Science, 191, 1131-1137, 1976.

CLIMAP Project Members, Seasonal reconstruction of the Earth's surface at the last glacial maximum, Geol. Soc. Am. Map Chart Ser. MC-36, 1-18, 1981 .

Cro11, J., Climate and Time in Their Geological Relations, Appleton, New York, 1875.

Crowley, T. J., The geologic record of climatic change, Rev. Geophys., 21(4), 828-877, 1983.

Darwin, C., On the Origin of Species by Means of Natural Selection, D. Appleton, New York, 1859.

Duplessy, J. C., Isotope studies, in Climatic Change, edited by J. Gribbln, pp. 46-68, Cambridge University Press, New York, 1978.

Duplessy, J. C., and N. J. Shackleton, Response of global deep-water circulation to Earth's climatic change 135,000-107,000 years ago, Nature, $316,500-507,1985$.

Duplessy, J. C., L. Labeyrie, and P.L. Blanc, Norwegian sea deep water variations over the last climatic cycle: Paleo-oceanographical implications, in Long and Short Term Variability of Climate, edited by $H$. Wanner and $U$. Siegenthaler, pp. 83-116, Springer-Verlag, New York, 1988.

Ekholm, N., On the variations of the climate of the geological and historical past and their causes, Q. J. R. Meteorol. Soc., 27, 1-61, 1901 .

Emiliani, C., Pleistocene temperature, J. Geol., 63, 538-578, 1955.

Emiliani, C., and J. Geiss, on glaclations and their causes, Geol. Rundsch., 46, 576, 1957.

Evans, P., The present status of age determination In the Quaternary (with special reference to the period between 70,000 and $1,000,000$ years ago), in Quaternary Geology, Proceedings of International Geological Congress, pp. 16-21, Harpe11, Gardenva1e, Que., 1972.

Fairbridge, R. W., Convergence of evidence on climatic change and ice ages, Ann. N.Y. Acad. Sci., 91(1), 542-579, 1961 .

Fisher, A. G., C1imatlc rhythms recorded in strata, Annu. Rev. Earth Planet Sci., 14, 351$376,1986$.

Fouquart, Y., and B. Bonne1, Computations of solar heating of the Earth's atmosphere: A new parameterization, Contrib. Atmos. Phys., 53, 35-62, 1980.

Frakes, L. A., Climates Throughout Geological Time, E1sevier, New York, 1979.

Genthon, C., J. M. Barnola, D. Raynaud, C. Lorius, J. Jouzel, N. I. Barkov, Y. S. Korotkevitch, and V. M. Kotlyakov, Vostok ice core: The climate response to $\mathrm{CO}_{2}$ and orbital forcing changes over the last climatic cycle, Nature $329(6138), 414-418,1987$.

Ghil, M., Internal climatic mechanisms participating in glaciation cycles, in Climatic Variations and Variability: Facts and Theories, ediced by A. Berger, pp. 539-557, D. Reidel, Hingham, Mass., 1981. 
Ghil, M., and H. Le Treut, A climate model with cryodynamics and geodynamics, J. Geophys. Res., $86,5262-5270,1981$.

Hasselman, K., Stochastic climate mode1s, I, Te1lus, 28, 473, 1976.

Hays, J. D., J. Imbrie, and N. J. Shackleton, Variations in the Earth's orbit: Pacemaker of the ice ages, Science, 194, 112l-1132, 1976.

Hecht, A. (Ed.), Paleoclimate Analysis and Mode1ing, John Wiley, New York, 1985.

Herbert, T. D., and A. G. Fisher, Milankovitch climatic origin of mid-Cretaceous black shale rhythms, central Italy, Nature, 321(6072], 739$743,1986$.

Herterich, K., and M. Sarnthein, Brunhes time scale: Tuning by rates of calclum-carbonate dissolution and cross-spectral analyses with solar insolation in Milankovitch and Climate, edited by A. Berger et al., pp. 447-466, D. Reidel, Hingham, Mass., 1984.

Hildebrandt, M. ,Die Eiszeiten der Erde, Berlin, 1901.

Hughes, T. J., G. H. Denton, B. G. Andersen, D. H. Schilling, J. L. Fastook, and C. S. Lingle, The last great ice sheets: A global view, in The Last Great Ice Sheets, edied by G. H. Denton and T. J. Hughes, 263-317, J. Wiley, New York, 1981 .

Hyde, W. T. and W. R. Peltier, Sensitivity experiments with a model of the Ice Age cycle: The response to harmonic forcing, J. Atmos. Sci., 42(20), 2170-2188, 1985.

Imbrie, J., Astronomical theory of the Pleistocene ice ages: A brief historical review, Icarus, $50,408-422,1982$.

Imbrie, J., and K. P. Imbrie, Ice Ages, Solving the Mystery, Enslow, Hillside, N. J., 1979.

Imbrie, J., and J. Z. Imbrie, Modelling the climatic response to orbital variations, Science, 207, 943-953, 1980 .

Inbrie, J., and N. G. Kipp, New micropaleontological method for quantitative paleoclimatology: Application to a Late Paleistocene Caribbean core, in Late Cenozolc Glacial Ages, edited by K. K. Turekian, pp. 71-181, Yale University Press, New Haven, Conn., 1971.

Imbrie, J., and N. Shackleton, Climatic variability: The spectrum of high-latttude sea-surface temperature over 10 frequency decades (abstract), Eos Trans. AGU, 67(44), 878, 1986.

Imbrie, J., J. Hays, D. G. Martinson, A. McIntyre, A. C. Mix, J. J. Morley, N. G. Pisias, W. L. Prell, and N. J. Shackleton, The orbital theory of Plelstocene climate: Support from a revised chronology of the marine $18_{0}$ record, in Milankovitch and Climate, edited by A. Berger et al., pp. 269-305, D. Reidel, Hingham, Mass., 1984.

Jardetsky, W. S., Investigations of Milankovitch and Quaternary curve of effective solar radiation, Ann. N.Y. Acad. Sci., 95, 118-423, 1961.

Jouze1, J., C. Lorius, J. R. PetLt, C. Genthon, N. I. Barkov, V. M. Kotlyakov, and V. N. Petrov, Vostok ice core: A continuous isotope temperature record over the last climatic cycle, Nature, 329(6138), 403-408, 1987.

Kalien, E., C. Crafoord, and M. Ghi1, Free oscillations in a coupled atmosphere-hydrospherecryosphere system, J. Atmos. Sci., 36, 2292$2302,1978$.

Kennett, J. P., Cenozoic evolution of Antarctic glaciation, the circum-Antarctic ocean, and their impact on global paleoceanography, J. Geophys. Res., 82(27), 3843-3860, 1977.
Kominz, M. A., and N. G. Pisias, Pleistocene climate: Deterministic or stochastic? Science, $204,171-173,1979$.

Ku, T. L., M. N. Kimmel, W. H., Easton, and T. J. 0 'Neil, Eustatic sea-level 120,000 years ago on Oahu, Hawaii, Science, 183, 959-962, 1974.

Kukla, G., Insolation and glacials, Boreas, $1(1)$, $63-96,1972$.

Kukla, G., Missing link between Milankovitch and c1imate, Nature, 253, 600-603, 1975.

Kutzbach, J. E., Monsoon climate of the early Holocene: Climate experiment with the Earth's orbital parameters for 9,000 years ago, Science, 214, 59-61, 1981 .

Kutzbach, J. E., Modeling of paleoclimates, Adv. Geophys., 28A, 159-196, 1985.

Kutzbach, J. E., and P. J. Guetter, The influence of changing orbital parameters and surface boundary conditions on climatic simulations for the past 18,000 years, J. Atmos. Sci., 43(16), $1726-1759,1986$.

Kutzbach, J. E., and B. L. Otto-Bliesner, The sensitivity of the African-Astan monsoonal climate to orbital parameter changes for 9000 years BP in a low-resolution general circulation model, J. Atmos. Sci., 39(6), 1177-1188, 1982.

Labeyrie, L. D., J. C. Duplessy, and P. L. Blanc, Deep water formation and temperature variation over the last 125,000 years, Nature, 327, 477$482,1987$.

Lamb, H. H., Climate: Present, Past and Future, vol. 2, Climatic History and the Future, Methuen, London, 1977.

Laskar, J., Theorie generale planetaire: Elements orbitaux des planetes sur 1 million d'annees, these de doctorat de 3ième cycle, Observatoire de Paris, Paris, 1984.

Le Treut, H., and M. Ghil, Orbital forcing, climatic interactions, and glaciation cycles, J. Geophys. Res., 88(C9), 5167-5190, 1983.

Le Verrier, U. J. J., Recherches astronomiques, Ann. Observ. Imp. Paris, II, 1855.

Lindzen, R. S., A simple model for $100 \mathrm{~K}$-year oscillations in glaciation, J. Atmos. Sci., 43(10), 986-996, 1986.

Lloyd, C. R., Pre-Pleistocene paleoclimates: The geological evidence; modelling strategies, boundary conditions, and some preliminary results, Adv. Geophys. 26, 36-140, 1984.

Lorenz, E. N., Climatic determinism, Meteorol. Monogr., $8(30), 1-3,1968$.

Lorius, C., J. Jouze1, C. Ritz, L. Merlivat, N. I. Barkov, Y. S. Kofogkevich, and V. M. Kotlyakov, A 150,000-year climatic record from Antarctic ice, Nature, 316, 591-596, 1985.

Malone, T. F., and J. G. Roederer, Global Change, a Symposium of the International Council of Scientific Unions, ICSU Press, Paris, 1984.

Manabe, S., and A. J. Broccoli, The influence of continental ice sheets on the climate of an ice age, J. Geophys. Res., 90(D1), 2167-2190, 1985.

Manage, S., and D. G. Hahn, Simulation of the tropical climate of an ice age, J. Geophys. Res., 82(27), 3889-3913, 1977.

Martinson, D. G., N. G. Pisias, J. D. Hays, J. Imbrie, T. C. Moore, and N. J. Shackleton, Age dating and the orbital theory of the ice ages: Development of a high-resolution 0 to 300,000-year chronostratigraphy, Quat. Res., 27(1), 1-29, 1987.

Mason, B. J., Towards the understanding and pre- 
diction of climatic variations, Q. J. R. Meteorol. Soc., 102, 473-499, 1976.

Meech, L. N., On the relative intensity of the heat and light of the Sun upon different latitudes of the Earth, Smithon. Contrib. Knowl., IX, 1857 .

Mesole11a, K. J., R: K. Matthews, W. S. Broecker, and D. L. Therber, The astronomical theory of climatic change: Barbados data, J. Geol., 77, 250-274, 1969.

Milankovitch, M. M., Théorie Mathématique des Phénomènes Thermiques Produits par la Radiation Solaire, Academie Yougoslave des Sciences et des Arts de Zagreb, Gauthier-Villars, Paris, 1920.

Milankovitch, M., Kanon der Erdbestrahlung, R. Serbian Acad. Spec. Publ. 132, Sect. Math. Nat. Sci., 33, 1941. (Canon of insolation and the Ice-age problem, English translation by Israel Program for Scientific Translations, Jerusalem, 1969.)

Milankovitch, M., Memories, professional experlence and knowledge, vol. 1: 1879-1909, vol. 2: 1909-1944, vol. 3: after 1944, Serbian Academy of Sciences, section of Mathematical and Natural Sciences, $n^{\circ} 50,6$ and 16,1950 (1979), 1952, 1957. (in Serbo-Croation).

Mitchel1, J. F. B., N. S. Gahame, and K. J. Needham, Climate simulations for 9,000 years before present: Seasonal variations and the effect of the Laurentide Ice sheet, Dynamical Meteorol. Rep. DCTN57, Meteorol. Office, Bracknel1, England, 1987.

Mitchell, J. M., Jr., An overview of climatic variability and its causal mechanisms, Quat. Res., 6, 481-493, 1976.

Mitche11, J. M., Jr., Carbon dioxide and future climate, report, U.S. Dep. of Commer., Washington, D.C., 1977.

Morley, J. J., and J. D. Hays, Towards a highresolution, global, deep-sea chronology for the last 750,000 years, Earth Planet. Sci. Lett., 53, 279-295, 1981.

Murphy, J. J., The glacial climate and the polar ice-cap, Q. J. Geol. Soc. London, 32, 400-406, 19876.

National Research Counctl, Climate in Earth History, Stud. Geophys. Ser., National Academy Press, Washington, D. C., 1982.

National Research Council, U.S. Committee for an International Geosphere-Biosphere Program, Global Change in the Geosphere-Biosphere, National Academy Press, Washington, D. C., 1986.

Neftel, A., H. Oeschger, J. Schwander, B. Stauffer, and R. Zumbrunn, Ice core sample measurements give atmospheric $\mathrm{CO}_{2}$ content during the past 40,000 yr, Nature, 295, 220-223, 1982.

Nicolis, C., Response of the Earth-atmesphere system to a fluctuating solar input, in Sun and Climate, pp. 385-396, Centre National d'Etudes Spatiales, Toulouse, France, 1980.

Nicolis, C., Stochastic aspects of climatic transitions--Response to a periodic forcing, Tellus, $34,1-9,1982$.

Nicolis, C., and G. Nicolis, Reconstruction of the dynamics of the climate system from time series data, Proc. Natl. Acad. Sci., 83, 536-540, 1986.

North, G. R., and J. A. Coakley, Jr., Differences between seasonal and mean annual energy balance model calculations of climate and climate sensitivity, J. Atmos. Sci., 36, 1189-1204, 1979.
North, G. R., J. G. Mengel, and D. A. Short, Simple energy balance model resolving the seasons and the continents: Application to the astronomical theory of the ice ages, J. Geophys. Res., 88(C11), 6576-6586, 1983.

Oerlemans, J., Model experiments on the 100,000-yr glacial cycle, Nature, 287(2), 430-432, 1980.

Oerlemans, J., and J. M. Bienfait, Linking ice sheet evolution to Milankovitch radiation variations: A model simulation of the global ice volume record, in Sun and Climate, pp. 357-368, Centre National d'Etudes Spatiales, Toulouse, France, 1980.

Ohmura, A., H. Blatter, and M. Funk, Latitudinal variation of seasonal solar radiation for the period 200,000 years BP to 20,000 years AP, in IRS 84 Current Problems in Atmospheric Radiation, Proceedings to the International Radiation symposium, edited by G. Fiocco, pp. 338341, A. Deepak, Hampton, Va., 1984.

0lsen, P. E., A 40-million-year lake record of early Mesozoic orbital climatic forcing, Science, 234, 842-848, 1986.

Penck, A., and E. Brückner, Die Alpen im Eiszeitalter, Tauchnitz, Leipzig, 1909.

Pestiaux, P., and A. Berger, An optimal approach to the spectral characteristics of deep-sea climatic records, in Milankovitch and Climate, edited by A. Berger et al., pp. 417-446, D. Reidel, Hingham, Mass., 1984.

Pestlaux, P., J. C. Duplessy, I. van der Mersch, and $A$. Berger, Paleoclimatic variability at frequencles ranging from 1 cycle per 10,000 years to l cycle per l,000 years: Evidence for nonlinear behavior of the climate system, C1im. Change, 12(1), 9-37, 1988 .

Pisias, N. G., and N. J. Shackleton, Modelling the global climate response to orbital forcing and atmospheric carbon dioxide changes, Nature, $310,757-759,1984$.

Pokras, E. M., and A. C. Mix, Earth's precession cycle and Quaternary climatic change in equatorial Africa: Tropical Africa, Nature, $326(6112), 486-487,1987$.

Pollack, J. B., Solar, astronomical and atmospheric effects on climate, in Climate in Earth History, pp. 68-76, National Acaderny Press, Washington, D.C., 1982.

Pollard, D., An investigation of the astronomical theory of the ice ages using a simple climatic1ce sheet model, Nature, 272, 233-235, 1978.

Pollard, D., A simple ice sheet model yields realistic $100 \mathrm{kyr}$ glacial cycles, Nature, 296, $334-338,1982$.

Prell, W. L., and J. E. Kutzbach, Monsoon variability over the past 150,000 years, J. Geophys. Res., 92(D7), 8411-8425, 1987.

Rossignol-Strick, M., African monsoons, an immediate climate response to orbital insolation, Nature, 303, 46-49, 1983.

Royer, J. F., M. Deque, and P. Pestiaux, Orbital forcing of the inception of the Laurentide ice sheet, Nature, 304, 43-46, 1983.

Ruddiman, W. F., and A. McIntyre, Warmth of the subpolar North Atlantic Ocean during northern hemisphere ice-sheet growth, Science, 204(4389), 173-175, 1979.

Ruddiman, W. F., and A. McIntyre, Oceanic mechanisms for amplification of the 23,000-year 1cevolume cycle, Science, 212, 617-627, 1981.

Ruddiman, W. F., and A. McIntyre, Ice-age thermal response and climatic role of the surface At- 
lantic Ocean, $40^{\circ} \mathrm{N}$ to $63^{\circ} \mathrm{N}$, Geol. Soc. Am. Bul1., 95, 381-396, 1984.

Ruddiman, W. F., N. J. Shackleton, and A. McIntyre, North Atlantic sea-surface temperatures for the last 1.1 million years, in North Atlantic Palaeoceanography, Spec. Publ., 21, edited by C. P. Summerhayes and N. J. Shackleton, pp. 155-173, Geological Society of America, Boulder, Colo., 1986.

Saltzman, B., and A. D. Vernekar, Note on the effect of Earth orbital radiation variations on climate, J. Geophys. Res., 76, 4195-4198, 1971.

Saltzman, B., A. R. Hansen, and K. A. Maasch, The late Quaternary glaciations as the response of a three-component feedback system to Earthorbital forcing, J. Atmos. Sc1., 41(23), 3380$3389,1984$.

Savin, S. M., The history of the Egrth's surface temperature for the last $10010^{6}$ years, Annu. Rev. Earth Planet. Sc1., 5, 319-355, 1977.

Schneider, S. H., and S. L. Thompson, Ice ages and orbital variations: Some simple theory and modeling, Quat. Res., 12, 188-203, 1979.

Schwarzbach, M., Wegener, le Père de la Dérive des Continents, Belin, Paris, 1985.

Seliers, $W . D_{.}$, The effect of changes in the Earth's obliquity on the distribution of mean annual sea-level temperatures, J. Appl. Meteorol., 9, 960-961, 1970.

Sergln, V. Ya., Numerical modeling of the glaclers-ocean-atmosphere global system, J. Geophys, Res., 84, 3191-3204, 1979.

Shackleton, N. J., and N. D. Opdyke, Oxygen isotope and paleomagnetic strattgraphy of equatorlal Pacific core V28-238: Oxygen isotope temperatures and ice volumes on $a 10^{5}$ and $10^{6}$ year scale, Quat. Res., 3, 39-55, 1973.

Shackleton, N. J., and N. D. Opdyke, Oxygen 1sotope and paleomagnetic stratigraphy of Pacific core V28-239 late Pliocene to latest Pleistocene, Mem. Geol. Soc. Am., 145, 449-464, 1976.

Shackleton, N. J., M. A. Hall, J. Line, and Cang Shux1, Carbon isotope data in core V19-30 confirm reduced carbon dioxide concentration in the 1ce age atmosphere, Nature, 306, 319-322, 1983.

Sharaf, S. G., and N. A. Budnikova, Secular perturbations in the elements of the Earth's orbit and the astronomical theory of climate varlations (in Russian), Tr. Inst. Teor. AStron., $14,48-85,1969$.

Shaw, D. M., and W. L. Donn, Milankovitch radiation variations, a quantitative evaluation, Science, 162, 1270-1272, 1968.

Short, D. A., and J. G. Menge1, Tropical climate phase lags and Earth's precession cycle, Nature, $322,48-50,1986$.

Simpson, G. C., World climate during the Quaternary perlod, Q. J. R. Meteorol. Soc., 59, 425$471,1934$.

Simpson, G. C., Possible causes of change in climate and their limtations, Proc. Linnean Soc. London, 152, 190-219, 1940.

simpson, G. C., World temperature during the Pleistocene, Q. J. R. Meteorol. Soc., 85, 332$349,1957$.

Smagorinsky, J., General circulation experiments with the primitive equations, I, The basic experiment, Mon. Weather Rev., 91, 99-165, 1963.

Soerge1, W., Die Verisunggkurve, Berlin, 1937.
Spitaler, R., Das Klima des Eiszeitalters, Prague, 1921 .

Suarez, M., and I. Held, The sensitivity of an energy balance climate model to variations in the orbital parameters, J. Geophys. Res., $84(C 8), 4825-4836,1979$.

Sundquist, E. T., and W. S. Broecker (Eds.), The Carbon Cycle and Atmospheric $\mathrm{CO}_{2}$ : Natural Variations Archean to Present, Geophys. Monogr. Ser., vol. 32, 627 Pp., AGU, Washington, D. C., 1985.

Tricot, C., and A. Berger, Sensitivity to presentday climate to astronomical forcing, Long and Short-Term Variability of Climate, edited by $\mathrm{H}$. Wanner and U. Siegenthaler, PP. 132-152, Springer-Verlag, New York, 1988.

van den Heuve1, E. P. J., Ice shelf theory of Plelstocene glaclations, Nature, 210, 363-365, 1966.

Van Eysinga, F. W. B. (Ed.), Geological Time Scale, Elsevier, New York, 1983.

Veeh, H. H., and J. Chappell, Astronomical theory of climatic change: Support from New Guinea, Sclence, 167, 862-865, 1970.

vernekar, A. D., Long-period global vartations of incoming solar radiation, Meterol. Monogr., $12(34), 130$ pp. 1972 .

von Bacsak, G., On the explanation of the interglacial periods (in Hungarian), Weather, $44,1940$.

Ward, W. R., Climatic variations on Mars, l, Astronomical theory of insolation, J. Geophys. Res., 79, 3375-3387, 1974.

Ward, W. R., J. A. Burns, and O. B. Toon, Past obliquity oscillations of Mars: The role of the Tharsis uplift, J. Geophys. Res., 84, 243$259,1979$.

Washington, W. M., and C. L. Parkinson, An Introduction to Three-Dimenstonal Climate Modeling, 422 pp., Oxford University Press, New York, 1986 .

Webb, T., III, J. Kutzbach, and F. A. Street-Perrott, 20,000 years of global climatic change: Paleoclimatlc research plan, in Global Change, Symp. Ser., no. 5, edited by T. F. Malone and J. G. Roederer, pp. 182-219, ICSU Press, New York, 1985.

Weertman, J., Milankovitch solar radiation variations and ice age ice sheet sizes, Nature, 261, $17-20,1976$.

Wigley, T. M. L., Spectral analysis: Astronomical theory of climatic change, Nature, 264, 629$631,1976$.

Wigley, T. M. L., Climate and paleoclimate: What we can learn about solar luminosity variations, Sol. Phys., 74, 435-471, 1981.

woldstedt, P., Das Elszeltalter: Grundinten einer Geologie des Quartärs, F. Enke, Stuttgart, 1961 .

Wundt, W., Die Astronomische Theorie der Eiszeiten, Naturwiss. Monatsschr. Dtsch. Naturk., $51(11), 257-274,1938$.

Zeuner, F. E., The Pleistocene Period: Its Climate, Chronology and Faunal Successions, HutchInson, London, 1959.

A. Berger, Institut d'Astronomie et de GéophysIque G. Lemaitre, Université Catholique de Louvain, 2 Chemin du Cyclotron, B-1348, Louvain-laNeuve, Belglum.

(Recelved October 28, 1987; accepted March 15, 1988.) 